\title{
DESENVOLVIMENTO E VALIDAÇÃO DE METODOLOGIA ANALÍTICA DE MULTIRESÍDUOS PARA QUANTIFICAÇÃO DE RESÍDUOS DE PESTICIDAS EM MANGA (Mangifera indica)
}

\author{
EDSON MACIEL
}

Dissertação apresentada à Escola Superior de Agricultura “Luiz de Queiroz”, Universidade de São Paulo, para obtenção do título de Mestre em Ecologia de Agroecossistema.

\author{
P I R A C I C A B A
}

Estado de São Paulo - Brasil

Janeiro - 2005 


\title{
DESENVOLVIMENTO E VALIDAÇÃO DE METODOLOGIA ANALÍTICA DE MULTIRESÍDUOS PARA QUANTIFICAÇÃO DE RESÍDUOS DE PESTICIDAS EM MANGA (Mangifera indica)
}

\author{
EDSON MACIEL \\ Licenciado em Ciências (Habilitação em Química)
}

Orientador: Prof. Dr. VALDEMAR LUIZ TORNISIELO

Dissertação apresentada à Escola Superior de Agricultura "Luiz de Queiroz”, Universidade de São Paulo, para obtenção do título de Mestre em Ecologia de Agroecossistema.

\author{
P I R A C I C A B A \\ Estado de São Paulo - Brasil \\ Janeiro - 2005
}


Dados I nt er nacionai s de Cat al ogação na Publi cação ( $C l P$ ) DI VI SÃO DE BI BLI OTECA E DOCUMENTAÇÃO - ESALQI USP

\section{Maciel, Edson}

Desenvolvimento e validação de metodologia analítica de multiresíduos para

quantificação de resíduos de pesticidas em manga (Mangifera indica) / Edson Maciel. - Piracicaba, 2005.

$70 \mathrm{p}$

Dissertação (Mestrado) - - Escola Superior de Agricultura Luiz de Queiroz, 2005. Bibliografia.

1. Controle fitossanitário 2. Cromatografia a gás 3. Legislação ambiental 4. Manga

5. Resíduos de pesticidas em plantas 6. Saúde pública 7. Toxicologia de alimentos I. Título

CDD 634.441

"Permi tida a cópia total ou parcial deste documento, desde que citada a fonte - O aut or" 


\section{OFEREÇO}

Aos meus pais

José Ramos Maciel "in memorian"

e Jufersina M. N. Maciel.

A minha esposa Maria de Fátima,

A minha irmã Lucia Cristina e aos meus filhos José Edson, Ana Cláudia

e Luis Eduardo

DEDICO 


\section{AGRADECIMENTOS}

Ao Prof. Dr. Valdemar Luiz Tornisielo, pela orientação e amizade.

Ao Prof. Dr. Jorge José do Vale Oliveira, pela atenção e apoio nas correções desta dissertação.

A Profa. Dra. Regina T. R. Monteiro, pela simpatia e qualidade nas aulas ministrada.

Ao Dr. Paulo Marcos da Silva, pelos 10 anos de amizade e aprendizado ao seu lado, por ter me cedido seu laboratório para todo experimento e pelo incentivo para o inicio e a conclusão deste meu trabalho.

A Bioagri Laboratórios, por ceder os equipamentos, reagentes e a minha liberação para assistir as aulas.

Aos meus amigos que auxiliaram nas análises, Fábio Alexandre Vieira, Marcelo Viana de Moraes, Rodrigo Faganello e Dalton Prado.

Agradeço a todos os meus amigos da Bioagri que diretamente ou indiretamente me auxiliaram.

A Dra. Ana Paola, pelas primeiras correções deste trabalho.

Ao Prof. Dr. Plínio Barbosa de Camargo

Às secretárias Regina de Freitas e Eliane Navas, por sua disposição, em todos os momentos que foi lhe solicitado ajuda.

À Helena Cardoso, pelo auxilio com os formatos desta dissertação.

Agradeço a todos os amigos do Laboratório de Ecotoxicologia do CENA/USP. 


\section{SUMÁRIO}

Página

LISTA DE FIGURAS ................................................................................ viii

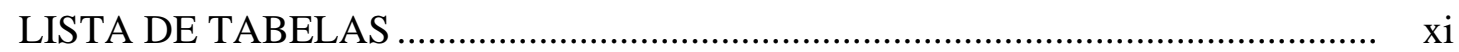

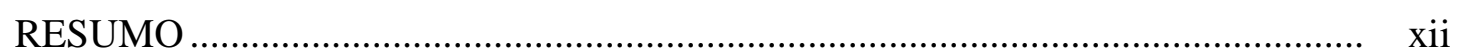

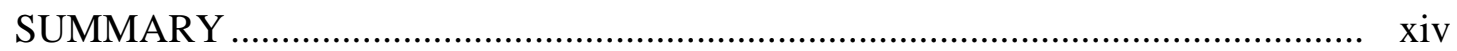

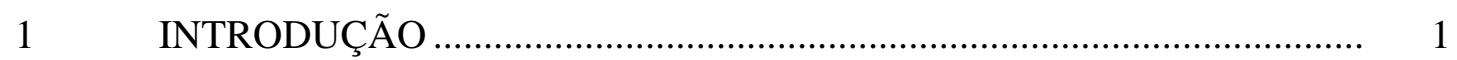

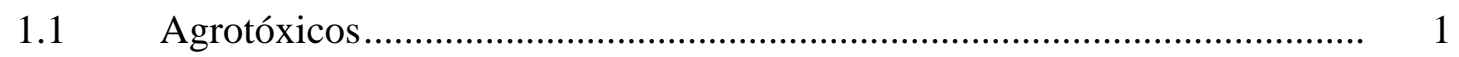

1.1.1 Origem ................................................................................................ 1

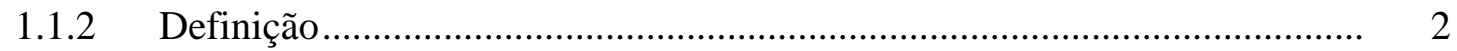

1.1.3 O uso e o impacto causado pelos agrotóxicos ……..................................... 3

1.1.4 Legislação .................................................................................................. 4

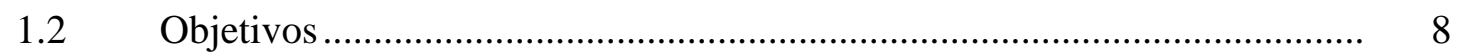

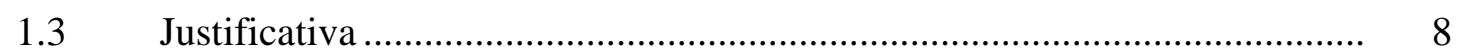

$2 \quad$ REVISÃO DA LITERATURA ……….......................................... 10

2.1 Classificação dos pesticidas ................................................................. 10

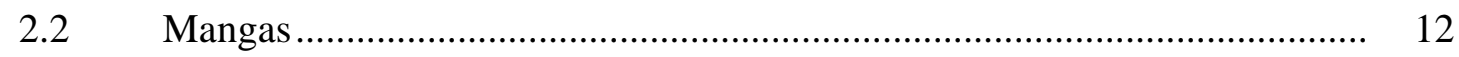

2.3 Métodos de extração .............................................................................. 14

3 MATERIAL E MÉTODOS ................................................................ 17

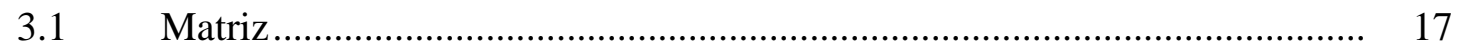

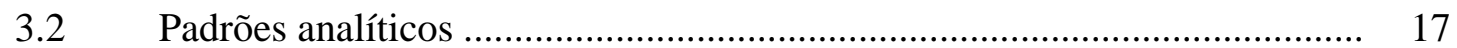

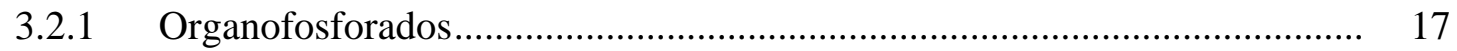

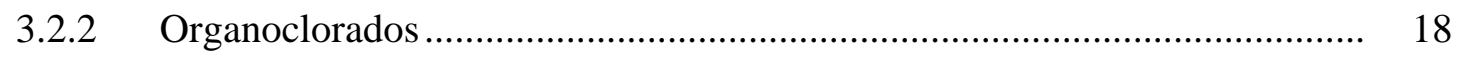

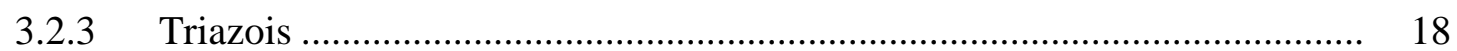




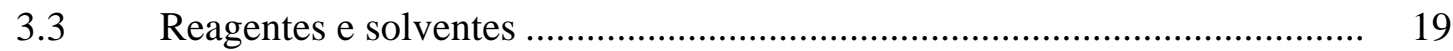

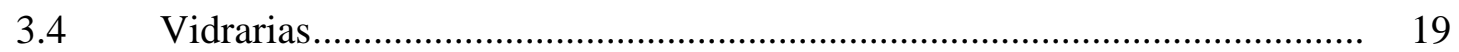

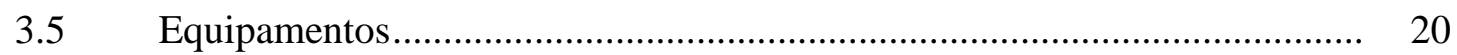

3.6 Coleta e armazenamento das amostras ................................................... 20

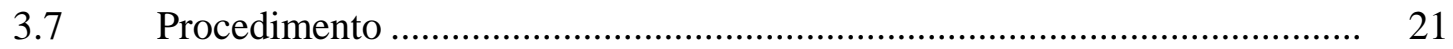

3.7.1 Preparo de soluções estoque de padrões analíticos......................................... 21

3.7.1.1 Solução padrão estoque / organofosforados (mix 1) .................................... 21

3.7.1.2 Solução padrão estoque / organoclorados (mix 2)........................................ 22

3.7.1.3 Solução padrão estoque / Triazois + Fention $(\operatorname{mix} 3)$................................... 23

3.7.2 Identificação.......................................................................................... 24

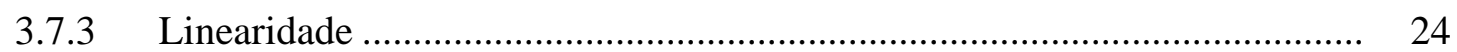

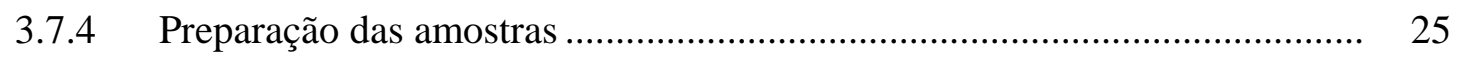

3.7.4.1 Método de extração de organofosforados .................................................. 25

3.7.4.2 Método de extração de organoclorados ...................................................... 25

3.7.4.3 Método de extração de triazois + fention ...................................................... 26

3.7.5 Especificidade ................................................................................... 27

3.7.6 Limites de quantificação e porcentagens de recuperação dos pesticidas adicionados em manga .......................................................................... 27

3.7.6.1 Limites de quantificação e porcentagens de recuperação de organofosforados em manga ..................................................................... 27

3.7.6.2 Limites de quantificação e porcentagens de recuperação de organoclorados em manga ................................................................... 28

3.7.6.3 Limites de quantificação e porcentagens de recuperação de triazois + fention em manga............................................................................ 28

3.8 Condições cromatográficas ...................................................................... 29

3.8.1 Cromatógrafo a gás: detector fotométrico de chama, filtro fósforo análise de organofosforados..................................................................... 29

3.8.2 Cromatógrafo a gás - detector $\mu$ Ecd - análise de organoclorados ............... 30 
3.8.3 Cromatógrafo a gás: acoplado ao detector de espectrometria de massas análise de triazois e fention................................................................ 30

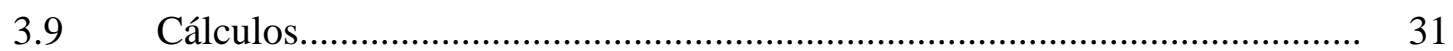

3.9.1 Média aritmética ............................................................................... 31

3.9.2 Estimativa do desvio padrão $( \pm)$.............................................................. 31

3.9.3 Coeficiente de variação $(\mathrm{cv} \%)$..................................................................... 31

3.9.4 Coeficiente linear (A) e coeficiente angular (B)....................................... 32

3.9.5 Cálculo do coeficiente de correlação ........................................................... 32

3.9.6 Cálculo da recuperação ............................................................................. 32

$4 \quad$ RESULTADOS E DISCUSSÃO ……................................................. 33

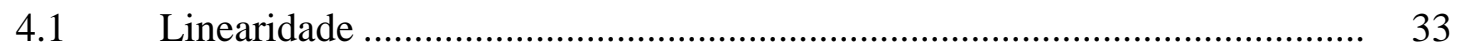

4.1.1 Linearidade do detector fotométrico de chama para os organofosforados ... 33

4.1.2 Linearidade do detector de captura de elétrons para os organoclorados ...... 37

4.1.3 Linearidade do detector de espectrometria de massa para os triazois .......... 43

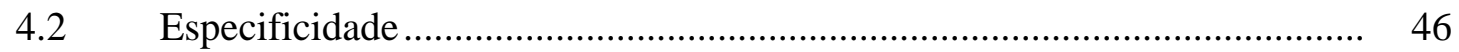

4.3 Estudos de recuperação............................................................................. 50

4.3.1 Recuperação dos organofosforados ........................................................... 50

4.3.2 Recuperação de organoclorados ................................................................ 51

4.3.3 Recuperação de triazois ........................................................................... 52

4.3.4 Resultado das amostras de manga compradas nos supermercados de

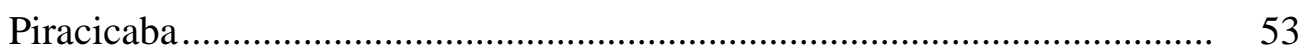

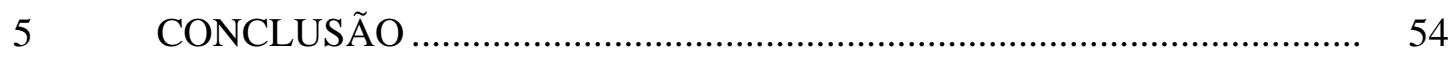

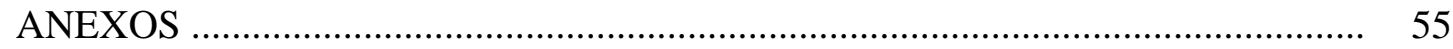

REFERÊNCIAS BIBLIOGRÁFICAS ............................................................... 66 


\section{LISTA DE FIGURAS}

Página

1 Paration etil

2 Paration metil

3 Área do pico em função da concentração de triclorfon ....

4 Área do pico em função da concentração de malation

5 Área do pico em função da concentração de monocrotofos

6 Área do pico em função da concentração de diclorvos. 35

7 Área do pico em função da concentração de diazinon. 36

8 Área do pico em função da concentração de dimetoato 36

9 Área do pico em função da concentração de fention 36

10 Área do pico em função da concentração de paration-metilico 37

11 Área do pico em função da concentração de etion 37

12 Área do pico em função da concentração de hexaclorobenzeno . 38

13 Área do pico em função da concentração de lindano 38

14 Área do pico em função da concentração de heptacloro 38

15 Área do pico em função da concentração de aldrin 39

16 Área do pico em função da concentração de metalacloro. 39

17 Área do pico em função da concentração de heptacloro epoxido.. 39

18 Área do pico em função da concentração de trans-clordano 40

19 Área do pico em função da concentração de óp-dde... 40

20 Área do pico em função da concentração de endosulfan alfa. 40

21 Área do pico em função da concentração de dieldrin 41

22 Área do pico em função da concentração de p`p-dde 
23 Área do pico em função da concentração de cis clordano ................................... 41

24 Área do pico em função da concentração de endrin ............................................ 42

25 Área do pico em função da concentração de endosulfan beta ............................ 42

26 Área do pico em função da concentração de o`p-ddt........................................... 42

27 Área do pico em função da concentração de endosulfan sulfato ......................... 43

28 Área do pico em função da concentração de metoxicloro .................................... 43

29 Área do pico em função da concentração de fention ............................................ 44

30 Área do pico em função da concentração de tetraconazole ................................. 44

31 Área do pico em função da concentração de paclobutrazol................................. 45

32 Área do pico em função da concentração de tebuconazol ................................... 45

33 Área do pico em função da concentração de bromuconazol................................. 45

34 Área do pico em função da concentração de procloraz ....................................... 46

35 Área do pico em função da concentração de difenoconazol............................... 46

36 Cromatograma do branco dos reagentes analisados por cromatografia a gás com detector fotométrico de chama .................................................................. 47

37 Cromatograma da amostra testemunha analisada por cromatografia a gás com detector fotométrico de chama ......................................................................... 47

38 Cromatograma do branco dos reagentes analisados por cromatografia a gás com detector de captura de elétrons .............................................................. 48

39 Cromatograma da amostra testemunha analisada por cromatografia a gás com detector de captura de elétrons

40 Cromatograma do branco dos reagentes analisados por cromatografia a gás acoplada a detector de espectrometria de massa

41 Cromatograma da amostra testemunha analisada por cromatografia a gás acoplada a detector de espectrometria de massa

42 Cromatograma da fortificação de $0,1 \mathrm{mg} / \mathrm{kg}$ de triclorfon e malation e 0,05 $\mathrm{mg} / \mathrm{kg}$ para os demais organofosforados em manga .....

43 Cromatograma da fortificação de $1,0 \mathrm{mg} / \mathrm{kg}$ de triclorfon e malation e 0,5 $\mathrm{mg} / \mathrm{kg}$ para os demais organofosforados em manga 
44 Cromatograma da fortificação de $0,01 \mathrm{mg} / \mathrm{kg}$ de organoclorados em manga ..... 51

45 Cromatograma da fortificação de $0,1 \mathrm{mg} / \mathrm{kg}$ de organoclorados em manga ....... 52

46 Cromatograma da fortificação no LOQ de triazois em manga ........................... 52

47 Cromatograma da fortificação de 10 x LOQ de triazois em manga .................... 53 


\section{LISTA DE TABELAS}

Página

1 Tolerância e intervalo de segurança para os pesticidas estudados na cultura da manga

2 Tolerância e intervalo de segurança nas culturas de maçã (1), soja e trigo (2), feijão (3), pêra (4) e Cacau (5) para os pesticidas estudados na cultura da manga.

3 Solução padrão estoque / organofosforados (mix 1) ............................................ 22

4 Solução padrão estoque / organoclorados (mix 2) .................................................. 23

5 Solução padrão estoque / Triazois + Fention (mix 3) ............................................. 23 


\section{DESENVOLVIMENTO E VALIDAÇÃO DE METODOLOGIA ANALÍTICA DE MULTIRESÍDUOS PARA QUANTIFICAÇÃO DE RESÍDUOS DE PESTICIDAS EM MANGA (Mangifera indica)}

Autor: EDSON MACIEL

Orientador: Prof. Dr. VALDEMAR LUIZ TORNISIELO

\section{RESUMO}

O objetivo principal deste estudo foi o desenvolvimento e validação de metodologia de análise de multiresíduos para quantificação de resíduos de pesticidas em manga. Foram analisados 32 pesticidas, sendo dos seguintes grupos: 9 Organofosforados, 17 Organoclorados e 6 triazois sendo que neste mesmo método foi analisado novamente o Organofosforado fention. Os organofosforados foram analisados em cromatógrafo a gás (CG) acoplado ao detector fotométrico de chamas e os organoclorados foram analisados em cromatógrafo a gás (CG) acoplado ao detector de captura de elétrons (ECD). Os triazois foram analisados em cromatógrafo a gás acoplado a espectrômetro de massa (CG/MS). A curva de linearidade para todos os padrões analíticos, foi realizada em triplicata e com 6 diferentes concentrações. As fortificações das amostras foram realizadas em dois níveis de concentração, no limite do método e 10 vezes o limite do método, sendo que a concentração do limite de quantificação do método (LOQ) foi realizada com sete repetições $(\mathrm{N}=7)$ e a concentração de 10 vezes o LOQ foi realizada com $\mathrm{N}=5$, usando-se mangas tratadas no sistema orgânico (livres de 
pesticidas). Os métodos desenvolvidos e validados neste estudo apresentaram-se: a) Linear na faixa de: $0,1-4,0 \mu \mathrm{g} / \mathrm{mL}$ para o triclorfon e malation; 0,05 - 2,0 $\mu \mathrm{g} / \mathrm{mL}$ para os demais organofosforados; $0,05-1,6 \mu \mathrm{g} / \mathrm{mL}$ para os organoclorados; $0,1-1,0 \mu \mathrm{g} / \mathrm{mL}$ para o paclobutrazol; 0,25 - 2,5 $\mu \mathrm{g} / \mathrm{mL}$ para o fention e bromuconazol; 0,5 - 5,0 $\mu \mathrm{g} / \mathrm{mL}$ para o tetraconazol e tebuconazol e 1,0 - $10 \mu \mathrm{g} / \mathrm{mL}$ para o procloraz e difenoconazol respectivamente, uma vez que o coeficiente de determinação foi maior que 0,99 para todos os ativos. b) Específicos, pois o nível de contaminação e/ou interferente na análise do branco dos reagentes e da amostra testemunha, foram inferiores a 30\% do limite de quantificação. c) Exato, Preciso e Repetitivo, pois todos os ativos apresentaram recuperação dentro do intervalo de aceitabilidade de 70 a 120\%, com coeficiente de variação porcentual (CV\%) inferior a 15\% em relação à média global de todos os níveis de fortificação. Foram também analisados os mesmos pesticidas em 15 amostras de mangas compradas nos supermercados de Piracicaba, procedentes do Nordeste do Brasil. Em nenhuma das amostras foram encontrados resíduos acima do limite estabelecido por lei ou acima do limite de quantificação deste método, no caso dos pesticidas não autorizados. 


\section{DEVELOPMENT AND VALIDATION OF A MULTIRESIDUE ANALYTICAL METHODOLOGY FOR THE QUANTIFICATION OF PESTICIDE RESIDUES IN MANGOS (Mangifera indica)}

Author: EDSON MACIEL

Adviser: Prof. Dr. VALDEMAR LUIZ TORNISIELO

\section{SUMMARY}

The principal objective of this study was the development and validation of a multiresidue analytical methodology for the quantification of pesticide residues in mangos. Quantitative analyses were made for 32 pesticides, from the following classes: organophosphorus (9), organochlorine (17) and triazole (6). The results from the method include the first analysis for the organophosphorus pesticide fenthion. The organophosphorus pesticides were analyzed by a gas chromatograph (GC) coupled to a flame photometric detector, while the organochlorine pesticides were analyzed using a gas chromatograph (GC) coupled to an electron capture detector (ECD). The triazoles were analyzed with a gas chromatograph coupled to a mass spectrometer (GC/MS). For each of the analytes, calibration curves were constructed in triplicate using solutions with six different concentrations, prepared from the analytical standards. Recovery experiments were performed at two levels of fortification, the limit of quantification of the method (LOQ) and 10 times this limit. Seven repetitions $(N=7)$ were performed at the limit of quantification, and five $(N=5)$ at the 10 times higher level of fortification. 
Mangos raised by organic farming methods (free from pesticides) were used for the recovery experiments. The methods developed and validated in this study have the following characteristics: a) linear range: $0.1-4.0 \mu \mathrm{g} / \mathrm{mL}$ for trichlorfon and malathion; $0.05-2.0 \mu \mathrm{g} / \mathrm{mL}$ for the other organophosphorus pesticides; $0.05-1.6 \mu \mathrm{g} / \mathrm{mL}$ for the organochloro pesticides; $0.1-1.0 \mu \mathrm{g} / \mathrm{mL}$ for paclobutrazol; $0.25-2.5 \mu \mathrm{g} / \mathrm{mL}$ for fenthion and bromuconazole; $0.5-5.0 \mu \mathrm{g} / \mathrm{mL}$ for tetraconazole and tebuconazole; and $1.0-10.0 \mu \mathrm{g} / \mathrm{mL}$ for prochloraz and difenoconazole, in each case the coefficient of determination was greater than 0.99 . b) Specific: thus the level of contamination and/or intereference in analysis from the reagent blank and the control sample amounted to less than $30 \%$ of the limit of quantification. c) Exact, Precise and Repeatable, for each of the analytes the recovery was found to be within the acceptable interval of 70 to $120 \%$, and with a coefficient of variation, expressed as a percentage, of less than $15 \%$ in relation to the global average of the results obtained at the two levels of fortification. Analyses were made for the same pesticides in 15 samples of mangos bought from supermarkets in Piracicaba, which were raised in the Northeast of Brazil. None of these samples contained residue concentrations above the limit established by law or, in the case of non-authorized pesticides, above the limit of the quantification of the current methodology. 


\section{INTRODUÇÃO}

\subsection{Agrotóxicos}

\subsubsection{Origem}

A grande maioria dos compostos químicos usados como pesticidas foi desenvolvida na década de 1930, contudo o primeiro químico a sintetizar um pesticida foi Ottmar Zeidler em 1872. O pesticida organoclorado DDT foi desenvolvido em 1939 e foi muito usado em programas de saúde publica. Porém, a degradabilidade e o modo de dispersão deste pesticida tornaram-se grandes problemas para o ambiente e a saúde, levando-o a ser proibido comercialmente nos Estados Unidos em 1972 (Eto, 1977) e, nove anos depois, no Brasil.

Em 1897 o alemão Michaelis e o russo Arbuzov foram os primeiros a trabalhar com os clássicos ésteres contendo fósforo. Porém, o progresso dos pesticidas organofosforados é devido aos trabalhos de Gerhard Schrader, iniciados na Alemanha por volta de 1934. O mais conhecido foi o Octamethyl Pyrophosphoro Amidate (OMPA), primeiro inseticida de ação sistêmica descoberto em 1941 que passou a ser chamado de "Scharadan", em homenagem ao seu descobridor. Devido à possibilidade de ser usado como arma química, os resultados destas pesquisas permaneceram secretos durante a II Guerra Mundial (Eto, 1977).

No Brasil, a década de 70 foi à época de grande expansão da produção e do uso de pesticidas, em razão dos incentivos para a produção agrícola e a política de exportação. Desde então, com a expansão no mundo agrícola, dirigido pelo aumento de 
níveis populacionais, a pesquisa de novos pesticidas tem crescido consideravelmente (Lara \& Batista, 1992). Por exemplo, foram introduzidas novas famílias de produtos tais como carbamatos e piretroides.

\subsubsection{Definição}

O uso de pesticidas para proteger plantações ou alimentos em geral, destinado ao consumo humano ou animal pode, ás vezes, apresentar um resíduo remanescente na colheita.

Resíduo de pesticidas é definido como sendo a quantidade de pesticida e/ou seus derivados remanescentes no alimento, decorrente do emprego do pesticida, e expresso em partes dos pesticidas por um milhão de partes do alimento (ppm) (Gelmini, 1991).

Os níveis de tolerância são as quantidades máximas de resíduo de pesticida tolerado no alimento, como decorrência de sua aplicação adequada, numa fase específica desde a sua produção até o consumo, expresso em ppm (Gelmini, 1991).

Um grande número de substancias são utilizadas no combate às pragas, às ervas daninhas e doenças das plantações. Para estas várias denominações tem usado: defensivos agrícolas, biocidas, pesticidas, praguicidas e agrotóxicos.

A Resolução 12/74 da antiga Comissão Nacional de Normas e Padrões para Alimentos (CNNPA) do Ministério da Saúde definiu PESTICIDA como: "substância ou mistura de substâncias destinada a prevenir a ação, ou destruir direta ou indiretamente insetos, ácaros, roedores, fungos, nematóides, ervas daninhas, bactérias e outras formas de vida animal ou vegetal prejudiciais à lavoura, à pecuária, a seus produtos e outras matérias primas”, incluem-se os desfolhantes, os dessecantes, as substâncias reguladoras de crescimento vegetal, esterilizantes de sementes e feromônios; excluem-se as vacinas, 
medicamentos, antibióticos de uso veterinário e agentes de controle biológico. (Lara \& Batista, 1992).

\subsubsection{O uso e o impacto causado pelos agrotóxicos}

Com o objetivo de aumentar a produtividade, a partir da década de 1960 várias tecnologias foram associadas ao processo de modernização da agricultura, entre elas os agrotóxicos (Campanhola et. al., 1997). O uso generalizado e intensivo dessas substâncias tem gerado diversos problemas relacionados à saúde pública e ao desequilíbrio ambiental, incluindo: intoxicações de agricultores, contaminações de alimentos, de água e de solos, resistência de espécies combatidas às substâncias empregadas e danos em espécies não visadas (Campanhola et. al., 1997; Garcia, 2001). O desequilíbrio ecológico ocasionado acarreta problemas à própria agricultura, agravando o surgimento e proliferação de pragas e doenças e, conseqüentemente, aumentando a necessidade de usar agrotóxicos, conforme já alertava Paschoal (1979), no final da década de 1970, quando observou que, entre 1958 e 1976, quatrocentas novas espécies de pragas foram referidas no Brasil.

Embora de difícil avaliação, os custos sociais e ambientais decorrentes do uso de agrotóxicos são altos (Garcia, 2001). A Organização Mundial da Saúde (OMS) estima que, no mundo, mais de 500 milhões de pessoas se exponham aos agrotóxicos pelo trabalho agrícola e que ocorram 3 milhões de intoxicações severas, incluindo 1 milhão de casos de intoxicações agudas não intencionais com 20.000 mortes, anualmente, sendo 70\% desses casos por exposição ocupacional. Estima ainda que os efeitos crônicos, que são mais difíceis de serem avaliados, incluam 25.000 casos de seqüelas neuro-comportamentais, 37.000 casos de câncer, principalmente em países em desenvolvimento, e 700.000 casos de dermatoses, por ano.

No Brasil estima-se que em torno de 15 milhões de pessoas que trabalham na agricultura estejam potencialmente expostas aos agrotóxicos, a quantidades bastante 
significativas, e que, entre elas, ocorram de 150.000 a 200.000 intoxicações agudas anualmente, com 3.000 a 4.000 óbitos (Garcia, 2001; Garcia, 1997; Garcia \& Almeida, 1991).

O uso de produtos fitossanitários se intensificou em 1975, com a criação do PNDA (Plano Nacional de Defensivos Agrícolas) que financiou a compra de agrotóxicos pelos agricultores e levou a indústria a investir cerca de duzentos e cinqüenta milhões de dólares em 43 projetos de síntese de produtos técnicos e em unidades de formulações para cerca de 150 produtos. (Azevedo, 2001; Conceição, 2002).

Os pesticidas, quando usados corretamente, podem evitar que $40 \%$ das safras de diferentes culturas sejam perdidas (Richardson, 1998) porém, o mal uso deles pode gerar sérios riscos para o meio ambiente e para a saúde dos seres vivos em geral. O crescente aumento da população mundial nos leva à necessidade de aumentarmos cada vez mais a quantidade de alimentos produzidos e o uso de produtos fitossanitários é inevitável.

É necessário controlarmos os resíduos que permanecem das aplicações nas mais diversas culturas. Os resíduos remanescentes nas culturas dependem de muitos fatores de variada importância como grau de adsorção nas camadas superficiais, degradação química ou metabolismo, desaparecimento aparente devido à diluição pelo crescimento da planta e volatilidade do depósito (Lemes et al., 1993).

\subsubsection{Legislação}

A Legislação garante que o registro para novo produto agrotóxico será concedido se a sua ação tóxica sobre o ser humano e o meio ambiente for comprovadamente igual ou menor do que a daqueles já registrados para o mesmo fim. O 
Brasil proibiu o registro de agrotóxicos, que revelem características teratogênicas, carcinogênicas ou mutagênicas (Brasil, 1998).

Através da Lei 7.802 de 11 de julho de 1989 e da Portaria nº 03 de 16 de janeiro de 1992, tem-se as diretrizes para a utilização de pesticidas no Brasil. Os Ministérios da Saúde, Agricultura e o Instituto Brasileiro do Meio Ambiente e Recursos Naturais Renováveis (IBAMA), cada um na sua área de atuação ficam como os responsáveis pela autorização ou não da utilização dos pesticidas no Brasil. Compete aos Estados e ao Distrito Federal, legislar bem como fiscalizar sobre o uso, a produção, o consumo, o comércio e o armazenamento dos agrotóxicos, seus componentes e afins.

A resolução-RDC $n^{\circ} 44$, de 10 de maio de 2000, Altera as Diretrizes e Exigências Referentes a Autorização de Registro de Produtos Agrotóxicos e Afins, $\mathrm{n}^{\circ} 1$, de 09 de dezembro de 1991, ratificada pela Portaria nº 3 de 16 de Janeiro de 1992 (título de acordo com Decreto 991/93). As substituições mais significativas são: a) proposições quanto ao Limite Máximo de Resíduos (LMR) baseadas nas tabelas individuais apresentadas, referentes aos três ensaios de campo ou a dois ensaios pós-colheita, nos casos de Limites de Resíduos Estranhos (LME) estes deverão também ser propostos; b) delineamento experimental; c) unificação e padronização nos estudos de resíduo, onde a informação de campo e do laudo analítico passa a ter critérios mínimos a serem seguidos, os ensaios destinados a pesquisa de resíduos deverão ser conduzidos, no mínimo, em 3 (três) áreas distintas representativas do cultivo na mesma safra ou em duas safras consecutivas no mesmo local e outro, em local diferente. Para pós-colheita, deverão ser conduzidos, no mínimo, 2 (dois) ensaios de pesquisa de resíduos, em local representativo da operação de tratamento.

Os Limites Máximos de Resíduos (LMRs) de agrotóxicos, bem como a padronização internacional aplicada aos alimentos negociados no mercado mundial, são determinados pela Comissão Codex Alimentarius (CODEX). Um excesso de resíduos, segundo os padrões do CODEX, indica dois aspectos: primeiro, que os agrotóxicos foram aplicados de maneira inadequada na produção, processamento ou armazenagem 
do produto; e em segundo lugar, que há um risco em potencial à saúde do consumidor (Bull \& Hathaway, 1986).

A avaliação dos dados toxicológicos dos agrotóxicos, a recomendação da Ingestão Diária Aceitável (IDA) e os cálculos do Limite Máximo de Resíduo (LMR) são estabelecidos por órgãos subordinados às nações Unidas, como: Food and Agricultural Organization (FAO), World Health Organization (WHO) e o CODEX Alimentarius Mundial, através do seu Comitê de Resíduos de Pesticidas em Alimentos (CCPR) (Vetorazzi \& Radaeli-Benvenuti, 1982).

A IDA, expressa em $\mathrm{mg} / \mathrm{kg}$ de massa corpórea, estabelecida por longa avaliação toxicológica em animais experimentais, é definida como sendo a quantidade de uma substância química que pode ser ingerida diariamente pelo homem durante toda a vida, sem risco apreciável a sua saúde, à luz dos conhecimentos disponíveis na época da avaliação (WHO, 1987).

A Tabela 1, apresenta a tolerância e o intervalo de segurança para os pesticidas estudados neste trabalho os quais tem o seu uso permitido na cultura da manga.

Tabela 1.Tolerância e intervalo de segurança para os pesticidas estudados na cultura da manga.

\begin{tabular}{lcc}
\hline \multicolumn{1}{c}{ Pesticidas } & Tolerância $(\mathrm{mg} / \mathrm{kg})$ & Intervalo de Segurança (Dias) \\
\hline Fention & 0,05 & 21 \\
Triclorfon & 0,1 & 7 \\
Paclobutrazol & 0,02 & 278 \\
Bromuconazol & 0,05 & 20 \\
Tetraconazol & 0,1 & 7 \\
Tebuconazol & 0,1 & 20 \\
Procloraz & 0,2 & $(1)$ \\
Difenoconazol & 0,2 & 7 \\
\hline
\end{tabular}

Fonte: Agência Nacional de Vigilância Sanitária (ANVISA) (2004)

(1) Intervalo de segurança não determinado devido a modalidade de emprego 
A Tabela 2, apresenta informações da tolerância e do intervalo de segurança dos pesticidas estudados neste trabalho, os quais não tem o seu uso autorizado para manga, com isto os dados são baseados nas informações de outras frutas e cereais.

Tabela 2.Tolerância e intervalo de segurança nas culturas de maçã (1), soja e trigo (2), feijão (3), pêra (4) e Cacau (5) para os pesticidas estudados na cultura da manga.

\begin{tabular}{lcc}
\hline \multicolumn{1}{c}{ Pesticidas } & Tolerância $(\mathrm{mg} / \mathrm{kg})$ & Intervalo de Segurança (Dias) \\
\hline Diclorvos & $0,1^{(1)}$ & 7 \\
Diazinon & $0,5^{(1)}$ & 14 \\
Monocrotofós & $0,05^{(2)}$ & 21 \\
Dimetoato & $2,0^{(1)}$ & 3 \\
Paration metílico & $0,05^{(3)}$ & 15 \\
Etion & $2,0^{(1)}$ & 15 \\
Malation & $0,5^{(4)}$ & 15 \\
Endosulfan Alfa & $0,01^{(5)}$ & 30 \\
Endosulfan Beta & $0,01^{(5)}$ & 30 \\
Endosulfan Sulfato & $0,01^{(5)}$ & 30 \\
\hline
\end{tabular}

Fonte: ANVISA (2004)

A tolerância e o intervalo de segurança para os organoclorados (Lindano, Aldrin, Hexaclorobenzeno, Heptacloro, Metalacloro, Heptacloro Epoxido, Trans Clordano, O`p-DDE, Dieldrin, P`p-DDE, Cis Clordano, Endrin, O`p-DDT, Metoxiclor), estudados neste trabalho não foram apresentados por não terem o seu uso autorizado na agricultura. 


\subsection{Objetivos}

a) Desenvolver e validar métodos de extração dos resíduos de pesticidas em manga, para três diferentes grupos: Organoclorados, Organofosforados e Triazois, os quais auxiliarão no monitoramento de resíduo de pesticidas nas mangas.

b) Determinar quantitativamente resíduos de pesticidas em mangas adquiridas em supermercados.

\subsection{Justificativa}

Existe um grande número de registros de pesticidas por cultura e também muitos produtos comerciais no mercado. Geralmente os agricultores aplicam vários pesticidas em uma mesma cultura. Em função desta realidade é economicamente inviável e operacionalmente não prático utilizar métodos analíticos individuais com o objetivo de quantificar os resíduos de vários pesticidas nos alimentos. Por isto cada vez mais precisamos validar métodos que tenham a capacidade de identificar e quantificar uma grande quantidade de ativos ao mesmo tempo.

O Brasil é um país forte no setor agrícola e no que se refere ao comércio internacional de alimentos, é imprescindível atender às exigências do país importador, daí a necessidade de termos métodos validados que avaliem eficazmente diversos ativos.

Os países do Hemisfério Norte, a fim de protegerem a própria agricultura e indústria da concorrência do Hemisfério Sul, consolidaram notáveis barreiras alfandegárias e, para conter a própria inflação, reduziram a liquidez monetária do mundo todo. Com isso, as dificuldades para exportação aumentaram muito nos países em vias de desenvolvimento (Fellenberg, 1980).

Uma dessas barreiras tem se mostrado através da exportação de frutas no Brasil. A falta de controle quanto à presença de resíduos de pesticidas nas frutas brasileiras para exportação tem gerado desconfiança nos compradores internacionais. O 
agronegócio de frutas é um mercado aberto, com grandes possibilidades de crescimento, geração de divisas e de empregos, que está sendo ameaçado pelo despreparo e escassez de tecnologia e recursos humanos para análise de resíduo de pesticidas em frutas e processados. 


\section{REVISÃO DA LITERATURA}

\subsection{Classificação dos pesticidas}

Os pesticidas químicos podem ser classificados quanto a sua origem e são divididos em inorgânicos e orgânicos. Os inorgânicos (chumbo, arsênio, mercúrio) foram utilizados por muito tempo, mas foram substituídos pelos compostos orgânicos por serem biodegradáveis. Os orgânicos são atualmente os principais e se subdividem em: de origem animal (óleos animais), de origem petrolífera (óleos minerais), de origem vegetal (óleos vegetais, nicotina, piretrinas), organo-sintéticos (clorados, fosforados, piretróides, carbamatos etc.). Os organo-sintéticos são os mais usados atualmente (Eto, 1977)

A maioria dos pesticidas fosforados são ésteres neutros ou amidas derivados do ácido fosfórico, seu anidrido ou o análogo com enxofre. Portanto, eles podem ser classificados nos tipos fundamentais: fosfato, fosforotioato, fosforoditioato, fosforotiolato, fosforoamidato e pirofosfato. Outras combinações também são possíveis (Eto, 1977).

A atividade depende dos diversos radicais ligados ao átomo de fósforo e, às vezes, pequenas modificações nestes radicais podem afetar grandemente a toxicidade do composto. A substituição de radicais metil em $\mathrm{R}_{1}$ e $\mathrm{R}_{2}$ por radicais etil aumenta a toxicidade do composto. Por exemplo, o paration etil é mais tóxico que o paration metil, assim como o clortion e malation. Quase todos os inseticidas organofosforados apresentam grupos metil, etil ou isopropil. Homólogos mais superiores perdem 
rapidamente a atividade (Batista, 1974). As figuras 1 e 2 ilustram o exemplo do paration etil e o paration metil.

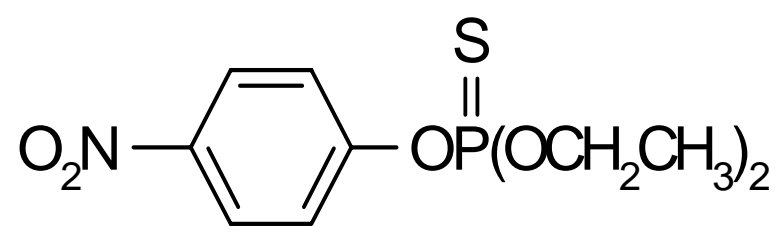

Figura 1 - Paration etil

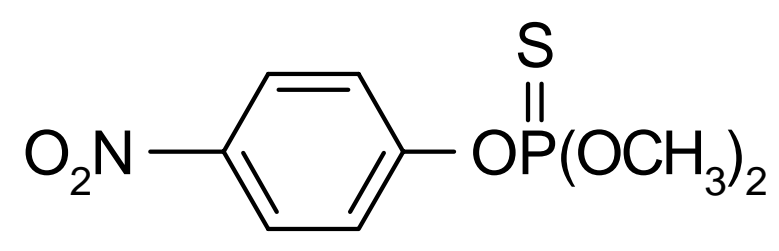

Figura 2 - Paration Metil

Os compostos organoclorados são facilmente solúveis em tecido adiposo (lipossolúveis), o que permite um tempo maior no organismo porque nestes locais não existem enzimas para provocar a reação. Esta propriedade torna o pesticida clorado perigoso devido a sua acumulação no organismo. O pesticida organofosforado, por sua vez, ataca mais o sistema nervoso central e o sistema nervoso periférico (Matolesy et. al., 1988).

Sabe-se que muitos dos pesticidas aplicados às culturas agrícolas possuem vida média elevada no meio ambiente e apresentam efeito cumulativo (Lara \& Batista, 1992).

Os fungicidas são substâncias químicas ou biológicas que atacam os fungos sem atacar as culturas. Protegem as plantas contra a evasão de patógenos ou são usados 
para erradicar infecções já estabelecidas. O início da aplicação de fungicidas em grande escala para o controle de doenças se deu com a descoberta da calda bolonhesa (mistura de sulfato de cobre e cal hidratada) em 1882. Por mais de 50 anos foi um dos fungicidas mais utilizados (Azevedo, 2001). De acordo com a Food and Agricultural Organization (FAO) os fungicidas são insumos importantes para a produção mundial de alimentos. Os fungicidas além de terem na manutenção do potencial produtivo das culturas, contribuem também para a manutenção da germinação e vigor das sementes, e no prolongamento da vida útil dos frutos na pós-colheita (Azevedo, 2001).

\subsection{Mangas}

A manga é uma das frutas mais procuradas no mundo, e esta demanda tem se mostrado crescente. De acordo com informações da Empresa Brasileira de Pesquisa Agropecuária (EMBRAPA), a procura tem aumentado bastante tanto no mercado interno quanto no externo, o que tem se refletido em preços compensadores.

O mundo produziu no ano de 2003, 26.196.090 mil toneladas de manga, distribuídas em cerca de 3.400 mil hectares, o que resulta em um rendimento médio de 7,7 toneladas por hectare. Os principais países produtores dessa fruta (dados de 2003) são Índia, China, Tailândia e México, sendo que o Brasil ocupa a nona colocação nesse ranking (Rozane et. al., 2004).

A manga tem seu uso bem diversificado, dentre eles, o consumo como fruta fresca, em estado verde, ou completamente maduro. Utiliza-se só ou combinada com outras frutas, no preparo de purês, néctares, refrescos e sorvetes. Mangas maduras são também utilizadas na elaboração de sorvetes, geléias, polpas, fatias para enlatamento e flocos de cereais, um excelente produto de desjejum (Medina, 1981).

Existem elementos adicionais que podem servir de referência otimista para a produção e comercialização da manga. De acordo com Fernandes et. al. (2004), o 
crescimento da manga no exterior foi muito expressivo no período 1998-2002, ficando atrás apenas da uva de mesa e, de acordo com projeções realizadas pelo Instituto Brasileiro de Fruticultura (IBRAF), as vantagens devem se manter nos próximos anos.

De acordo com notícias da Folha On-Line (Brasília), depois de 32 anos de negociações, o governo do Japão assinou um decreto abrindo seu mercado para as mangas produzidas no Brasil. De acordo com a citada reportagem, o decreto do governo japonês permite a exportação de um volume inicial de 5.200 toneladas por ano da variedade “Tommy Atkins”, produzida principalmente no Nordeste (Vale do São Francisco e Livramento, Bahia) e em São Paulo. “O assessor para Assuntos Internacionais da Secretaria de Defesa Agropecuária, Gilson Cosenza, disse que 90\% das 820 mil toneladas de manga produzidas todo ano no Brasil são dessa variedade. Em 2003. o Brasil exportou 126 mil toneladas da fruta para Estados Unidos e União Européia, gerando US\$ 71 milhões em divisas. As mangas destinadas ao mercado japonês, ainda mais exigente que o norte-americano e o europeu, devem ser comercializadas a US\$ 2 mil por tonelada. Nessa primeira etapa, as exportações para o Japão devem render anualmente cerca de US\$ 10,4 milhões ao país” (Rozane et. al., 2004).

O cultivo da mangueira (Mangifera indica L.) no Vale do São Francisco permite produzir frutos de excelente qualidade em qualquer época do ano, desde que sejam seguidas as tecnologias do manejo da indução floral com a utilização do regulador de crescimento vegetal, Cultar (Paclobutrazol), ou abreviadamente PBZ e dos métodos de controle fitossanitário (Rozane et. al., 2004).

\subsection{Métodos de extração}

Um simples e rápido procedimento para extração de bifenilas de amostras de frutas cítricas é descrito por Pyysalo et. al. (1979). Os compostos são detectados com alta sensibilidade por GC. As recuperações estão presentes na faixa de 80-98\%. 
Davis e Munroe (1979) desenvolveram um procedimento para extração e determinação de bifenilas em frutas cítricas. Sabe-se que bifenilas são freqüentemente usadas para proteção deste tipo de cultura. Além disso, baixos níveis de tolerância são permitidos por alguns países importadores, o que acarreta o desenvolvimento de um método com maior sensibilidade. O método consiste na extração com acetato de etila, filtração e análise das alíquotas por GC/FID.

Os fungicidas benomil, thiabendazol e procloraz foram estudados em mangas por Muller e Burt (1989), os autores verificaram que os três foram mantidos na casca da fruta. O nível de resíduo de procloraz foi reduzido em 50\%, 14 dias após o tratamento sendo de 0,1 $\mu \mathrm{g} / \mathrm{g}, 6,8 \mu \mathrm{g} / \mathrm{g}$ e $0,7 \mu \mathrm{g} / \mathrm{g}$ na polpa, casca e fruto inteiro, respectivamente. Em outro experimento realizado por Scalon et al., 1996 com benomil em mangas foi observado que o fungicida não atingiu a polpa, pois segundo os autores a casca da manga é altamente cerosa, espessa e conseqüentemente pouco permeável, acreditando-se que devido a estes fatores o fungicida ficou retido na camada superficial.

Resíduos de inseticidas organofosforados como: Paration, Metidation e Dimetoato foram encontrados na casca da laranja por Russo et. al. (1983).

Iwata et. al. (1983) apresentaram um método de “clean-up”, tanto para pesticidas organofosforados como para organoclorados em frutas, incluído laranja. A fruta é extraída com MeCN e transferida para uma coluna de Amberlite XAD-8, eluída com vários solventes $(\mathrm{NaCl}$ aquoso, $\mathrm{MeOH})$. O extrato eluído foi analisado por GC/ECD e FPD. As recuperações para BHC, DDT, Aldrin e Endrin foram superiores a $70 \%$.

Regitano et. al. (1982) verificaram através de GC, que resíduo de Fenitrotion é mais persistente do que o de Etion na casca de laranja. Estes inseticidas não foram detectados na polpa.

Um estudo foi realizado por Zadrozinska et. al. (1983), para a determinação de resíduo de pesticidas em frutas cítricas. Os resíduos de fungicidas, inseticidas 
organoclorados e inibidores da colinesterase foram determinados em limões e laranjas. Na casca de todas as frutas foi encontrado Tiabendazole, na concentração de 0,25-10 ppm. Nenhum traço de fungicida foi encontrado na polpa da fruta. Inseticidas organoclorados foram encontrados na casca e na polpa em baixas concentrações (0,0002-0,0046 ppm), principalmente DDE, $\alpha$-, $\beta$ - e $\gamma$-HCH.

Kato e Saeki (1983) analisaram pesticidas organofosforados em frutas cítricas importadas. Limão, laranja e “grapefruit” foram examinadas para verificar a ocorrência de pesticidas organofosforados. Metidation, Etion e Paration foram encontrados (0,012-0,267 ppm). Verificaram que a coluna de “clean-up” empregando carvão foi superior à de sílica e de Florisil para separar Metidation, que também foi determinado por GC. A recuperação de Metidation foi de 80,3-93,9\%.

Uma comparação da eficiência de diferentes métodos multiresíduos por GC em frutas, contendo resíduo de pesticidas foi investigada por Anderson e Paelsheden (1991). Comparou-se também a eficiência de método de extração líquido-líquido com acetona e acetato de etila. O método com acetato de etila produz melhores recuperações para pesticidas polares, além disso, é mais rápido, de fácil procedimento e barato, mas alguns co-extratívos são observados. Em geral, ambos os métodos dão recuperações aceitáveis e equivalentes nos testes com pesticidas.

O equilíbrio é estabelecido quando as energias livres (potenciais químicos) do analito nos dois solventes (ou duas fases) são iguais. Na prática, isso ocorre em poucos minutos com agitação vigorosa (Fifield e Kealey, 1995).

A partição oferece muitas possibilidades de separações analíticas, porém em escala mais preparativa, com uma etapa importante na seqüência que leva a um produto puro. Uma vantagem dessa técnica é sua aplicabilidade em uma faixa ampla de concentração, desde quantidades traços até toneladas (Day e Underwood, 1991). 
Existem várias formas de operação com SPE, tais como pré-concentração de analitos a nível de traços, isolamento do analito da matriz ou isolamento da matriz do analito e como recipiente para estocar e transportar amostras (Majors, 1986).

Com a disponibilidade de várias fases sólidas, pôde -se ajustar a seletividade química com a limpeza de extrato. As fases mais comuns foram agrupadas com as classificações de não polar, polar e de troca ionica (Majors, 1998). A escolha da fase sólida está condicionada à polaridade do analito, se este for polar, a fase escolhida deverá ter características polar ou moderadamente polar.

O processo de dessorção é caracterizado pelas interações solvente-analito e solvente-adsorvente. O estado ideal seria ter um mínimo de retenção do analito no adsorvente, para se obter um fator de pré-concentração maior (Liska et. al., 1989). Para escolha do solvente-eluente apropriado pode ser usado o valor de força eluotrópica, que é a polaridade relativa do solvente em uma dada fase sólida. Para o acetato de etila, por exemplo, o índice de polaridade é intermediário ( $p^{\prime}=4,30$ ), sendo menos polar que acetona ( $p^{\prime}=5,40$ ). Porém, como poder de eluição em sílica é superior a acetona. 


\section{MATERIAL E MÉTODOS}

\subsection{Matriz}

- Manga (Mangifera indica).

\subsection{Padrões analíticos}

Os padrões foram adquiridos através da ChemServise; estão dentro da validade de uso e com certificado de analise com grau de pureza acima de $98 \%$.

\subsubsection{Organofosforados}

- Triclorfon;

- Diclorvos;

- Diazinon;

- Monocrotofós;

- Dimetoato;

- Malation;

- Fention;

- Paration;

- Etion. 


\subsubsection{Organoclorados}

- Hexaclorobenzeno;

- Lindano;

- Heptacloro;

- Aldrin;

- Metalacloro;

- Heptacloro Epoxido;

- Trans Clordano;

- óp DDE;

- Endosulfan Alfa;

- Dieldrin;

- p'p DDE;

- Cis Clordano;

- Endrin;

- Endosulfan Beta;

- óp DDT;

- Endosulfan Sulfato;

- Metoxicloro.

\subsubsection{Triazois}

- Tetraconazol;

- Paclobutrazol;

- Tebuconazol;

- Bromuconazol;

- Procloraz;

- Difenoconazol. 


\subsection{Reagentes e solventes}

- Acetonitrila - grau resíduo

- Acetona - grau resíduo

- Diclorometano - grau resíduo

- Éter de Petróleo - grau resíduo

- Acetato de Etila - grau resíduo

- Ciclohexano - grau resíduo

- Tolueno - grau resíduo

- Metanol grau - HPLC

- Água milli Q

\subsection{Vidrarias}

- Provetas graduadas;

- Pipetas volumétricas;

- Erlenmeyers;

- Funis de separação;

- Balões de fundo chato;

- Vial descartável para acondicionamento das amostras.

Todas as vidrarias utilizadas no estudo foram limpas de acordo com a seqüência abaixo:

Lavagem com acetona p.a. $\Rightarrow$ Água de torneira $\Rightarrow$ imersão em extran alcalino por 3 horas, $\Rightarrow$ Uso de escovas apropriadas. $\Rightarrow$ Enxágüe em água de torneira e finalmente acetona p.a.. 


\subsection{Equipamentos}

- Cromatógrafo a Gás Agilent 6890 acoplado a detector de captura de elétrons ( $\mu \mathrm{ECD}$ ), detector fotométrico de chamas com filtro de fósforo (FPD) e workstation para integração;

- Cromatógrafo a Gás Agilent HP 6890 acoplado com detector de espectrometria de massas e workstation para integração;

- Coluna Chrompack CPSIL 19 CB, 30m x 0,25 mm x 0,25 ㅆm;

- Coluna HP-5MS (30m x 0,25mm x 0,25 $\mu \mathrm{m})$;

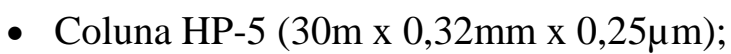

- Evaporador rotativo a vácuo MA 120 - Marconi;

- Bomba a vácuo MZ 2C - Vacuubrand;

- Balança semi-analítica Micronal B-160 - Micronal;

- Balança analítica série 1117082553 - Ohaus;

- Micropipetas com capacidade de $10-100 \mu \mathrm{L}$ e $100-1000 \mu \mathrm{L}$ - Jencons Sealpette;

- Agitador de tubos - Marconi

- Ultra som - Unique;

- Blendor de alta velocidade

\subsection{Coleta e armazenamento das amostras}

Para o desenvolvimento e validação deste método, mangas da variedade Tommy Atkins, cultivadas sem aplicação de pesticidas, foram obtidas em um sitio, localizado no município de Ortigueira, Paraná. O pomar é de propriedade particular e tem-se a certeza de que em um período de no mínimo 15 anos nunca foi aplicado nenhum tipo de pesticida.

Aproximadamente cinco quilos de mangas foram colhidos manualmente, acondicionados em caixa de isopor, previamente revestida com papel alumínio, e 
transportadas diretamente para armazenar na câmara fria $\left(-20^{\circ} \mathrm{C} \pm 5^{\circ} \mathrm{C}\right)$ do Laboratório de resíduo de pesticidas da Bioagri Laboratórios Ltda.

\subsection{Procedimento}

\subsubsection{Preparo de soluções estoque de padrões analíticos}

Padrões de cada pesticida foram pesados e diluídos para uma concentração de aproximadamente $1000 \mu \mathrm{g} / \mathrm{mL}$ em acetona. A partir destas soluções, foram preparadas soluções padrão estoque (mix), para cada grupo de compostos. As concentrações de cada ativo variaram de 10 a $100 \mu \mathrm{g} / \mathrm{mL}$, dependendo do fator de resposta no detector. Estas soluções foram armazenadas em geladeira.

\subsubsection{Solução padrão estoque / organofosforados (mix 1)}

A solução estoque mix1A, foi preparada a partir da solução dos padrões estoques individuais de concentração aproximada a $1000 \mu \mathrm{g} / \mathrm{mL}$, contendo os seguintes padrões analíticos e concentração em $\mu \mathrm{g} / \mathrm{mL}$ : $20 \mu \mathrm{g} / \mathrm{mL}$ triclorfon, $10 \mu \mathrm{g} / \mathrm{mL}$ diclorvos, $10 \mu \mathrm{g} / \mathrm{mL}$ diazinon, $10 \mu \mathrm{g} / \mathrm{mL}$ monocrotofós, $10 \mu \mathrm{g} / \mathrm{mL}$ dimetoato, $20 \mu \mathrm{g} / \mathrm{mL}$ malation, $10 \mu \mathrm{g} / \mathrm{mL}$ fention, $10 \mu \mathrm{g} / \mathrm{mL}$ paration e $10 \mu \mathrm{g} / \mathrm{mL}$ etion. A partir dessa solução estoque (Mix 1A), foram feitas outras diluições (conforme Tabela 3), para obter-se as concentrações utilizadas na construção da curva de calibração. 
Tabela 3. Solução padrão estoque / organofosforados (mix 1)

\begin{tabular}{lcccccc}
\hline \multirow{2}{*}{ Ativos } & \multicolumn{5}{c}{ Concentrações/Código } \\
& MIX(1G) & MIX(1F) & MIX(1E) & MIX(1D) & MIX(1C) & MIX(1B) \\
\hline Diclorvos & $0,05 \mu \mathrm{g} / \mathrm{mL}$ & $0,1 \mu \mathrm{g} / \mathrm{mL}$ & $0,2 \mu \mathrm{g} / \mathrm{mL}$ & $0,5 \mu \mathrm{g} / \mathrm{mL}$ & $1,0 \mu \mathrm{g} / \mathrm{mL}$ & $2,0 \mu \mathrm{g} / \mathrm{mL}$ \\
Diazinon & $0,05 \mu \mathrm{g} / \mathrm{mL}$ & $0,1 \mu \mathrm{g} / \mathrm{mL}$ & $0,2 \mu \mathrm{g} / \mathrm{mL}$ & $0,5 \mu \mathrm{g} / \mathrm{mL}$ & $1,0 \mu \mathrm{g} / \mathrm{mL}$ & $2,0 \mu \mathrm{g} / \mathrm{mL}$ \\
Monocrotofós & $0,05 \mu \mathrm{g} / \mathrm{mL}$ & $0,1 \mu \mathrm{g} / \mathrm{mL}$ & $0,2 \mu \mathrm{g} / \mathrm{mL}$ & $0,5 \mu \mathrm{g} / \mathrm{mL}$ & $1,0 \mu \mathrm{g} / \mathrm{mL}$ & $2,0 \mu \mathrm{g} / \mathrm{mL}$ \\
Dimetoato & $0,05 \mu \mathrm{g} / \mathrm{mL}$ & $0,1 \mu \mathrm{g} / \mathrm{mL}$ & $0,2 \mu \mathrm{g} / \mathrm{mL}$ & $0,5 \mu \mathrm{g} / \mathrm{mL}$ & $1,0 \mu \mathrm{g} / \mathrm{mL}$ & $2,0 \mu \mathrm{g} / \mathrm{mL}$ \\
Fention & $0,05 \mu \mathrm{g} / \mathrm{mL}$ & $0,1 \mu \mathrm{g} / \mathrm{mL}$ & $0,2 \mu \mathrm{g} / \mathrm{mL}$ & $0,5 \mu \mathrm{g} / \mathrm{mL}$ & $1,0 \mu \mathrm{g} / \mathrm{mL}$ & $2,0 \mu \mathrm{g} / \mathrm{mL}$ \\
Paration Metílico & $0,05 \mu \mathrm{g} / \mathrm{mL}$ & $0,1 \mu \mathrm{g} / \mathrm{mL}$ & $0,2 \mu \mathrm{g} / \mathrm{mL}$ & $0,5 \mu \mathrm{g} / \mathrm{mL}$ & $1,0 \mu \mathrm{g} / \mathrm{mL}$ & $2,0 \mu \mathrm{g} / \mathrm{mL}$ \\
Etion. & $0,05 \mu \mathrm{g} / \mathrm{mL}$ & $0,1 \mu \mathrm{g} / \mathrm{mL}$ & $0,2 \mu \mathrm{g} / \mathrm{mL}$ & $0,5 \mu \mathrm{g} / \mathrm{mL}$ & $1,0 \mu \mathrm{g} / \mathrm{mL}$ & $2,0 \mu \mathrm{g} / \mathrm{mL}$ \\
Triclorfon & $0,1 \mu \mathrm{g} / \mathrm{mL}$ & $0,2 \mu \mathrm{g} / \mathrm{mL}$ & $0,4 \mu \mathrm{g} / \mathrm{mL}$ & $1,0 \mu \mathrm{g} / \mathrm{mL}$ & $2,0 \mu \mathrm{g} / \mathrm{mL}$ & $4,0 \mu \mathrm{g} / \mathrm{mL}$ \\
Malation & $0,1 \mu \mathrm{g} / \mathrm{mL}$ & $0,2 \mu \mathrm{g} / \mathrm{mL}$ & $0,4 \mu \mathrm{g} / \mathrm{mL}$ & $1,0 \mu \mathrm{g} / \mathrm{mL}$ & $2,0 \mu \mathrm{g} / \mathrm{mL}$ & $4,0 \mu \mathrm{g} / \mathrm{mL}$ \\
\hline
\end{tabular}

\subsubsection{Solução padrão estoque / organoclorados ( $\operatorname{mix} 2)$}

A solução estoque mix2A, foi preparada a partir da solução dos padrões estoques individuais de concentração aproximada a $1000 \mu \mathrm{g} / \mathrm{mL}$, contendo os seguintes padrões analíticos: Lindano, aldrin, hexaclorobenzeno, heptacloro, metalacloro, heptacloro epoxido, trans clordano, o'p DDE, endosulfan alfa, dieldrin, p'p DDE, cis clordano, endrin, endosulfan beta, , o’́p DDT endosulfan sulfato e metoxicloro, todos na concentração de $10 \mu \mathrm{g} / \mathrm{mL}$. A partir dessa solução estoque (Mix 2A), foram feitas outras diluições (Conforme Tabela 4), para obter-se as concentrações utilizadas na construção da curva de calibração. 
Tabela 4. Solução padrão estoque / organoclorados (mix 2)

\begin{tabular}{lllllll}
\hline \multirow{2}{*}{ Ativos } & \multicolumn{5}{c}{ Concentrações/Código } \\
& $\operatorname{MIX}(2 \mathrm{G})$ & $\operatorname{MIX}(2 \mathrm{~F})$ & $\operatorname{MIX}(2 \mathrm{E})$ & $\operatorname{MIX}(2 \mathrm{D})$ & $\operatorname{MIX}(2 \mathrm{C})$ & $\operatorname{MIX}(2 \mathrm{~B})$ \\
\hline \multirow{2}{*}{ Organoclorados } & $0,05 \mu \mathrm{g} / \mathrm{mL}$ & $0,1 \mu \mathrm{g} / \mathrm{mL}$ & $0,2 \mu \mathrm{g} / \mathrm{mL}$ & $0,4 \mu \mathrm{g} / \mathrm{mL}$ & $0,8 \mu \mathrm{g} / \mathrm{mL}$ & $1,6 \mu \mathrm{g} / \mathrm{mL}$ \\
\hline
\end{tabular}

\subsubsection{Solução padrão estoque / Triazois + Fention (mix 3)}

A solução estoque mix3A, foi preparada a partir da solução dos padrões estoques individuais de concentração aproximada a $1000 \mu \mathrm{g} / \mathrm{mL}$, contendo os seguintes padrões analíticos e concentração em $\mu \mathrm{g} / \mathrm{mL}$ : 50 $\mu \mathrm{g} / \mathrm{mL}$ Tetraconazol, 10 $\mu \mathrm{g} / \mathrm{mL}$ paclobutrazol, $50 \mu \mathrm{g} / \mathrm{mL}$ tebuconazol, $25 \mu \mathrm{g} / \mathrm{mL}$ bromuconazol, $100 \mu \mathrm{g} / \mathrm{mL}$ procloraz, $100 \mu \mathrm{g} / \mathrm{mL}$ difenoconazol e $25 \mu \mathrm{g} / \mathrm{mL}$ fention. A partir dessa solução estoque (Mix 3A), foram feitas outras diluições (conforme tabela 5), para obter-se as concentrações utilizadas na construção da curva de calibração.

Tabela 5. Solução padrão estoque / Triazois + Fention (mix 3)

\begin{tabular}{lcccccc}
\hline \multirow{2}{*}{ Ativos } & \multicolumn{5}{c}{ Concentrações/Código } \\
& MIX(3G) & MIX(3F) & MIX(3E) & MIX(3D) & MIX(3C) & MIX(3B) \\
\hline Paclobutrazol & $0,1 \mu \mathrm{g} / \mathrm{mL}$ & $0,2 \mu \mathrm{g} / \mathrm{mL}$ & $0,4 \mu \mathrm{g} / \mathrm{mL}$ & $0,6 \mu \mathrm{g} / \mathrm{mL}$ & $0,8 \mu \mathrm{g} / \mathrm{mL}$ & $1,0 \mu \mathrm{g} / \mathrm{mL}$ \\
\hline Fention & $0,25 \mu \mathrm{g} / \mathrm{mL}$ & $0,5 \mu \mathrm{g} / \mathrm{mL}$ & $1,0 \mu \mathrm{g} / \mathrm{mL}$ & $1,5 \mu \mathrm{g} / \mathrm{mL}$ & $2,0 \mu \mathrm{g} / \mathrm{mL}$ & $2,5 \mu \mathrm{g} / \mathrm{mL}$ \\
Bromuconazol & $0,25 \mu \mathrm{g} / \mathrm{mL}$ & $0,5 \mu \mathrm{g} / \mathrm{mL}$ & $1,0 \mu \mathrm{g} / \mathrm{mL}$ & $1,5 \mu \mathrm{g} / \mathrm{mL}$ & $2,0 \mu \mathrm{g} / \mathrm{mL}$ & $2,5 \mu \mathrm{g} / \mathrm{mL}$ \\
Tetraconazol & $0,5 \mu \mathrm{g} / \mathrm{mL}$ & $1,0 \mu \mathrm{g} / \mathrm{mL}$ & $2,0 \mu \mathrm{g} / \mathrm{mL}$ & $3,0 \mu \mathrm{g} / \mathrm{mL}$ & $4,0 \mu \mathrm{g} / \mathrm{mL}$ & $5,0 \mu \mathrm{g} / \mathrm{mL}$ \\
Tebuconazol & $0,5 \mu \mathrm{g} / \mathrm{mL}$ & $1,0 \mu \mathrm{g} / \mathrm{mL}$ & $2,0 \mu \mathrm{g} / \mathrm{mL}$ & $3,0 \mu \mathrm{g} / \mathrm{mL}$ & $4,0 \mu \mathrm{g} / \mathrm{mL}$ & $5,0 \mu \mathrm{g} / \mathrm{mL}$ \\
Procloraz & $1,0 \mu \mathrm{g} / \mathrm{mL}$ & $2,0 \mu \mathrm{g} / \mathrm{mL}$ & $4,0 \mu \mathrm{g} / \mathrm{mL}$ & $6,0 \mu \mathrm{g} / \mathrm{mL}$ & $8,0 \mu \mathrm{g} / \mathrm{mL}$ & $10,0 \mu \mathrm{g} / \mathrm{mL}$ \\
Difenoconazol & $1,0 \mu \mathrm{g} / \mathrm{mL}$ & $2,0 \mu \mathrm{g} / \mathrm{mL}$ & $4,0 \mu \mathrm{g} / \mathrm{mL}$ & $6,0 \mu \mathrm{g} / \mathrm{mL}$ & $8,0 \mu \mathrm{g} / \mathrm{mL}$ & $10,0 \mu \mathrm{g} / \mathrm{mL}$ \\
\hline
\end{tabular}




\subsubsection{Identificação}

Os padrões dos mix 1 e 2, foram injetados individualmente em cromatógrafo a gás acoplado ao detector FPD/ECD, respectivamente, afins de obter o tempo de retenção para a identificação de cada pesticida.

Os padrões do mix 3, foram injetados individualmente em cromatógrafo a gás acoplado ao detetor de massa (CG/MS) no modo SCAN, a fim de obter o tempo de retenção e os íons de identificação de cada pesticida.

\subsubsection{Linearidade}

A linearidade foi obtida através da curva-padrão de cada pesticida, com seis níveis de concentração, injetados em triplicata.

Nas Figuras 1 a 9, observamos pelos gráficos e pelo coeficiente de determinação $\left(r^{2}>0,99\right)$ que a resposta do detector foi linear na faixa de 0,1 - 4,0 $\mu \mathrm{g} / \mathrm{mL}$ para o triclorfon e malation e de $0,05-2,0 \mu \mathrm{g} / \mathrm{mL}$ para os demais organofosforados. $\mathrm{O}$ Anexo A resume os valores encontrados para o método da linearidade.

Nas Figuras 10 a 26, observamos pelos gráficos e pelo coeficiente de determinação $\left(r^{2}>0,99\right)$ que a resposta do detector foi linear na faixa de $0,05-1,6 \mu \mathrm{g} / \mathrm{mL}$ para os organoclorados. O Anexo B resume os valores encontrados para o método da linearidade.

Nas Figuras 27 a 33, observamos pelos gráficos e pelo coeficiente de determinação $\left(r^{2}>0,99\right)$ que a resposta do detector foi linear na faixa de $0,1-1,0 \mu \mathrm{g} / \mathrm{mL}$ para o paclobutrazol, 0,25 - 2,5 $\mu \mathrm{g} / \mathrm{mL}$ para o fention e bromuconazol, 0,5 - 5,0 $\mu \mathrm{g} / \mathrm{mL}$ para o tetraconazol e tebuconazol e $1,0-10 \mu \mathrm{g} / \mathrm{mL}$ para o procloraz e difenoconazol 
respectivamente. O Anexo $\mathrm{C}$ resume os valores encontrados para o método da linearidade.

\subsubsection{Preparação das amostras}

As amostras de manga foram retiradas da câmara fria e deixadas por 15 minutos à temperatura ambiente, para um leve descongelamento. As mangas, semicongeladas, foram cortadas em pequenos pedaços, o seu caroço foi descartado, e a polpa juntamente com a casca, foram transferidas para um triturador onde foram completamente trituradas e homogeneizadas.

\subsubsection{Método de extração de organofosforados}

Pesou-se $20 \mathrm{~g}$ da amostra em frasco turrax. Adicionou-se $100 \mathrm{~mL}$ de Acetona/ diclorometano (1:1, v/v) e agitou-se em alta rotação durante 2 minutos. A seguir, filtrou-se a mistura para kitassato com auxílio de papel de filtro $n^{\circ} .42$. Recolheu-se o bolo e repetiu-se o processo. Lavou-se com 30mL da mistura acetona/diclorometano, filtrou-se e juntou-se os filtrados. Evaporou-se o extrato até a secura em evaporador rotativo a vácuo à temperatura de $40^{\circ} \mathrm{C}$. Ressuspendeu-se o resíduo com $10 \mathrm{~mL}$ de acetona e analisou-se por cromatografia gasosa com detector fotométrico de chama, filtro fósforo, conforme descrito no item 3.8.1.

\subsubsection{Método de extração de organoclorados}

Pesou-se 20g da amostra em frasco turrax. Adicionou-se $100 \mathrm{~mL}$ de diclorometano e agitou-se em alta rotação durante 2 minutos. A seguir, filtrou-se a amostra para kitassato com auxílio de papel de filtro $n^{\circ}$. 42. Recolheu-se o bolo e repetiu-se o processo. Lavou-se com mais $30 \mathrm{~mL}$ de diclorometano, filtrou-se e juntou-se os filtrados. Evaporou-se o extrato até a secura em evaporador rotativo a vácuo à temperatura de $40^{\circ} \mathrm{C}$. Ressuspendeu-se o resíduo com $2 \mathrm{~mL}$ de tolueno e analisou-se por 
cromatografia gasosa com detector de captura de elétrons, conforme descrito no item 3.8.2.

\subsubsection{Método de extração de triazois + fention}

a) Pesou-se $20 \mathrm{~g}$ da amostra em frasco turrax. Adicionou-se $50 \mathrm{~mL}$ de acetonitrila/ água (70:30,v/v) e agitou-se por 2 minutos a $22.000 \mathrm{rpm}$.

b) Após agitação a amostra ficou 2 minutos em ultra-som e a seguir, foi centrifugada a $2.500 \mathrm{rpm}$ por 15 minutos.

c) Transferiu-se com pipeta todo o sobrenadante para um funil de separação, adicionou-se $30 \mathrm{~mL}$ de diclorometano e agitou-se durante 1 minuto.

d) Após a separação das fases, a camada orgânica foi filtrada por um funil contendo sulfato de sódio o qual estava acoplado a balão de evaporação.

e) A amostra de manga precipitada no tubo de centrifuga (Item b) foi novamente ressuspendida com $30 \mathrm{~mL}$ da mistura acetonitrila/água (70:30) e todo o processo de extração foi repetido.

f) $\mathrm{O}$ extrato da primeira e da segunda extração, foi recolhido no mesmo frasco e evaporado até a secura em evaporador rotativo a vácuo à temperatura de $40^{\circ} \mathrm{C}$.

g) Ressuspendeu-se o resíduo com $2 \mathrm{~mL}$ de acetona e analisou-se por cromatografia gasosa, acoplado ao detector de espectrometria de massa, nas condições descritas no item 3.8.3. 


\subsubsection{Especificidade}

Para avaliar a especificidade do método, amostras de manga sem o uso de agrotóxico (testemunha) e todos os reagentes (branco de reagente), foram preparados e analisados no mesmo método descritos nos itens 3.7.4.1 a 3.7.4.3.

Uma fração do extrato de cada amostra analisada foi injetada no cromatógrafo a gás, nas mesmas condições cromatográficas apresentadas nos itens 3.8.1 a 3.8.3, a fim de avaliar a presença de picos interferentes nos tempos de retenção dos pesticidas investigados.

\subsubsection{Limites de quantificação e porcentagens de recuperação dos pesticidas adicionados em manga}

\subsubsection{Limites de quantificação e porcentagens de recuperação de organofosforados em manga}

Para o estudo dos limites de quantificação e porcentagem de recuperação dos resíduos dos organofosforados em manga, foram realizadas fortificações em dois níveis de concentração, no limite de quantificação do método (LOQ) e dez vezes o limite de quantificação (10 LOQ), sendo que a fortificação do LOQ foi realizada com 7 repetições $(\mathrm{N}=7)$ e a concentração de 10 LOQ foi realizada com $\mathrm{N}=5$.

Para a determinação do LOQ, $1 \mathrm{~mL}$ da solução mix(1C) foi adicionado à $20 \mathrm{~g}$ da amostra, obtendo-se a concentração de $0,1 \mathrm{mg} / \mathrm{kg}$ para o triclorfon e malation e 0,05 mg/kg para (Diclorvos, Diazinon, Monocrotofós, Dimetoato, Fention, Paration e Etion).

Para a determinação de $10 \mathrm{LOQ}, 1 \mathrm{~mL}$ da solução $\operatorname{mix}(1 \mathrm{~A})$, foi adicionado à $20 \mathrm{~g}$ da amostra, obtendo-se a concentração de $1 \mathrm{mg} / \mathrm{kg}$ para o triclorfon e malation e 0,5 $\mathrm{mg} / \mathrm{kg}$ para os demais organofosforados. 
Estas soluções foram injetadas no cromatógrafo a gás com detector fotométrico de chama (CG/FPD) nas mesmas condições cromatográficas apresentadas no item 3.8.1., a fim de avaliar a exatidão do método.

\subsubsection{Limites de quantificação e porcentagens de recuperação de organoclorados em manga}

Para o estudo dos limites de quantificação e porcentagem de recuperação dos resíduos dos organoclorados em manga, foram realizadas fortificações em dois níveis de concentração, no limite de quantificação do método (LOQ) e dez vezes o limite de quantificação (10 LOQ), sendo que a fortificação do LOQ foi realizada com 7 repetições $(\mathrm{N}=7)$ e a concentração de 10 LOQ foi realizada com $\mathrm{N}=5$. Foram adicionados $0,2 \mu \mathrm{g}$ e 2,0 $\mu \mathrm{g}$ de cada um dos ingredientes ativos estudados em $20 \mathrm{~g}$ de amostra de manga obtendo-se assim, concentrações de 0,01mg/kg e 0,1mg/kg, respectivamente.

Estas soluções foram injetadas no cromatógrafo a gás com detector de captura de elétrons (CG/ $\mu E C D)$ nas mesmas condições cromatográficas apresentadas no item 3.8.2., a fim de avaliar a exatidão do método. As fortificação de 10 LOQ foram ressuspendidas com $4 \mathrm{~mL}$ de tolueno.

\subsubsection{Limites de quantificação e porcentagens de recuperação de triazois + fention em manga}

Todo ingrediente ativo estudado nesta fortificação tem o uso de seus produtos agrícola autorizado em manga, pela ANVISA. Com isto, o método foi validado no limite estabelecido pela legislação.

Para o estudo dos limites de quantificação e porcentagem de recuperação dos resíduos dos triazois + fention em manga, foram realizadas fortificações em dois níveis 
de concentração, no limite de quantificação do método (LOQ) e dez vezes o limite de quantificação (10 LOQ), sendo que a fortificação do LOQ foi realizada com 7 repetições ( $\mathrm{N}=7$ ) e a concentração de 10 LOQ foi realizada com $\mathrm{N}=5$.

Para a determinação do LOQ, 0,04mL da solução mix (3A) foi adicionado à $20 \mathrm{~g}$ da amostra, obtendo-se a concentração de 0,02 mg/kg para o paclobutrazol; 0,05 $\mathrm{mg} / \mathrm{kg}$ para o (fention e bromuconazol); 0,1 mg/kg para o (tetraconazol e tebuconazol) e $0,2 \mathrm{mg} / \mathrm{kg}$ para o (procloraz e difenoconazol). Esta fortificação foi extraída de acordo com o item 3.7.4.3, a fim de avaliar a exatidão do método.

Para a determinação de $10 \mathrm{LOQ}, 0,4 \mathrm{~mL}$ da solução mix (3A) foi adicionado à $20 \mathrm{~g}$ da amostra, obtendo-se a concentração de $0,2 \mathrm{mg} / \mathrm{kg}$ para o paclobutrazol; 0,5 $\mathrm{mg} / \mathrm{kg}$ para o (fention e bromuconazol); $1,0 \mathrm{mg} / \mathrm{kg}$ para o (tetraconazol e tebuconazol) e $2,0 \mathrm{mg} / \mathrm{kg}$ para o (procloraz e difenoconazol). Esta fortificação foi extraída de acordo com o item 3.7.4.3, a fim de avaliar a exatidão do método, com uma única modificação; o resíduo foi ressuspendido com $20 \mathrm{~mL}$ de acetona, para que o resíduo esperado ficasse dentro da faixa de linearidade.

\subsection{Condições cromatográficas}

3.8.1 Cromatógrafo a gás: detector fotométrico de chama, filtro fósforo - análise de organofosforados

- Cromatógrafo a gás Agilent HP 6890 (CG\#08) acoplado a detector fotométrico de chama com filtro fósforo, workstation para integração;

- Coluna: DB-17 (15m x 530 $\mu \mathrm{m}$ x $1 \mu \mathrm{m})$;

- Gás de arraste: Nitrogênio: $5 \mathrm{~mL} / \mathrm{min}$;

Hidrogênio: 50mL/min;

Ar: $100 \mathrm{~mL} / \mathrm{min}$;

- $\quad$ Temperatura da coluna: $50^{\circ} \mathrm{C}(1 \mathrm{~min}) / 10^{\circ} \mathrm{C} / \mathrm{min} / 250^{\circ} \mathrm{C}(20 \mathrm{~min})$; 
- $\quad$ Temperatura do injetor: $250^{\circ} \mathrm{C}$;

- Temperatura do detector: $250^{\circ} \mathrm{C}$;

- Volume de injeção: $3 \mu \mathrm{L}$.

\subsection{Cromatógrafo a gás: detector $\mu E C D$ - análise de organoclorados}

- $\quad$ Cromatógrafo a gás Agilent HP 6890 (CG\#08) equipado com detector $\mu E C D$ e workstation para integração;

- $\quad$ Coluna: HP-5 (30m x 0,25 $\mu \mathrm{m}$ x 0,32mm);

- $\quad$ Gás de arraste: Nitrogênio: $1 \mathrm{~mL} / \mathrm{min}$;

- $\quad$ Temperatura da coluna: $120^{\circ} \mathrm{C}$ (7min) / $5^{\circ} \mathrm{C} / \mathrm{min}$. / $200^{\circ} \mathrm{C}(3 \mathrm{~min}) /$ $7^{\circ} \mathrm{C} / \mathrm{min} / 250^{\circ} \mathrm{C}(2 \mathrm{~min}) / 20^{\circ} \mathrm{C} / \mathrm{min} / 270^{\circ} \mathrm{C}(5 \mathrm{~min})$;

- $\quad$ Temperatura do injetor: $280^{\circ} \mathrm{C}$;

- $\quad$ Temperatura do detector: $280^{\circ} \mathrm{C}$;

- $\quad$ Volume de injeção: $1 \mu \mathrm{L}$.

3.8.3 Cromatógrafo a gás: acoplado ao detector de espectrometria de massas análise de triazois e fention

- $\quad$ Cromatógrafo a gás Agilent HP 6890 equipado com detector de espectrometria de massas e workstation para integração;

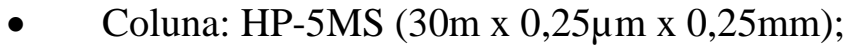

- $\quad$ Gás de arraste: Helio: $1 \mathrm{~mL} / \mathrm{min}$;

- $\quad$ Temperatura da Coluna: $100^{\circ} \mathrm{C}(1 \mathrm{~min}) / 20^{\circ} \mathrm{C} / \mathrm{min}$. / $280^{\circ} \mathrm{C}(10 \mathrm{~min})$;

- $\quad$ Temperatura do injetor: $280^{\circ} \mathrm{C}$;

- $\quad$ Temperatura do detector: $180^{\circ} \mathrm{C}$;

- $\quad$ Volume de injeção: $1 \mu \mathrm{L}$. 


\subsection{Cálculos}

\subsubsection{Média aritmética}

A média aritmética foi determinada pela seguinte equação:

$$
\bar{x}=\frac{x_{1}+x_{2}+\ldots+x_{n}}{n}=\frac{\sum x_{i}}{n}
$$

onde:

$\bar{X}=$ média aritmética dos valores;

$x=\quad$ valor obtido;

$n=$ números de resultados obtidos;

$x_{i}=\quad$ índice do valor de $\mathrm{x}$.

\subsubsection{Estimativa do desvio padrão $( \pm)$}

A estimativa do desvio padrão (s) foi determinada pela seguinte equação:

$$
S=\sqrt{\frac{\sum\left(x_{i}-\bar{x}\right)^{2}}{(n-1)}}
$$

onde:

$s$ = estimativa do desvio padrão.

\subsubsection{Coeficiente de variação (CV\%)}

O coeficiente de variação porcentual (CV\%) em relação à média global (de todos os níveis de fortificação) foi determinado pela seguinte equação: 


$$
C V(\%)=\frac{s}{\bar{x}} \times 100
$$

onde:

$\bar{X}=$ média aritmética dos valores;

$s=$ estimativa do desvio padrão.

\subsubsection{Coeficiente linear (A) e coeficiente angular (B)}

Os coeficientes linear e angular foram obtidos em função da equação da reta gerados no cálculo estatístico do software da workstation de cada um dos equipamentos utilizados nas análises.

\subsubsection{Cálculo do coeficiente de correlação}

Foi gerado pelo software da Workstation o coeficiente de determinação $\left(\mathrm{r}^{2}\right)$.

Para obter o coeficiente de correlação (r), efetua-se a seguinte equação:

$$
r=\sqrt{r^{2}}
$$

\subsubsection{Cálculo da recuperação}

As porcentagens de recuperação foram calculadas pela seguinte equação:

$$
\text { Recuperação }(\%)=\frac{\mathrm{mg} / \mathrm{kg} \text { encontrado }}{\text { nível de fortificação }(\mathrm{mg} / \mathrm{kg})} \times 100
$$




\section{RESULTADOS E DISCUSSÃO}

Os três métodos estudados foram baseados no Analytical Methods for Pesticide Residues in Foodstuffs, este é um método que já trabalha com um volume reduzido de solvente.

Para as análises de organodosforados este método não teve desvio.

Para análise dos organoclorados a modificação do método mais significativa foi utilizar o diclorometano, sem a mistura de acetona, com isto a quantidade de interferentes foi reduzida em mais de $50 \%$.

Para as análises dos triazois, a modificação mais significativa foi à extração com acetonitrila e água, a partição com diclorometano e o sobrenadante do extraído possibilitou que a maioria dos interferentes ficasse com a fase aquosa e os ativos de interesse na camada orgânica.

\subsection{Linearidade}

\subsubsection{Linearidade do detector fotométrico de chama para os organofosforados}

Os resultados do estudo de linearidade estão apresentados nas Figuras 3 a 11. Pode-se observar por estes gráficos e pelo coeficiente de determinação $\left(r^{2}>0,99\right)$ que a resposta do detector foi linear na faixa de $0,1-4,0 \mu \mathrm{g} / \mathrm{mL}$ para o triclorfon e malation e de $0,05-2,0 \mu \mathrm{g} / \mathrm{mL}$ para os demais organofosforados. 
O Anexo A, resume os valores encontrados da linearidade.

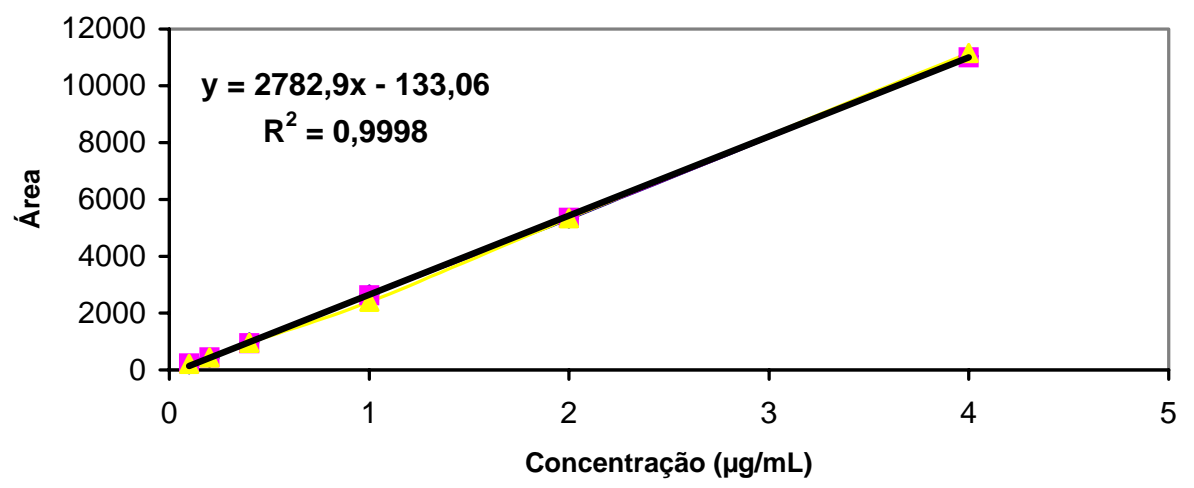

Figura 3 - Área do pico em função da concentração de triclorfon

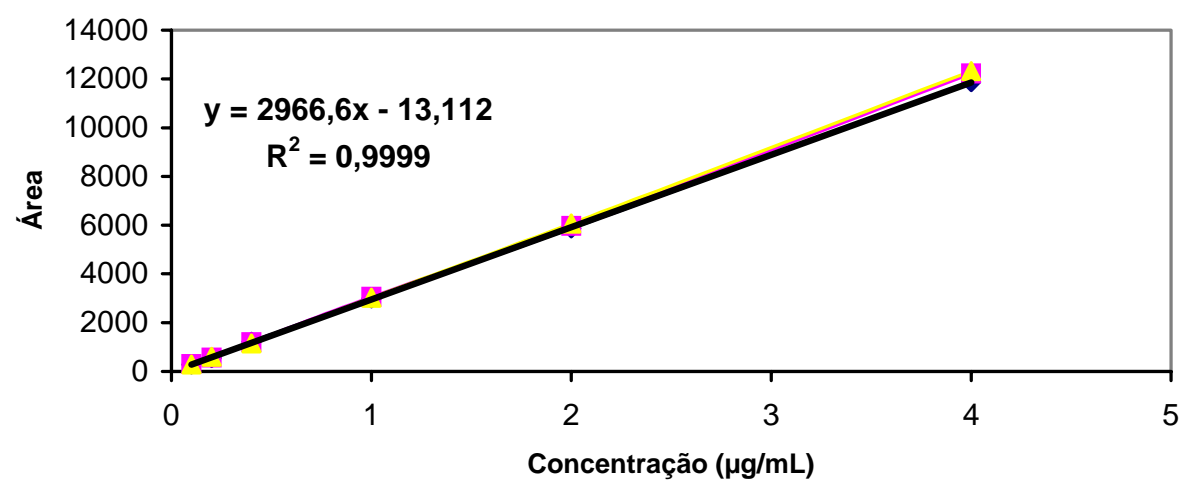

Figura 4 - Área do pico em função da concentração de malation 


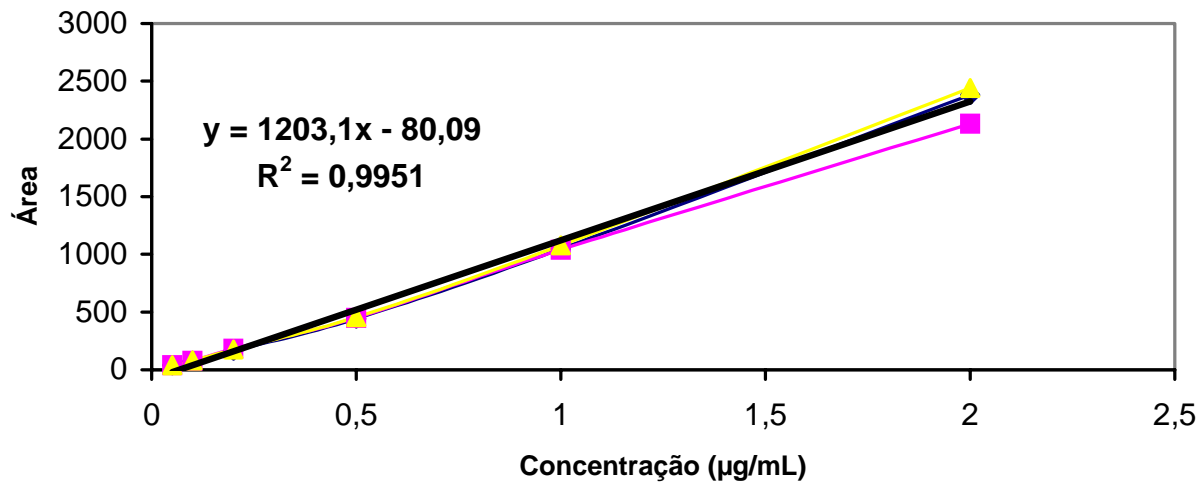

Figura 5 - Área do pico em função da concentração de monocrotofos

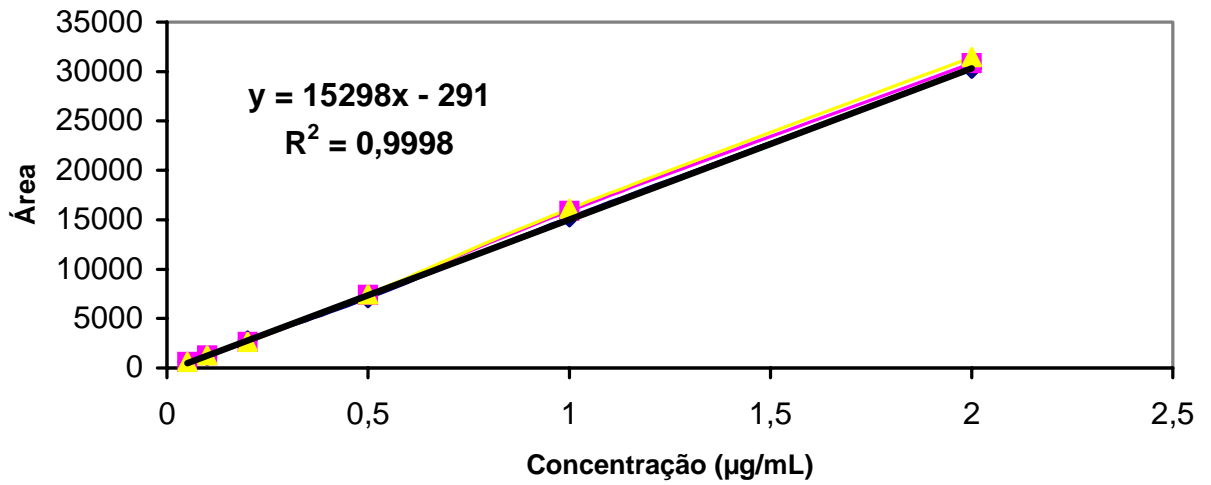

Figura 6 - Área do pico em função da concentração de diclorvos 


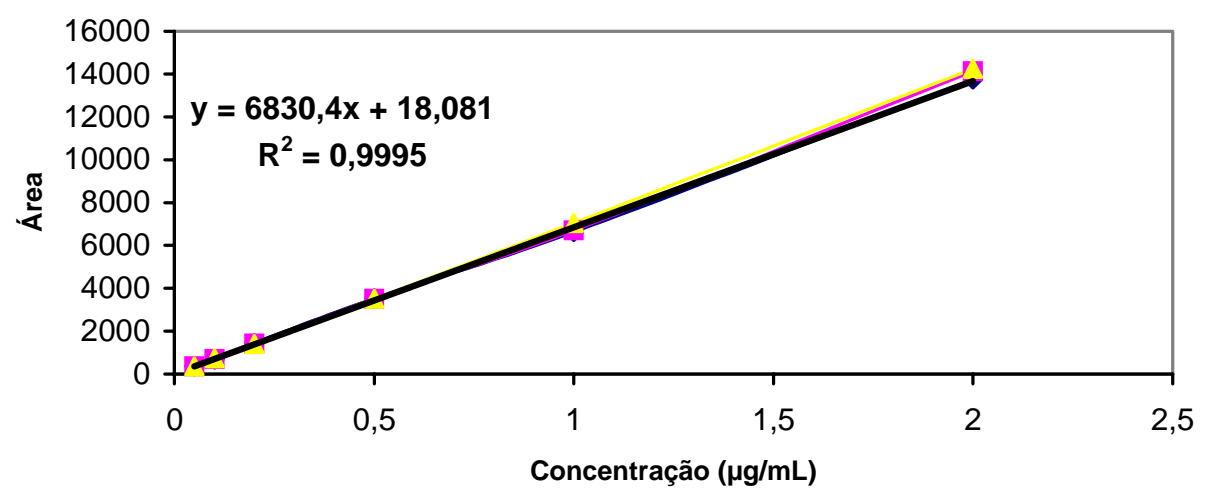

Figura 7 - Área do pico em função da concentração de diazinon

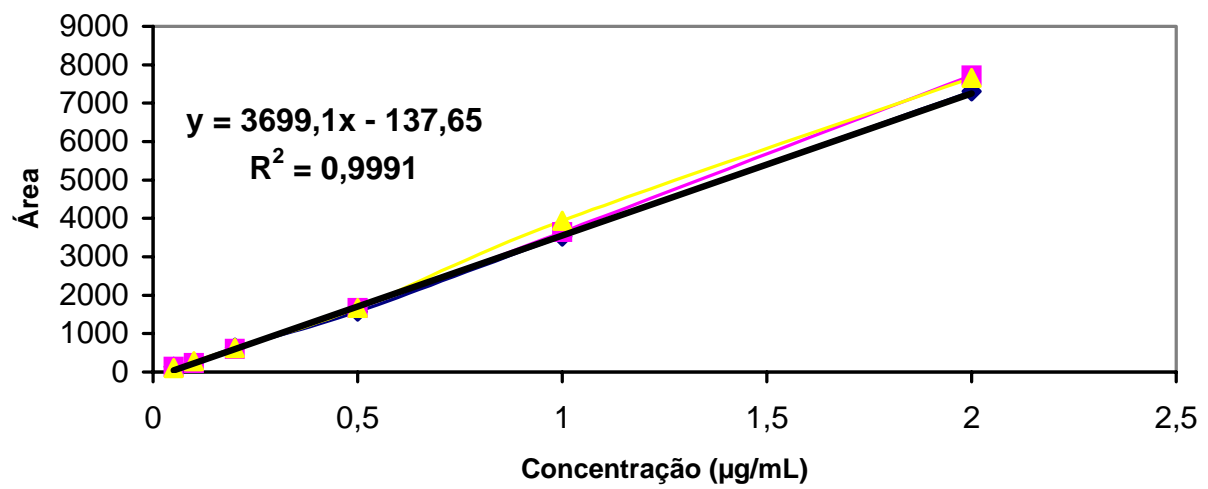

Figura 8 - Área do pico em função da concentração de dimetoato

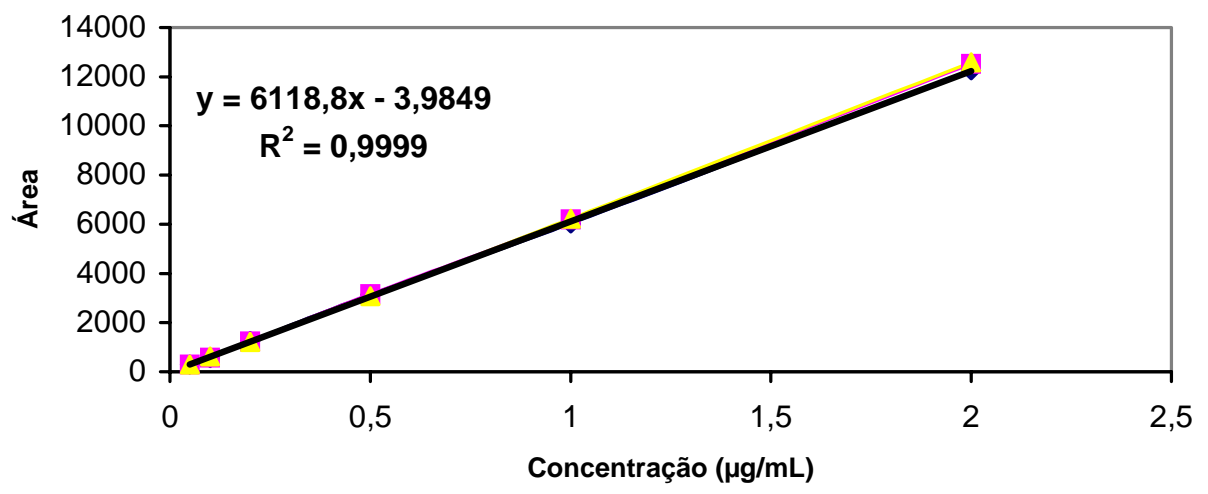

Figura 9 - Área do pico em função da concentração de fention 


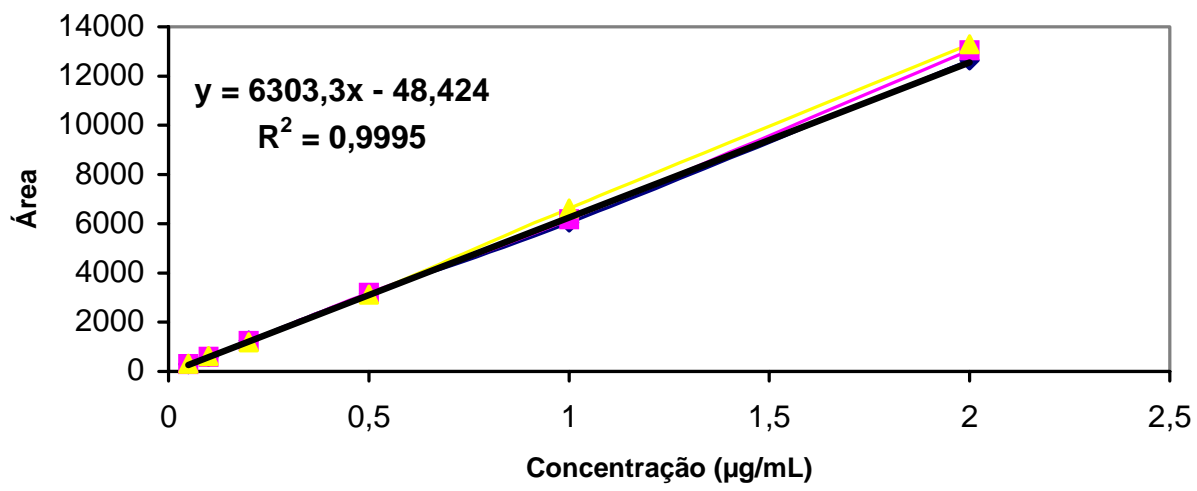

Figura 10 - Área do pico em função da concentração de paration metílico

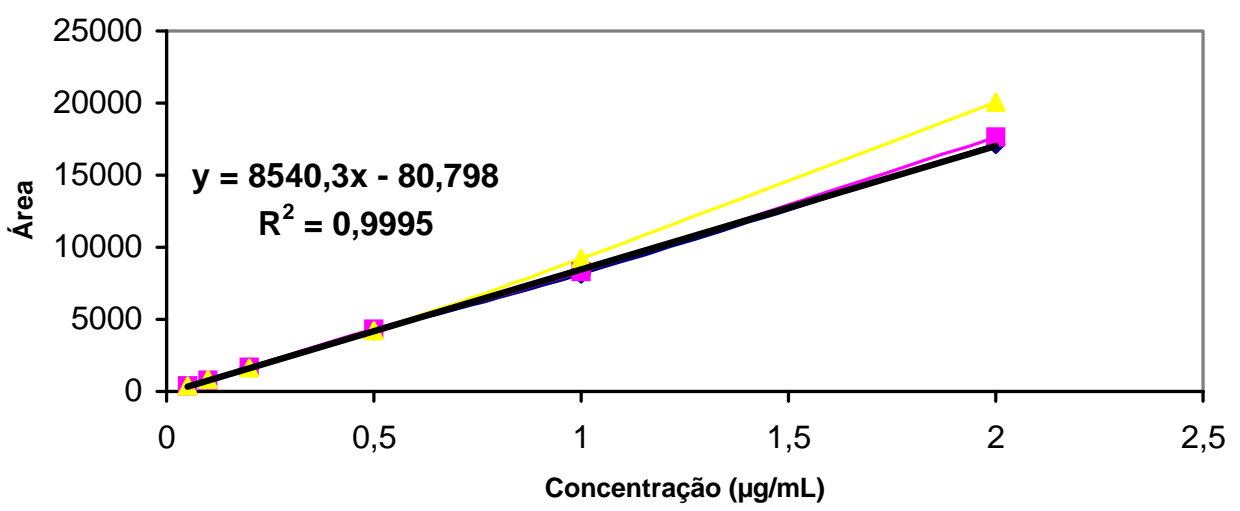

Figura 11 - Área do pico em função da concentração de etion

\subsubsection{Linearidade do detector de captura de elétrons para os organoclorados}

Os resultados do estudo de linearidade estão apresentados nas Figuras 12 a 28. Pode-se observar por estes gráficos e pelo coeficiente de determinação $\left(r^{2}>0,99\right)$ que a resposta do detector foi linear na faixa de $0,05-1,6 \mu \mathrm{g} / \mathrm{mL}$ para os organoclorados.

O Anexo B, resume os valores encontrados da linearidade. 


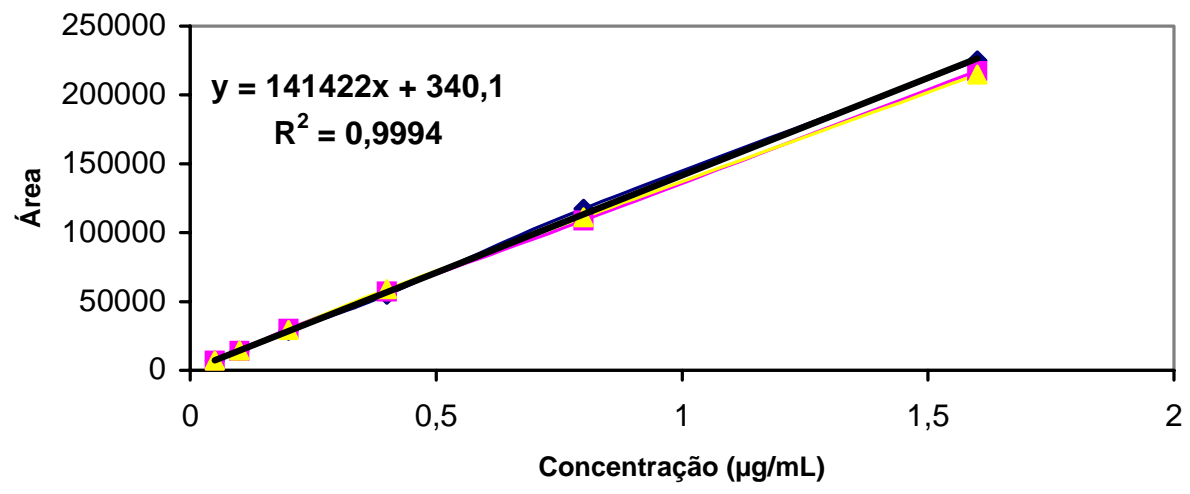

Figura 12 - Área do pico em função da concentração de hexaclorobenzeno

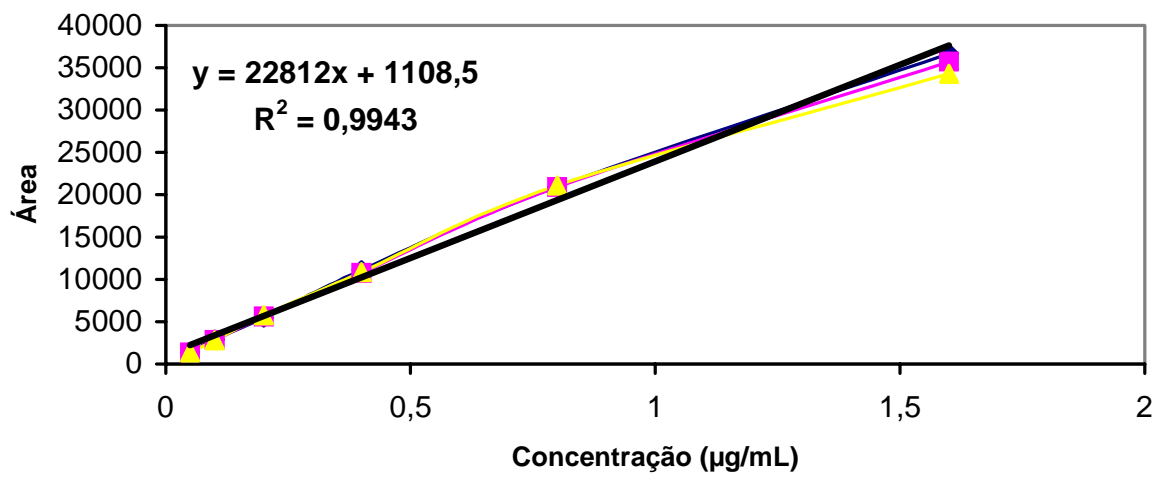

Figura 13 - Área do pico em função da concentração de lindano

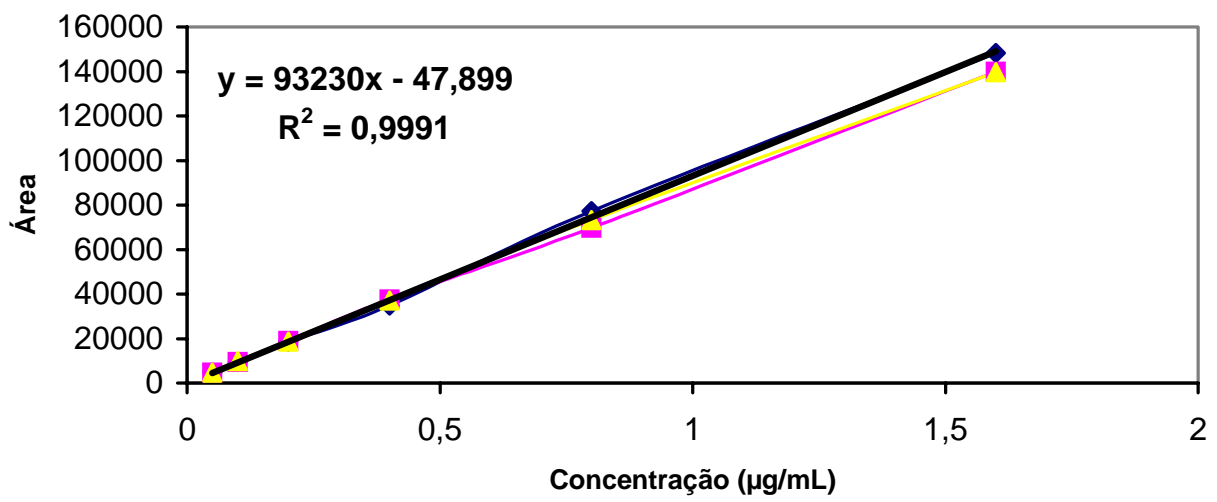

Figura 14 - Área do pico em função da concentração de heptacloro 


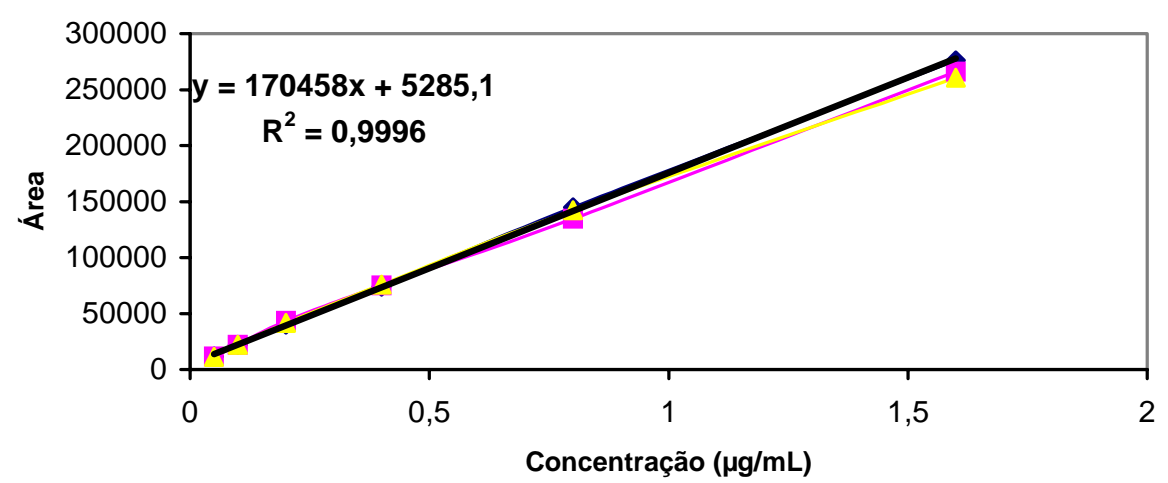

Figura 15 - Área do pico em função da concentração de aldrin.

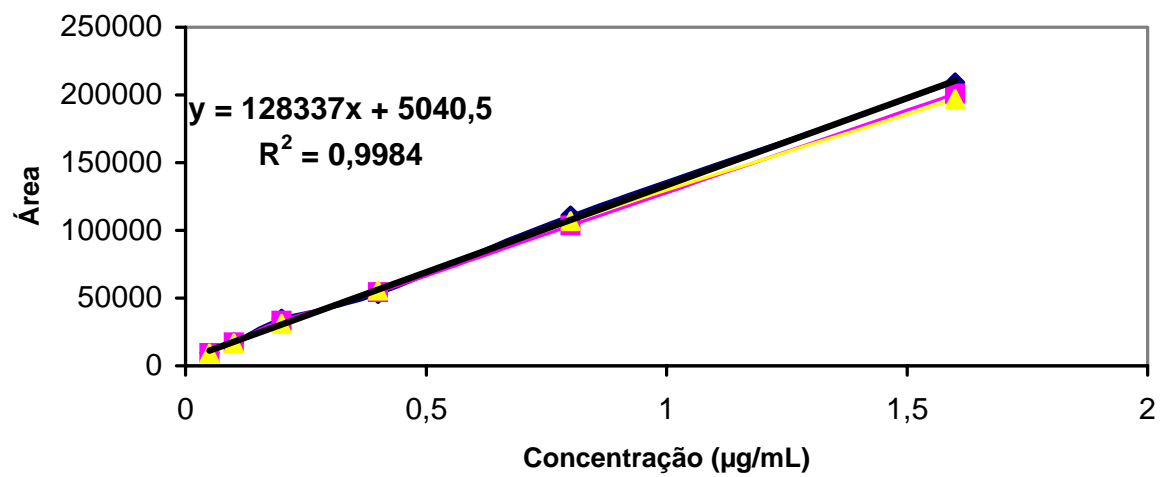

Figura 16 - Área do pico em função da concentração de metalacloro

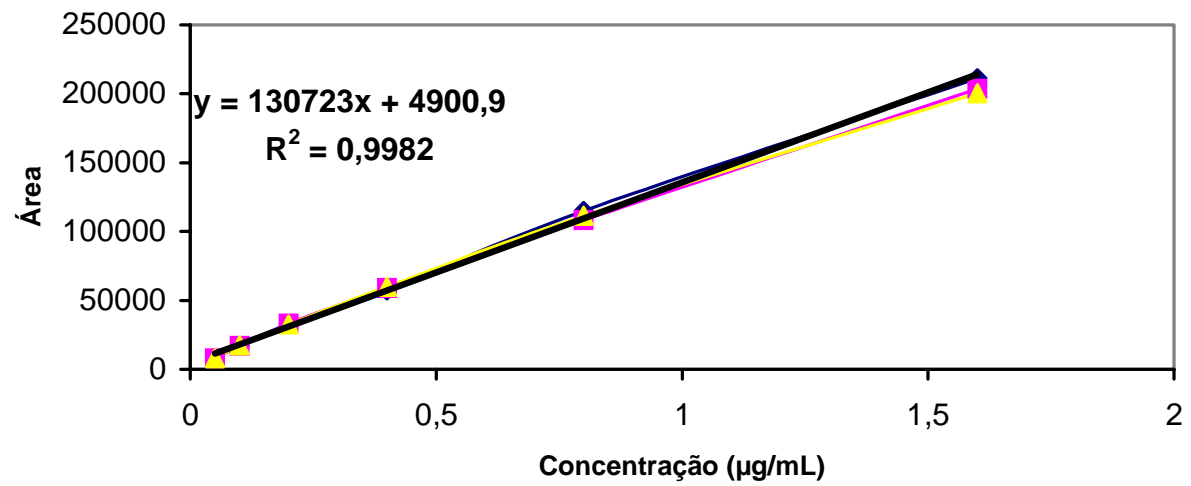

Figura 17 - Área do pico em função da concentração de heptacloro epoxido 


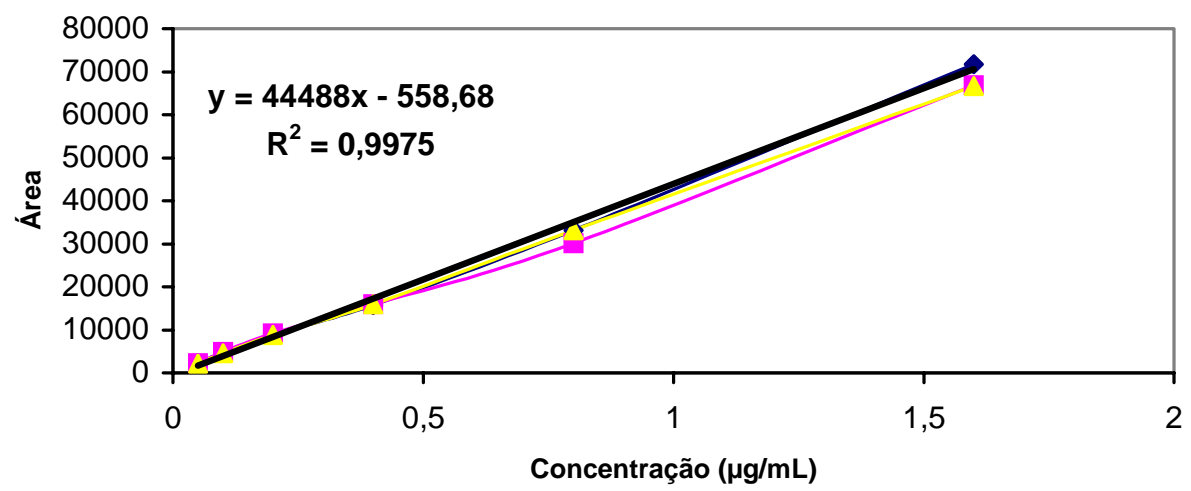

Figura 18 - Área do pico em função da concentração de trans clordano

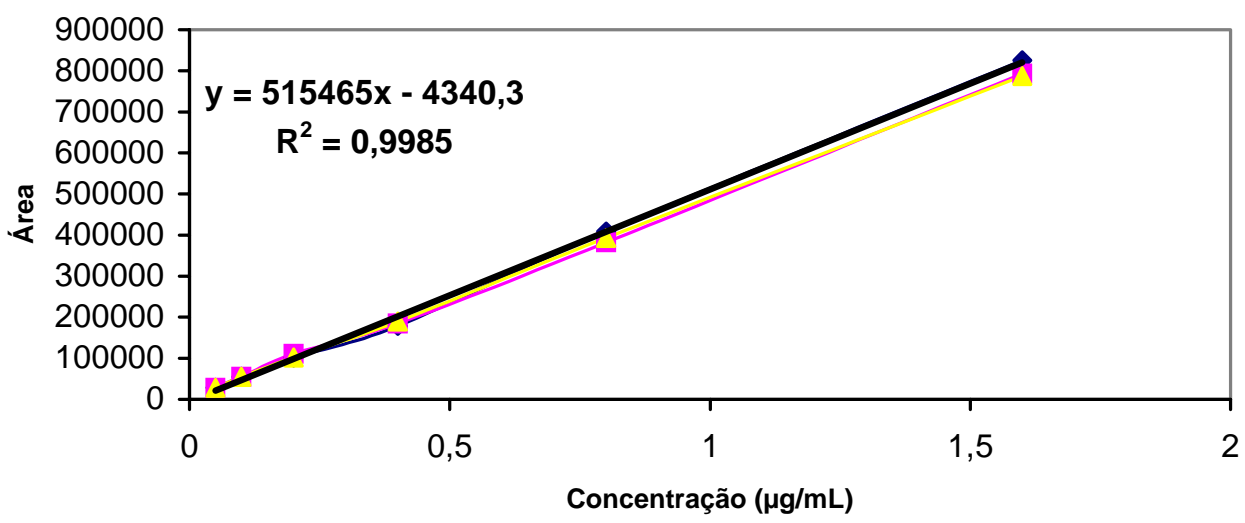

Figura 19 - Área do pico em função da concentração de o’́p-dde

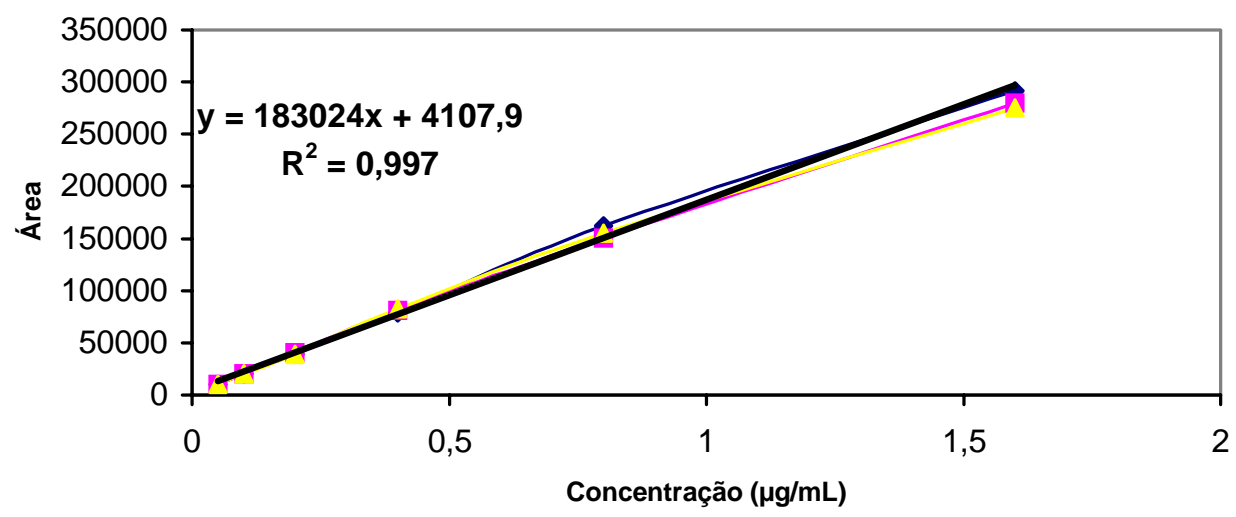

Figura 20 - Área do pico em função da concentração de endosulfan alfa 


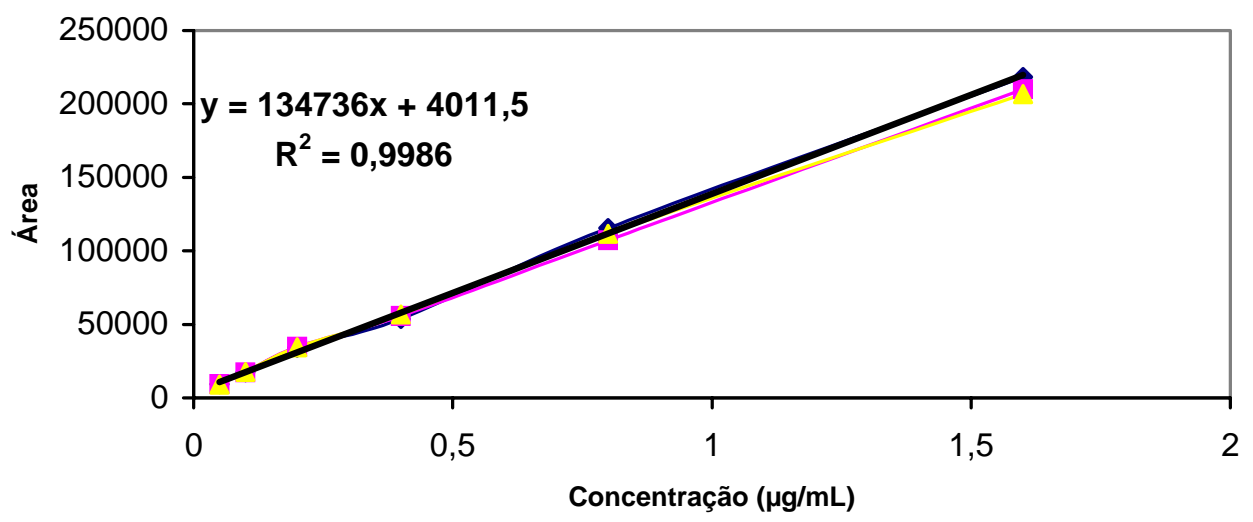

Figura 21 - Área do pico em função da concentração de dieldrin

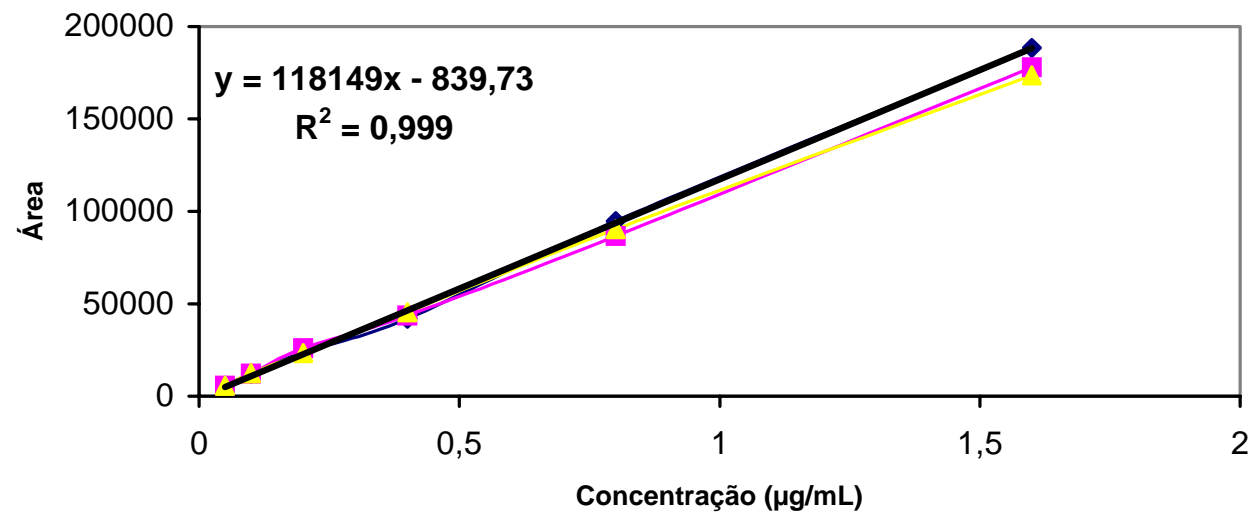

Figura 22 - Área do pico em função da concentração de p`p-dde

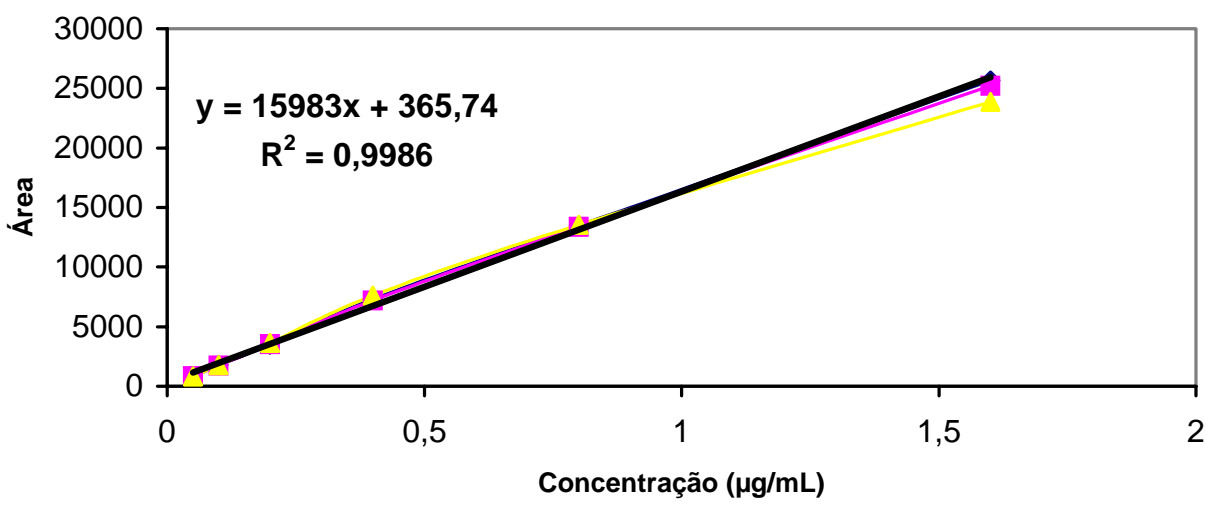

Figura 23 - Área do pico em função da concentração de cis clordano 


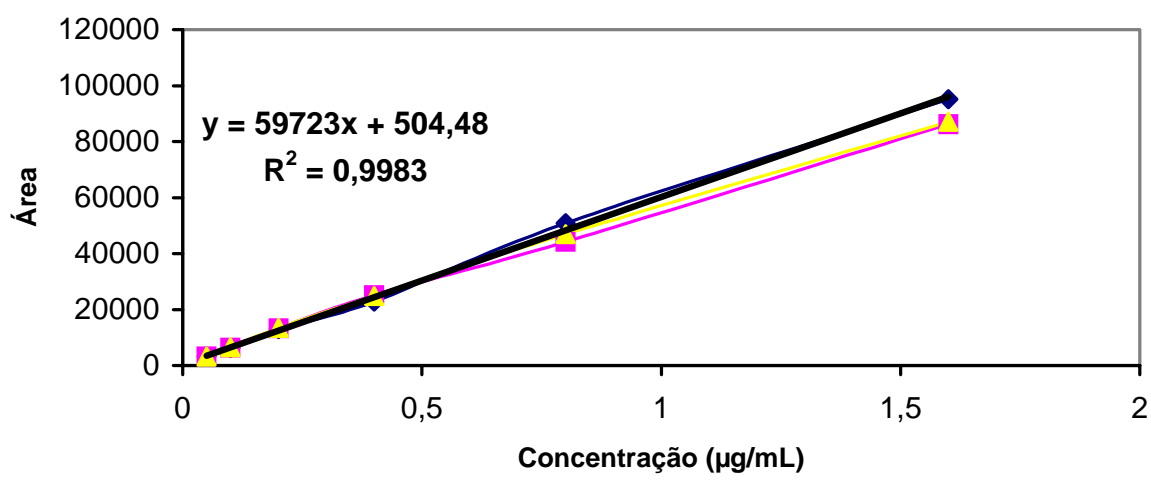

Figura 24 - Área do pico em função da concentração de endrin

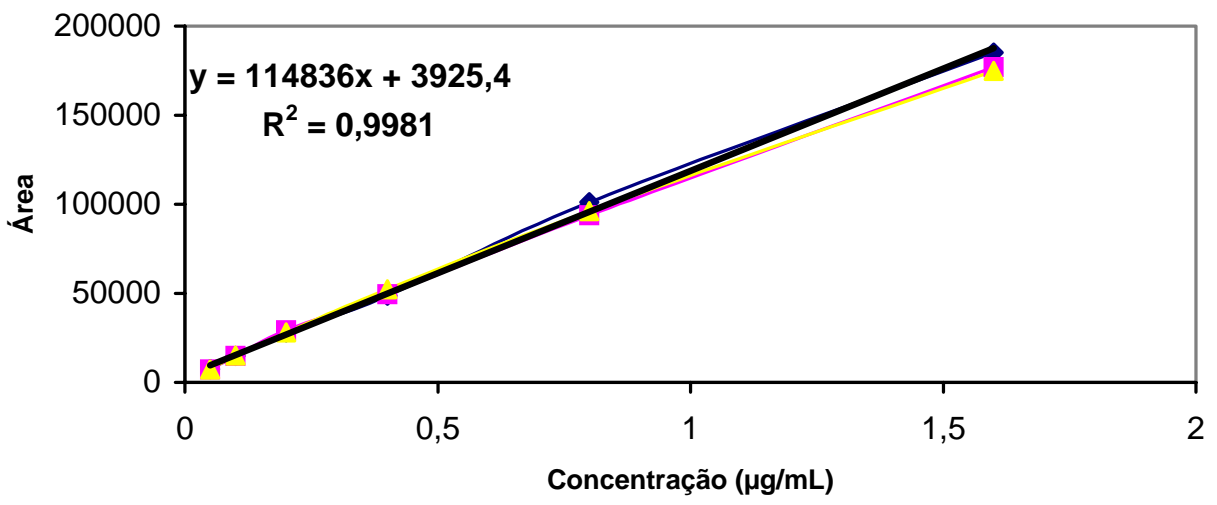

Figura 25 - Área do pico em função da concentração de endosulfan beta

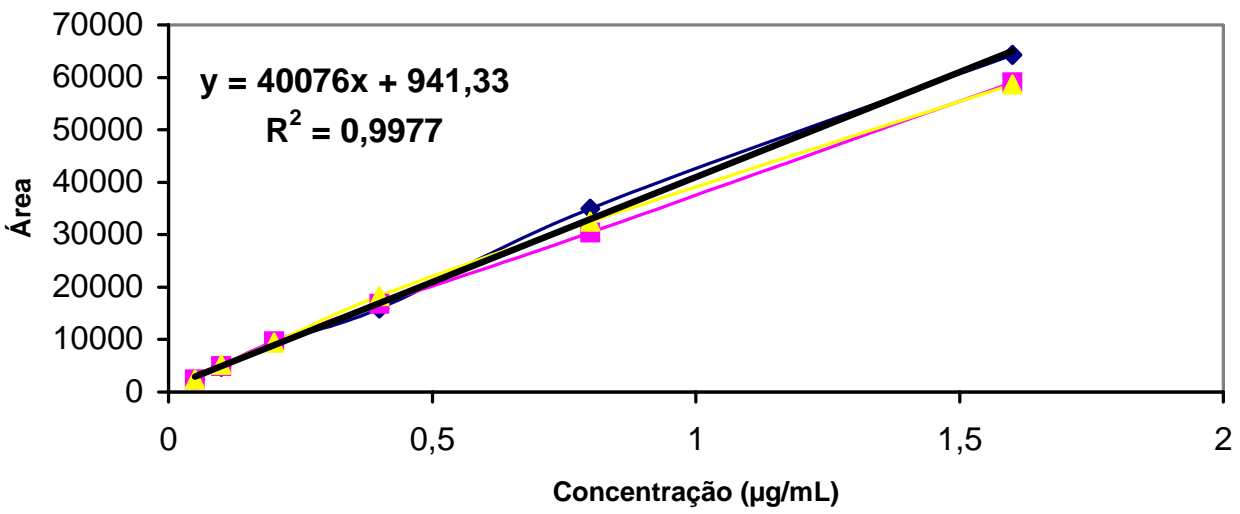

Figura 26 - Área do pico em função da concentração de o`p-ddt 


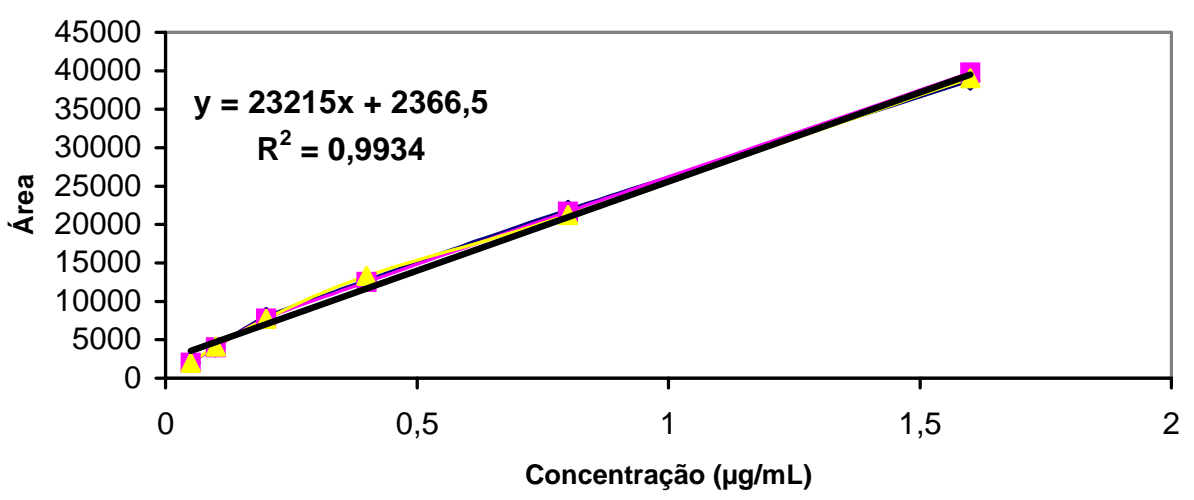

Figura 27 - Área do pico em função da concentração de endosulfan sulfato

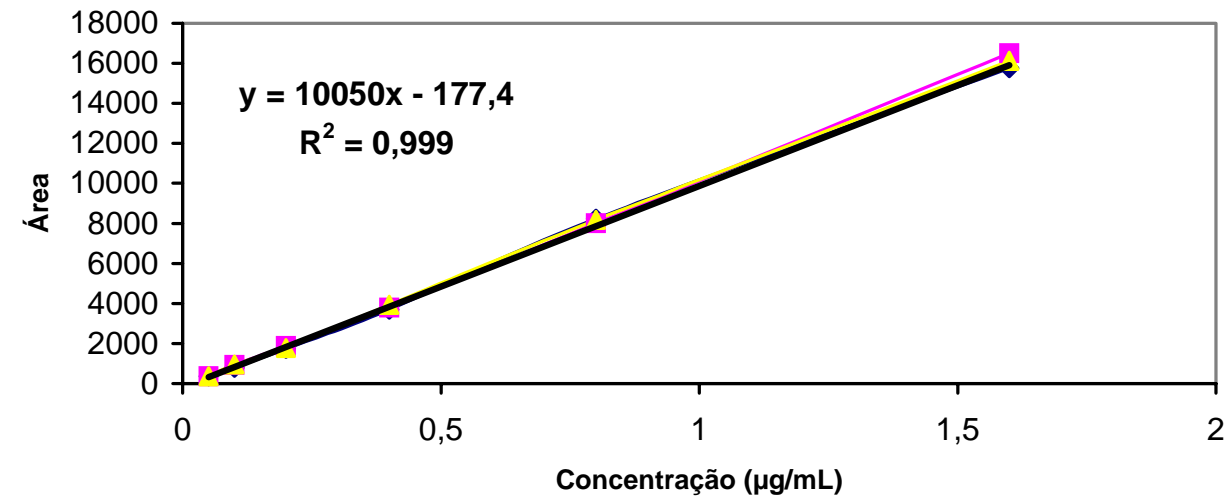

Figura 28 - Área do pico em função da concentração de metoxiclor

\subsubsection{Linearidade do detector de espectrometria de massa para os triazois}

Os resultados do estudo de linearidade estão apresentados nas Figuras 29 a 37. Pode-se observar por estes gráficos e pelo coeficiente de determinação $\left(r^{2}>0,99\right)$ que a resposta do detector foi linear na faixa de $0,1-1,0 \mu \mathrm{g} / \mathrm{mL}$ para o paclobutrazol, 0,25 2,5 $\mu \mathrm{g} / \mathrm{mL}$ para o fention e bromuconazol, $0,5-5,0 \mu \mathrm{g} / \mathrm{mL}$ para o tetraconazol e tebuconazol e $1,0-10 \mu \mathrm{g} / \mathrm{mL}$ para o procloraz e difeconazol respectivamente. 
O Anexo C, resume os valores encontrados da linearidade.

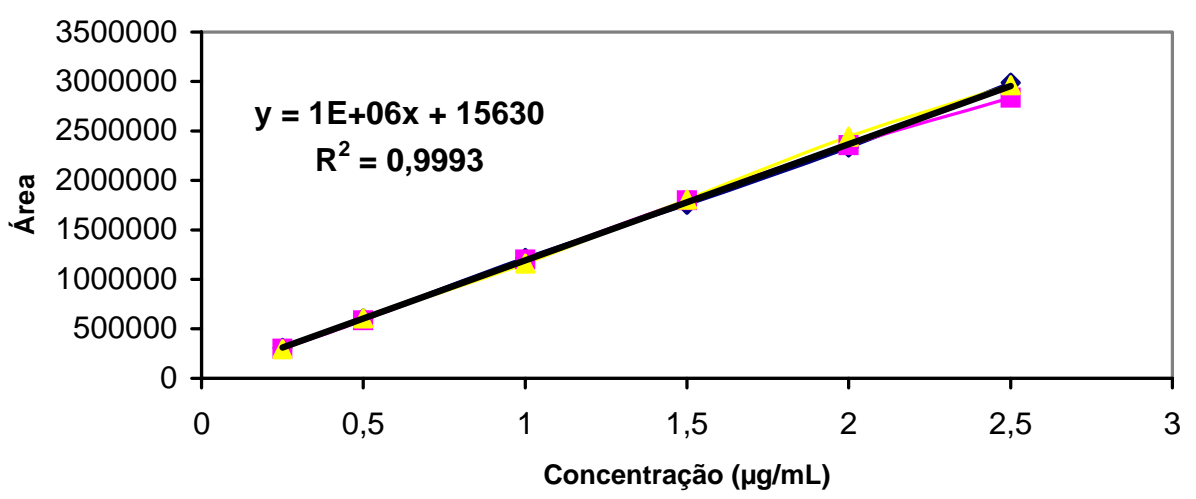

Figura 29 - Área do pico em função da concentração de fention

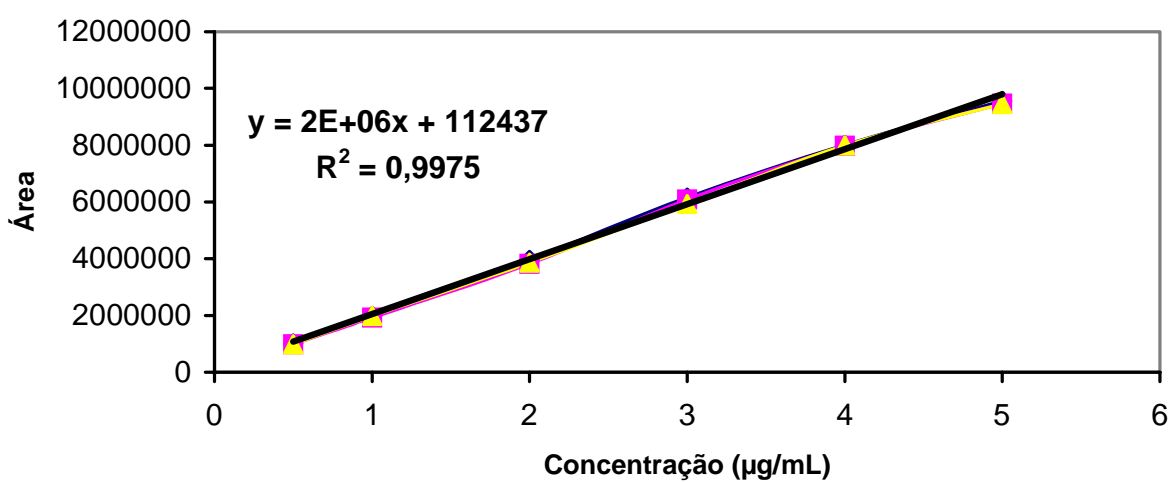

Figura 30 - Área do pico em função da concentração de tetraconazole 


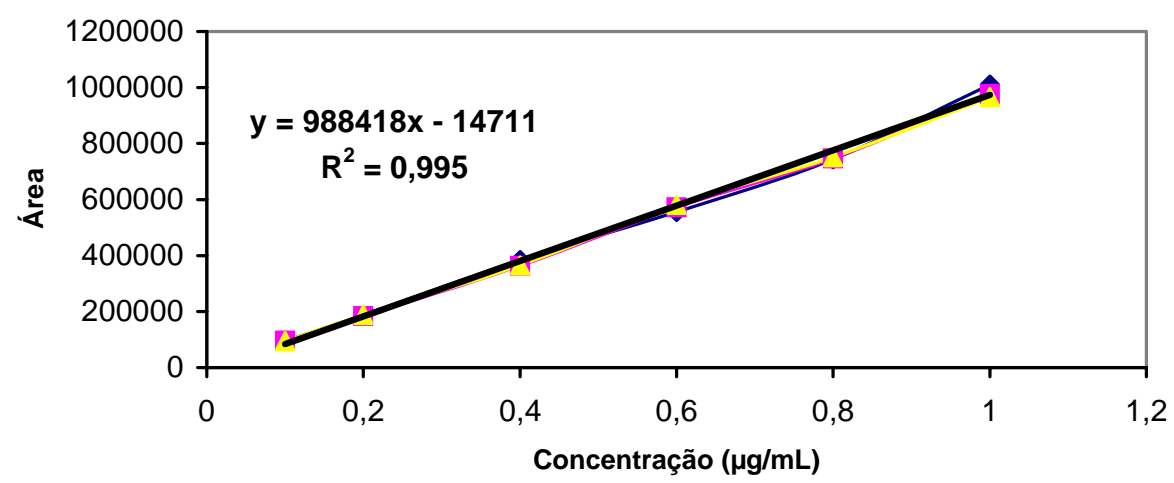

Figura 31 - Área do pico em função da concentração de paclobutrazol

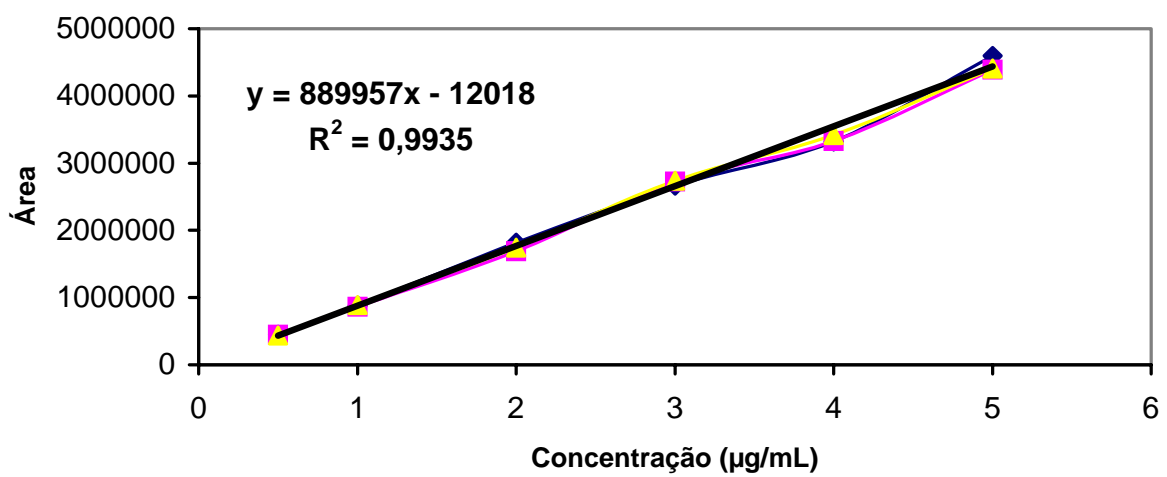

Figura 32 - Área do pico em função da concentração de tebuconazol

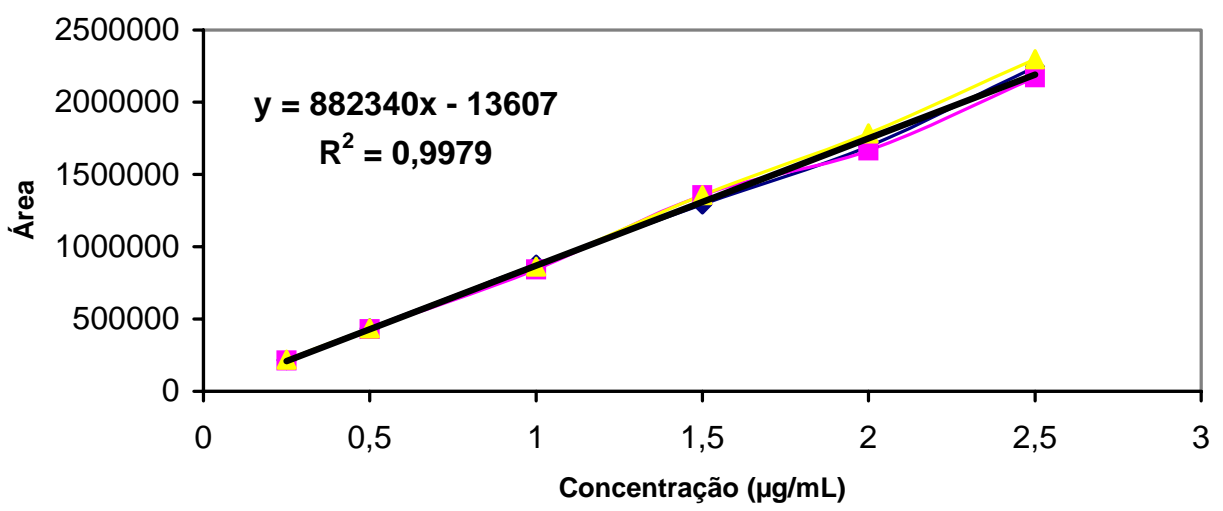

Figura 33 - Área do pico em função da concentração de bromuconazol 


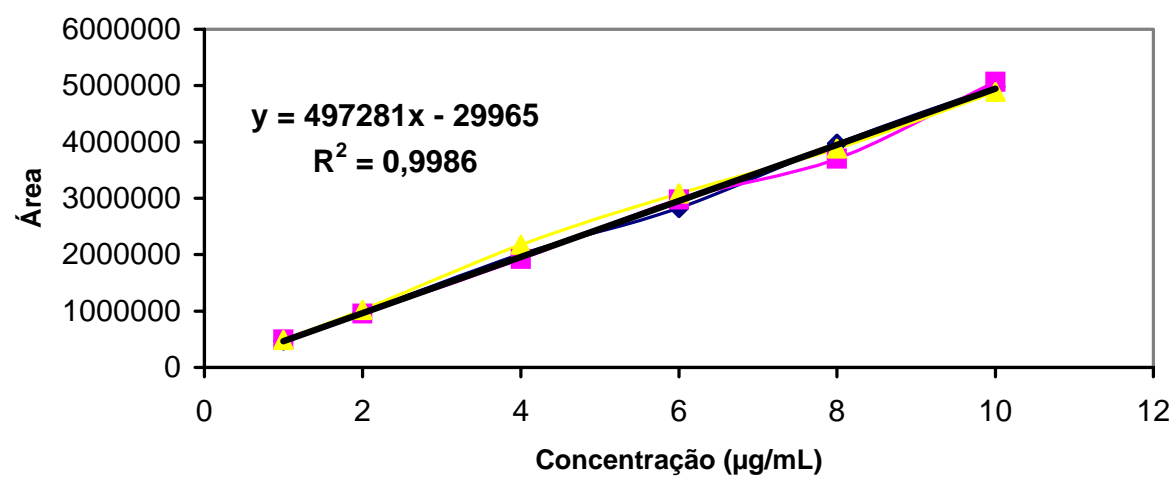

Figura 34 - Área do pico em função da concentração de procloraz

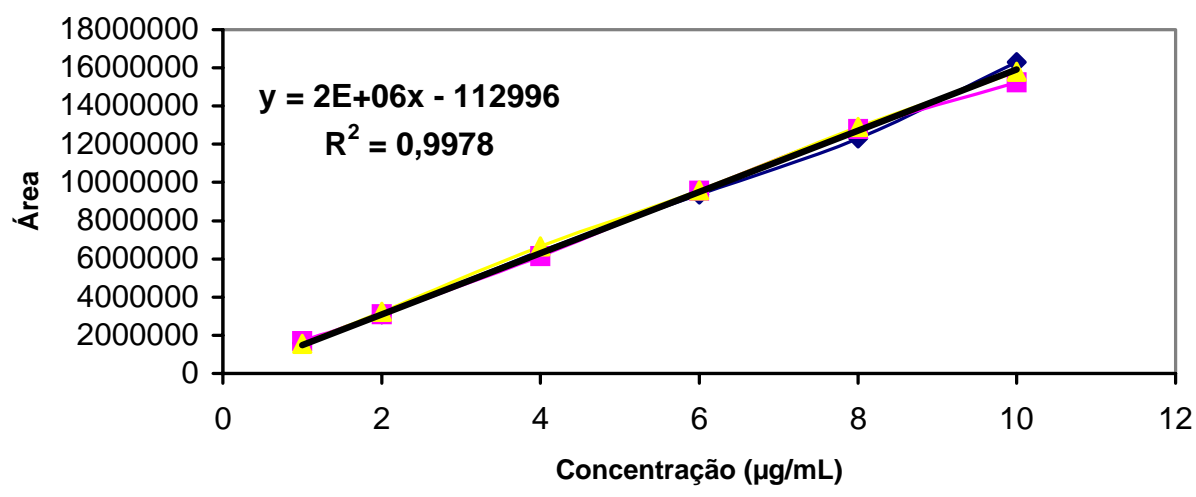

Figura 35 - Área do pico em função da concentração de difenoconazol

\subsection{Especificidade}

Os métodos desenvolvidos neste estudo demonstraram-se específicos, pois o nível de contaminação e/ou interferente na análise do branco dos reagentes e da amostra testemunha, foram inferiores a 30\% do limite de quantificação. As Figuras 36 e 37 mostram os cromatogramas obtidos da análise no FPD, as Figuras 38 e 39 as análises no ECD e as Figuras 40 e 41 as análises no CG/MS. 


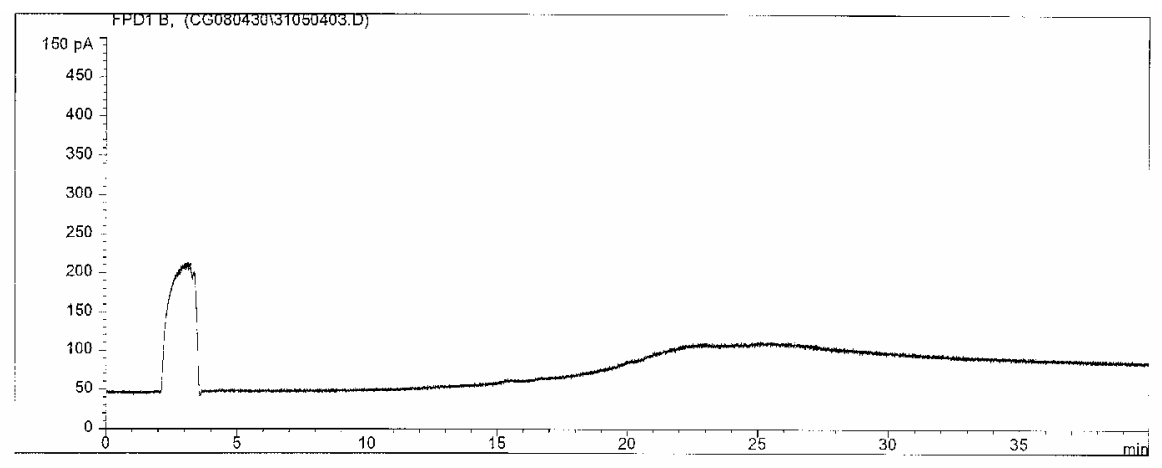

Figura 36 - Cromatograma do branco dos reagentes analisados por cromatografia a gás com detector fotométrico de chama

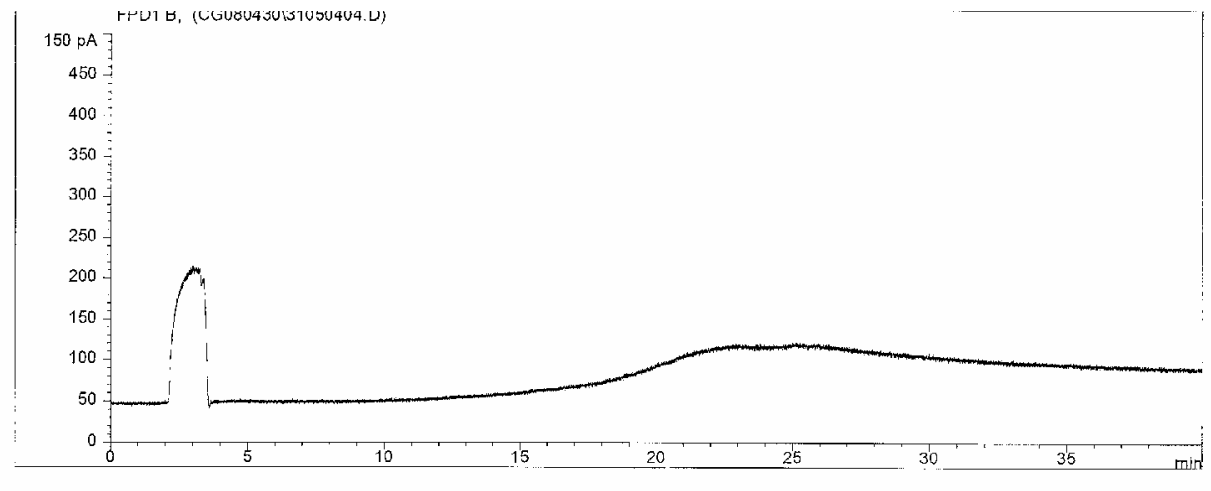

Figura 37 - Cromatograma da amostra testemunha analisada por cromatografia a gás com detector fotométrico de chama 


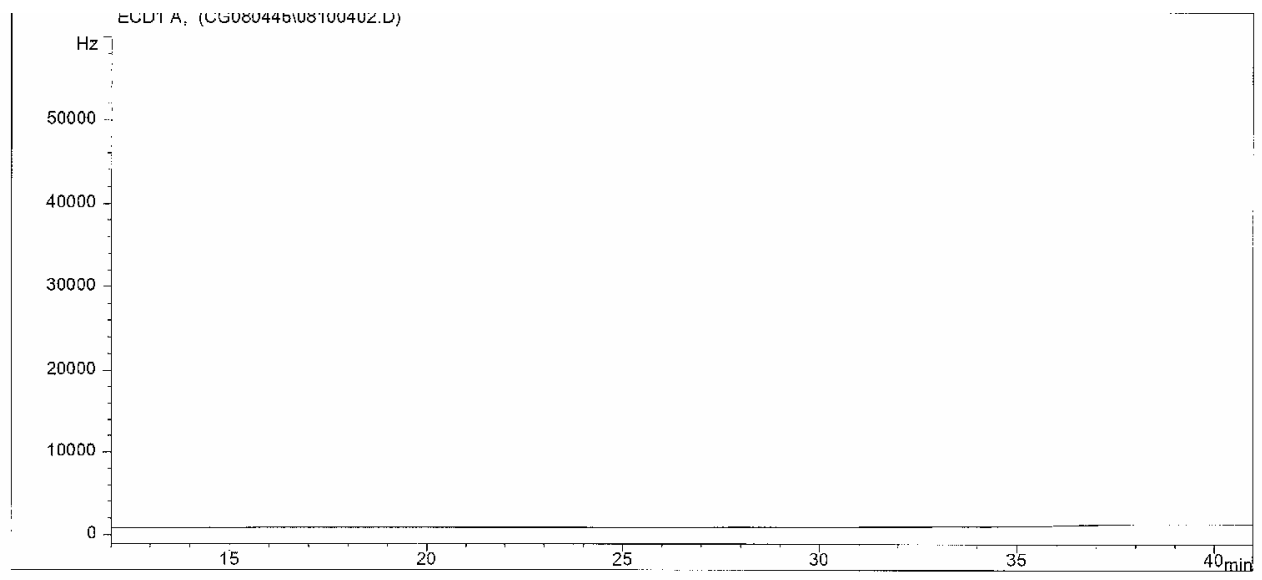

Figura 38 - Cromatograma do branco dos reagentes analisados por cromatografia a gás com detector de captura de elétrons

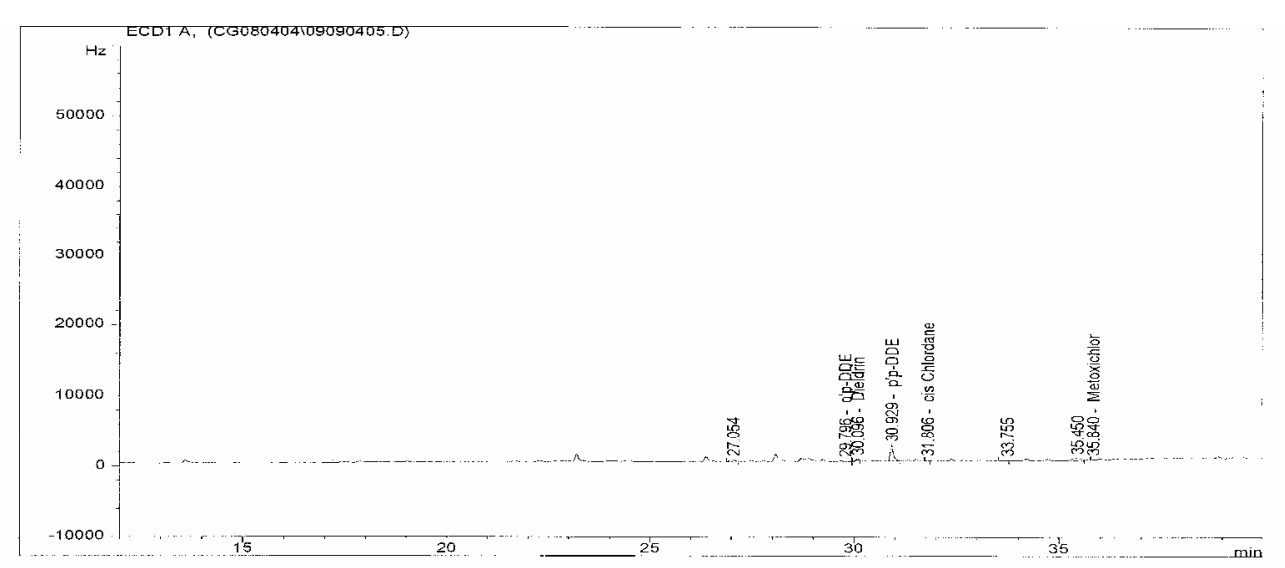

Figura 39 - Cromatograma da amostra testemunha analisada por cromatografia a gás com detector de captura de elétrons 


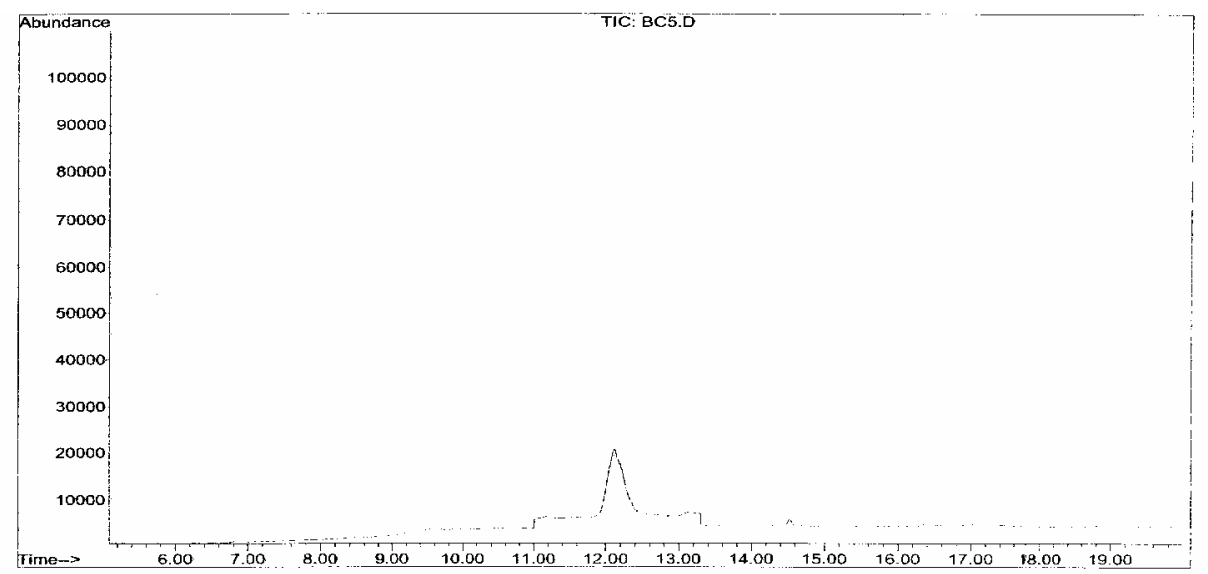

Figura 40 - Cromatograma do branco dos reagentes analisados por cromatografia a gás acoplada a detector de espectrometria de massa

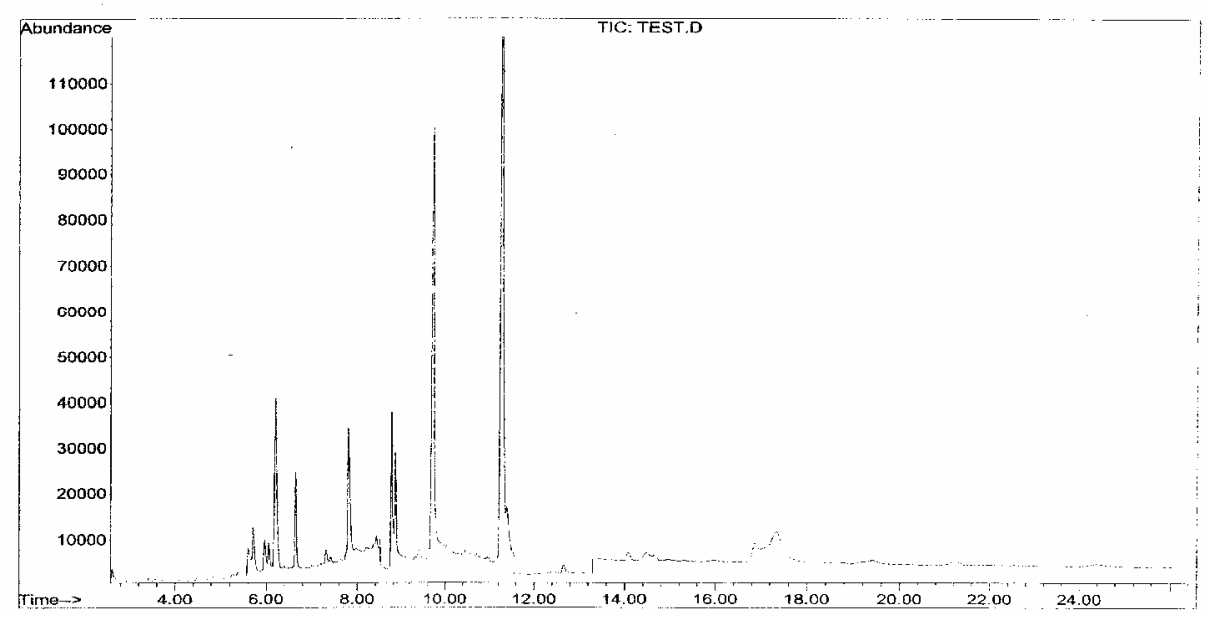

Figura 41 - Cromatograma da amostra testemunha analisada por cromatografia a gás acoplada a detector de espectrometria de massa 


\subsection{Estudos de recuperação}

Os métodos desenvolvido e validado neste estudo demonstraram-se: exato, preciso e repetitivo.

A recuperação do método foi testada através da fortificação de 12 amostras testemunha, sendo 7 amostras no limite de quantificação e 5 amostras 10 vezes o limite de quantificação. A recuperação de todos os ativos neste estudo, está dentro do intervalo de aceitabilidade, que é de 70 a 120\%. O coeficiente de variação porcentual (CV\%) em relação à média global de todos os níveis de fortificação foi inferior a 15\%.

\subsubsection{Recuperação dos organofosforados}

Os resultados estão apresentados no Anexo D. As figuras 42 e 43 são cromatogramas exemplo das fortificações de organofosforado.

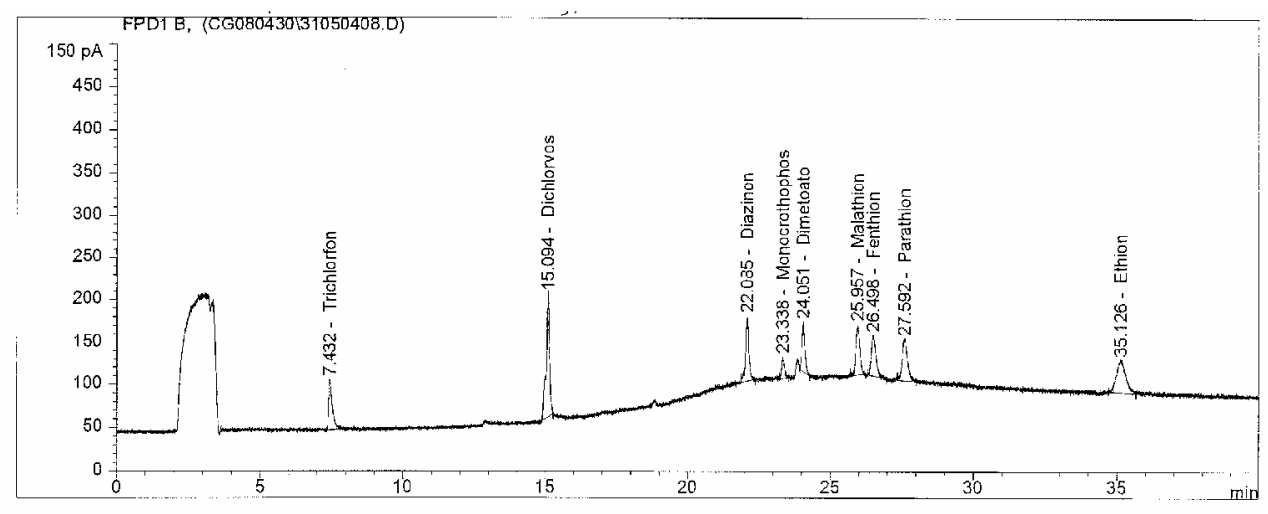

Figura 42 - Cromatograma da fortificação de $0,1 \mathrm{mg} / \mathrm{kg}$ de triclorfon e malation e 0,05 $\mathrm{mg} / \mathrm{kg}$ para os demais organofosforados em manga 


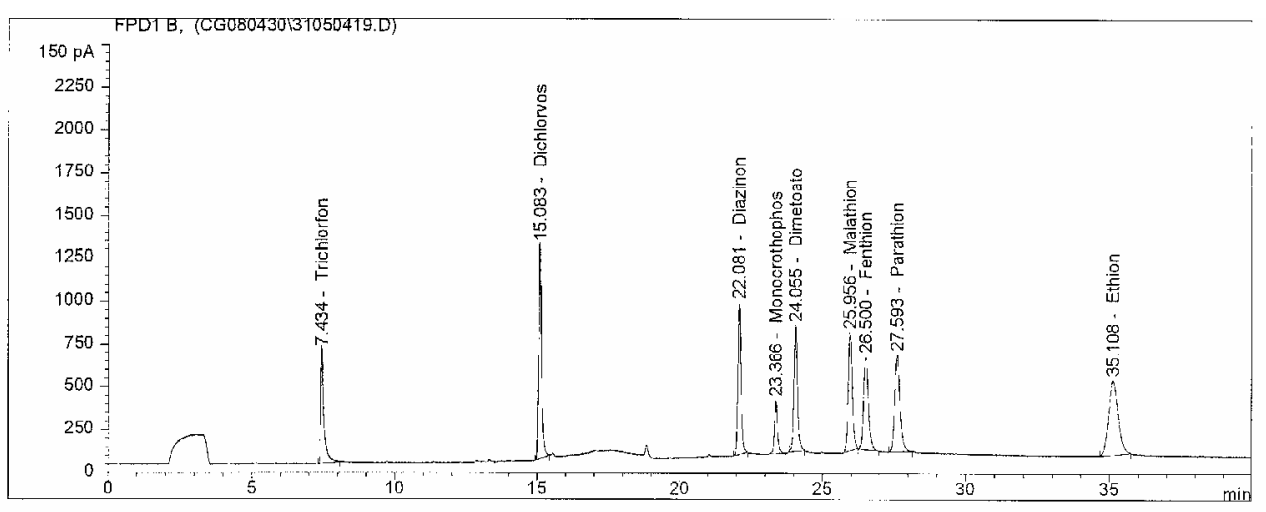

Figura 43 - Cromatograma da fortificação de $1,0 \mathrm{mg} / \mathrm{kg}$ de triclorfon e malation e 0,5 $\mathrm{mg} / \mathrm{kg}$ para os demais organofosforados em manga

\subsubsection{Recuperação de organoclorados}

Os resultados estão apresentados no anexo E. As Figuras 44 e 45 são cromatogramas exemplo das fortificações de organoclorado.

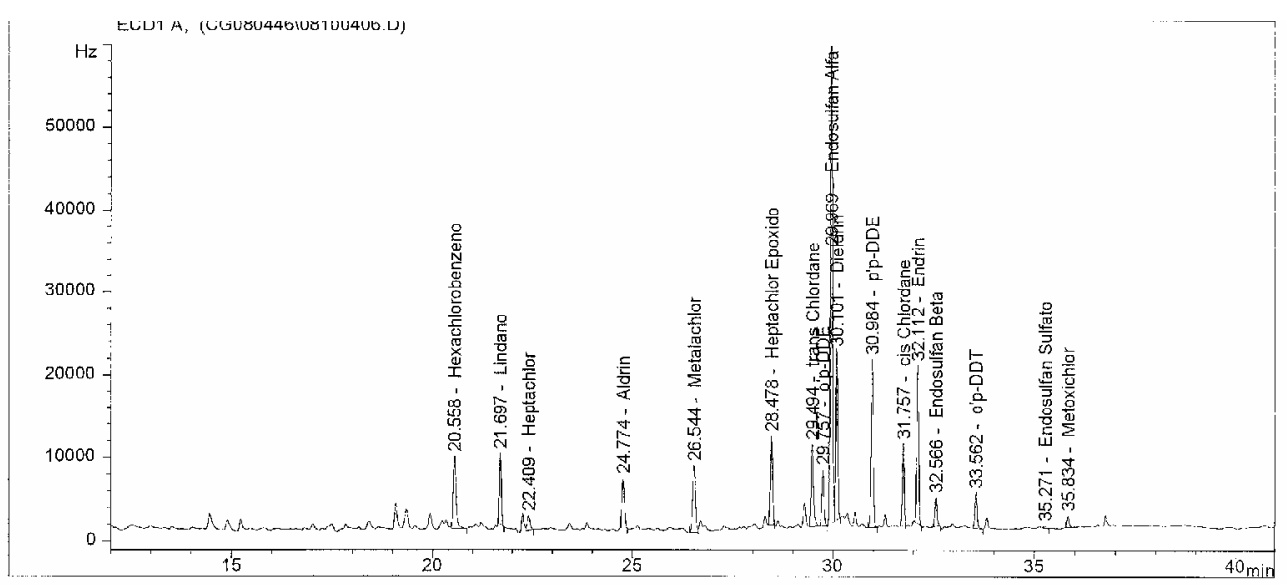

Figura 44 - Cromatograma da fortificação de $0,01 \mathrm{mg} / \mathrm{kg}$ de organoclorados em manga 


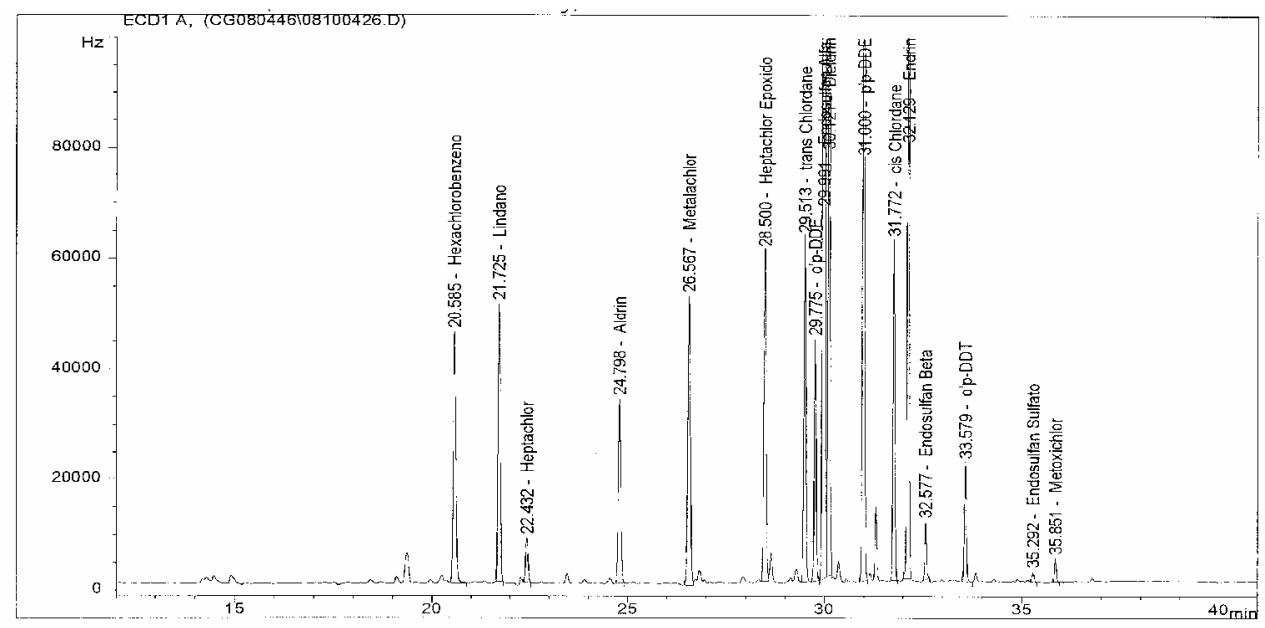

Figura 45 - Cromatograma da fortificação de $0,1 \mathrm{mg} / \mathrm{kg}$ de organoclorados em manga

\subsubsection{Recuperação de triazois}

Os resultados estão apresentados no anexo F. As Figuras 46 e 47 são cromatogramas exemplo das fortificações dos triazois.

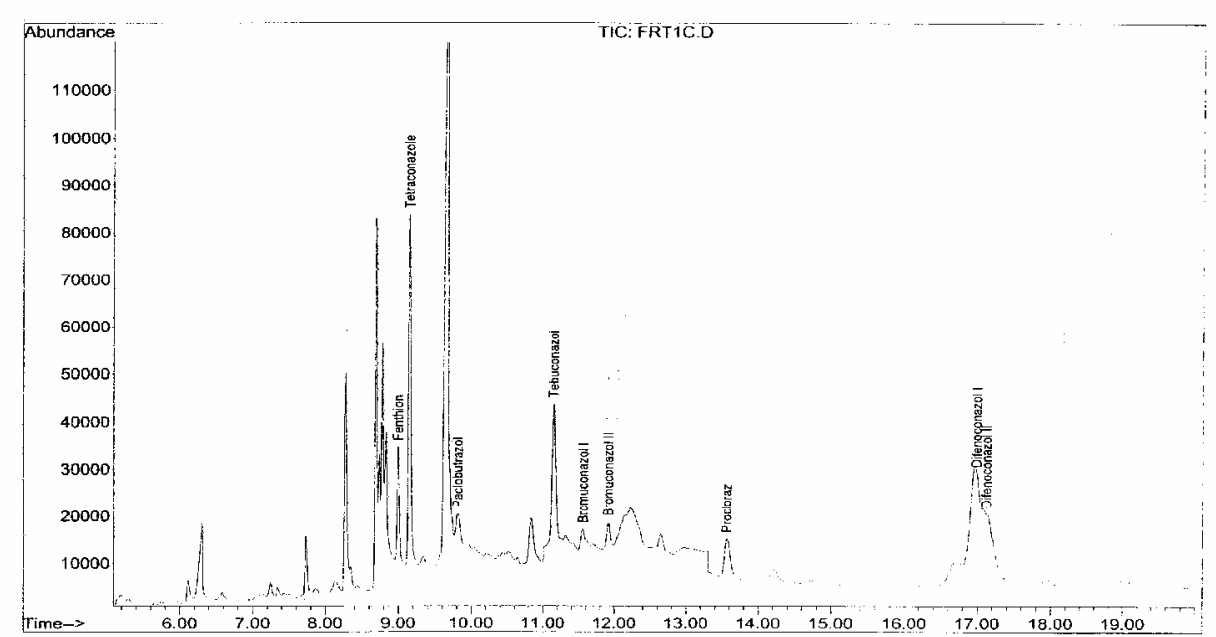

Figura 46 - Cromatograma da fortificação no LOQ de triazois em manga 


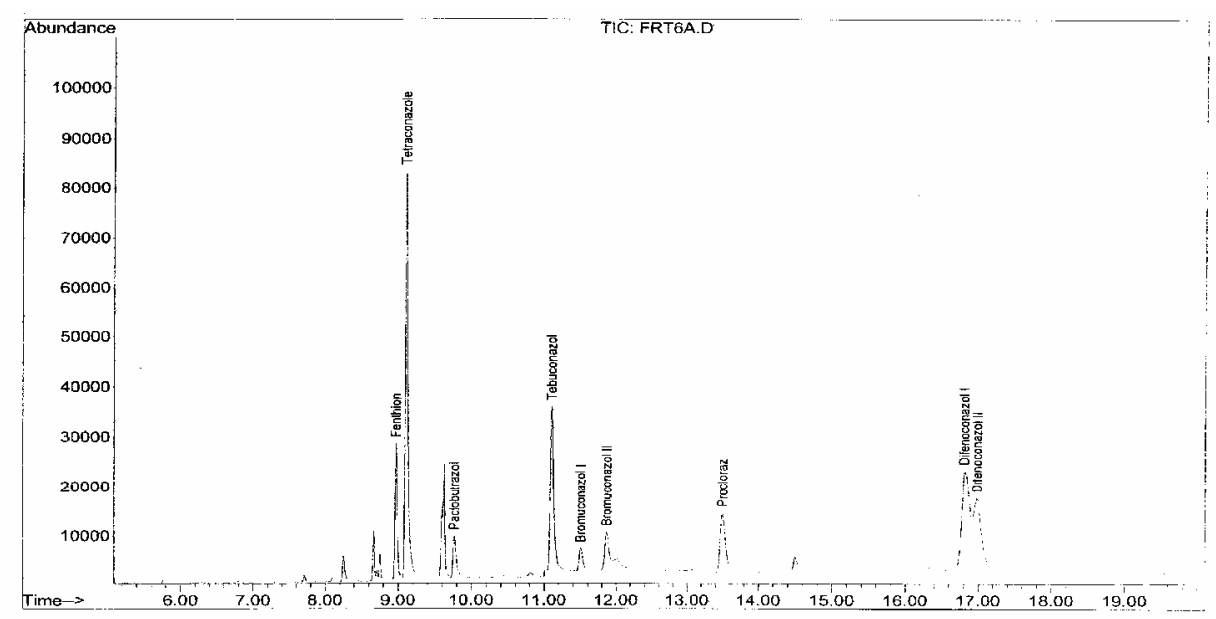

Figura 47 - Cromatograma da fortificação de 10 x LOQ de triazois em manga

\subsubsection{Resultado das amostras de manga compradas nos supermercados de Piracicaba}

Foram compradas 15 amostras de mangas nos supermercados de Piracicaba, sendo sua procedência do nordeste do Brasil. Em nenhuma das amostras foi encontrado resíduo acima do limite estabelecido por lei ou acima do limite de quantificação do método, no caso dos não autorizados por lei. 


\section{CONCLUSÃO}

\section{Baseado nos resultados obtidos deste trabalho, conclui-se que:}

Os métodos de: Organofosforados, Organoclorados e Triazois, descritos neste trabalho, são válidos para análise dos 32 pesticidas estudados na manga.

Estes métodos demonstraram-se: Específicos, linear, exato, preciso e repetitivo. Em nenhum destes métodos houve necessidade do processo de "clean-up" (limpeza) dos extratos.

A utilização do turrax de alta rotação reduziu o tempo de agitação e homogeneização da amostra, tornando este método um pouco mais rápido que os tradicionais.

Este trabalho tem o objetivo de contribuir com o monitoramento de multiresíduo de pesticidas em manga.

Ter um método validado é ter confiança nos resultados apresentado, pois através da validação é possível conhecermos e quantificarmos as variáveis.

\section{Perspectiva para trabalhos futuros:}

Aumentar o número de pesticidas extraídos nestes três métodos estudados.

Monitorar as amostras de mangas. 
ANEXOS 
ANEXO A - Área do pico em função da concentração dos organofosforados estudados

\begin{tabular}{|c|c|c|c|c|c|}
\hline \multirow[b]{2}{*}{ Ativos } & \multirow[b]{2}{*}{$\begin{array}{l}\text { Solução } \\
\text { (MIX) }\end{array}$} & \multirow{2}{*}{$\begin{array}{c}\text { Concentração } \\
\text { Ingred. Ativo } \\
(\mu \mathrm{g} / \mathrm{mL})\end{array}$} & \multicolumn{3}{|c|}{ Área do pico } \\
\hline & & & Rep. 1 & Rep.2 & Rep.3 \\
\hline \multirow{6}{*}{ Diclorvos } & $1 \mathrm{G}$ & 0,05 & 619,4 & 616,6 & 632,2 \\
\hline & $1 \mathrm{~F}$ & 0,1 & 1180,3 & 1258,2 & 1271,1 \\
\hline & $1 \mathrm{E}$ & 0,2 & 2778,4 & 2636,1 & 2629,8 \\
\hline & 1D & 0,5 & 7077,9 & 7388,4 & 7449,9 \\
\hline & $1 \mathrm{C}$ & 1,0 & 15238 & 15908 & 16089 \\
\hline & 1B & 2,0 & 30259 & 30865 & 31462 \\
\hline \multirow{6}{*}{ Diazinon } & $1 \mathrm{G}$ & 0,05 & 366,2 & 359,1 & 361,6 \\
\hline & $1 \mathrm{~F}$ & 0,1 & 676,8 & 698,3 & 732,0 \\
\hline & $1 \mathrm{E}$ & 0,2 & 1443,4 & 1425,9 & 1400,9 \\
\hline & 1D & 0,5 & 3528,0 & 3518,5 & 3513,2 \\
\hline & $1 \mathrm{C}$ & 1,0 & 6633,1 & 6708,4 & 7042,4 \\
\hline & 1B & 2,0 & 13758 & 14127 & 14236 \\
\hline \multirow{6}{*}{ Monocrotofós } & $1 \mathrm{G}$ & 0,05 & 39,7 & 38,4 & 38,8 \\
\hline & $1 \mathrm{~F}$ & 0,1 & 78,5 & 78,1 & 80,6 \\
\hline & $1 \mathrm{E}$ & 0,2 & 164,5 & 183,7 & 175,0 \\
\hline & 1D & 0,5 & 441,6 & 450,3 & 456,4 \\
\hline & $1 \mathrm{C}$ & 1,0 & 1046,7 & 1040,0 & 1077,9 \\
\hline & 1B & 2,0 & 2380,5 & 2133,0 & 2440,1 \\
\hline \multirow{6}{*}{ Dimetoato } & $1 \mathrm{G}$ & 0,05 & 141,3 & 135,2 & 108,0 \\
\hline & $1 \mathrm{~F}$ & 0,1 & 242,6 & 228,8 & 285,1 \\
\hline & $1 \mathrm{E}$ & 0,2 & 629,3 & 599,7 & 622,2 \\
\hline & 1D & 0,5 & 1569,1 & 1669,0 & 1672,9 \\
\hline & $1 \mathrm{C}$ & 1,0 & 3523,9 & 3643,9 & 3935,2 \\
\hline & 1B & 2,0 & 7309,5 & 7725,1 & 7660,2 \\
\hline \multirow{6}{*}{ Fention } & $1 \mathrm{G}$ & 0,05 & 297,6 & 298,0 & 294,0 \\
\hline & $1 \mathrm{~F}$ & 0,1 & 566,6 & 572,9 & 622,9 \\
\hline & $1 \mathrm{E}$ & 0,2 & 1246,6 & 1239,5 & 1213,1 \\
\hline & 1D & 0,5 & 3134,0 & 3148,2 & 3077,1 \\
\hline & $1 \mathrm{C}$ & 1,0 & 6035,5 & 6189,9 & 6226,7 \\
\hline & 1B & 2,0 & 12253 & 12523 & 12591 \\
\hline \multirow{6}{*}{$\begin{array}{l}\text { Paration } \\
\text { etílico }\end{array}$} & $1 \mathrm{G}$ & 0,05 & 290,7 & 288,2 & 308,0 \\
\hline & $1 \mathrm{~F}$ & 0,1 & 587,7 & 591,4 & 623,5 \\
\hline & $1 \mathrm{E}$ & 0,2 & 1255,7 & 1231,5 & 1188,7 \\
\hline & 1D & 0,5 & 3149,5 & 3195,7 & 3123,6 \\
\hline & $1 \mathrm{C}$ & 1,0 & 6049,4 & 6184,1 & 6616,8 \\
\hline & 1B & 2,0 & 12644 & 13054 & 13287 \\
\hline
\end{tabular}


ANEXO A - Área do pico em função da concentração dos organofosforados estudados

\begin{tabular}{cccccc}
\hline \multirow{3}{*}{ Ativos } & $\begin{array}{c}\text { Solução } \\
\text { (MIX) }\end{array}$ & $\begin{array}{c}\text { Concentração } \\
\text { Ingred. Ativo } \\
(\mu \mathrm{gg} / \mathrm{mL})\end{array}$ & Rep. 1 & $\begin{array}{c}\text { Área do pico } \\
\text { Rep.2 }\end{array}$ & Rep.3 \\
\hline \multirow{6}{*}{ Etion } & 1G & 0,05 & 395,0 & 383,0 & 383,3 \\
& IF & 0,1 & 777,5 & 769,1 & 860,2 \\
& 1E & 0,2 & 1704,7 & 1673,6 & 1605,8 \\
& 1D & 0,5 & 4221,6 & 4314,8 & 4225,4 \\
& 1C & 1,0 & 8168,4 & 8290,9 & 9225,5 \\
& 1B & 2,0 & 17128 & 17663 & 20031 \\
& & & & & \\
triclorfon & 1G & 0,1 & 197,1 & 233,7 & 220,0 \\
& 1F & 0,2 & 427,2 & 445,5 & 437,3 \\
& 1E & 0,5 & 968,7 & 940,3 & 953,9 \\
& 1D & 1,0 & 2662,0 & 2633,2 & 2406,3 \\
& 1C & 2,0 & 5326,7 & 5357,6 & 5346,6 \\
& 1B & 4,0 & 11048 & 10997 & 11150 \\
& & & & & \\
malation & 1G & 0,1 & 290,3 & 293,3 & 287,7 \\
& 1F & 0,2 & 544,0 & 561,9 & 602,4 \\
& 1E & 0,5 & 1205,9 & 1189,4 & 1144,2 \\
& 1D & 1,0 & 2987,5 & 3058,3 & 3033,7 \\
& 1C & 2,0 & 5866,4 & 5972,9 & 6070,9 \\
& 1B & 4,0 & 11870 & 12213 & 12325 \\
\hline
\end{tabular}


ANEXO B - Área do pico em função da concentração dos organoclorados estudados

\begin{tabular}{|c|c|c|c|c|c|c|}
\hline \multirow{3}{*}{ Ativos } & \multicolumn{6}{|c|}{ Código/Concentração } \\
\hline & $\operatorname{MIX}(2 \mathrm{G})$ & $\operatorname{MIX}(2 \mathrm{~F})$ & MIX(2E) & MIX(2D) & MIX(2C) & $\operatorname{MIX}(2 B)$ \\
\hline & $0,05 \mu \mathrm{g} / \mathrm{mL}$ & $0,1 \mu \mathrm{g} / \mathrm{mL}$ & $0,2 \mu \mathrm{g} / \mathrm{mL}$ & $0,4 \mu \mathrm{g} / \mathrm{mL}$ & $0,8 \mu \mathrm{g} / \mathrm{mL}$ & $1,6 \mu \mathrm{g} / \mathrm{mL}$ \\
\hline \multirow{3}{*}{ Hexaclorobenzeno } & 7043,6 & 14184 & 28869 & 54919 & 117306 & 225198 \\
\hline & 7068,1 & 14155 & 30098 & 57234 & 108872 & 217470 \\
\hline & 7008,9 & 14507 & 29363 & 58936 & 111337 & 214871 \\
\hline \multirow{3}{*}{ Lindano } & 1404,8 & 2896,9 & 5467,8 & 11105 & 20967 & 36669 \\
\hline & 1389,6 & 2851,5 & 5600,0 & 10776 & 20895 & 35691 \\
\hline & 1396,7 & 2831,3 & 5751,1 & 10841 & 21106 & 34285 \\
\hline \multirow{3}{*}{ Heptacloro } & 4834,9 & 9429,5 & 18682 & 34904 & 77182 & 148356 \\
\hline & 4780,7 & 9581,0 & 18999 & 37619 & 69844 & 139964 \\
\hline & 4746,2 & 9846,8 & 18673 & 37108 & 73155 & 139662 \\
\hline \multirow{3}{*}{ Aldrin } & 11430 & 22038 & 40154 & 73853 & 144870 & 276307 \\
\hline & 11443 & 21859 & 43475 & 75096 & 134688 & 266179 \\
\hline & 11323 & 22149 & 41491 & 75861 & 142094 & 260634 \\
\hline \multirow{3}{*}{ Metalacloro } & 7922,6 & 16955 & 32742 & 57352 & 114985 & 211225 \\
\hline & 7911,3 & 16876 & 33080 & 59023 & 108354 & 203520 \\
\hline & 7792,1 & 17198 & 32668 & 59755 & 111434 & 200497 \\
\hline \multirow{3}{*}{$\begin{array}{c}\text { Heptacloro } \\
\text { Epoxido }\end{array}$} & 9453,5 & 17187 & 34815 & 52885 & 110929 & 209235 \\
\hline & 9437,1 & 17169 & 33478 & 54521 & 103713 & 201020 \\
\hline & 9309,4 & 16647 & 30918 & 55704 & 106991 & 197101 \\
\hline \multirow{3}{*}{ Trans Clordano } & 2229,0 & 4834,1 & 9039,8 & 15745 & 33181 & 71756 \\
\hline & 2228,0 & 4883,3 & 9183,3 & 15949 & 30149 & 66817 \\
\hline & 2166,7 & 4582,7 & 8849,7 & 15931 & 33188 & 66671 \\
\hline \multirow{3}{*}{ O`p-DDE } & 28950 & 55126 & 101743 & 178558 & 408317 & 824980 \\
\hline & 28723 & 54760 & 110891 & 184851 & 382606 & 792779 \\
\hline & 28123 & 54855 & 101978 & 189454 & 392809 & 786931 \\
\hline \multirow{3}{*}{ Endosulfan Alfa } & 10290 & 20141 & 38683 & 78872 & 161755 & 291432 \\
\hline & 10249 & 19974 & 40288 & 81307 & 150393 & 279589 \\
\hline & 10010 & 20380 & 39146 & 82379 & 155188 & 275092 \\
\hline \multirow{4}{*}{ Dieldrin } & 9251,5 & 17450 & 34155 & 53635 & 115579 & 218417 \\
\hline & 9272,7 & 17360 & 34694 & 55559 & 107290 & 210009 \\
\hline & 9130,3 & 17721 & 34381 & 56685 & 111620 & 206863 \\
\hline & 5784,4 & 12162 & 23882 & 41981 & 94812 & 188508 \\
\hline
\end{tabular}




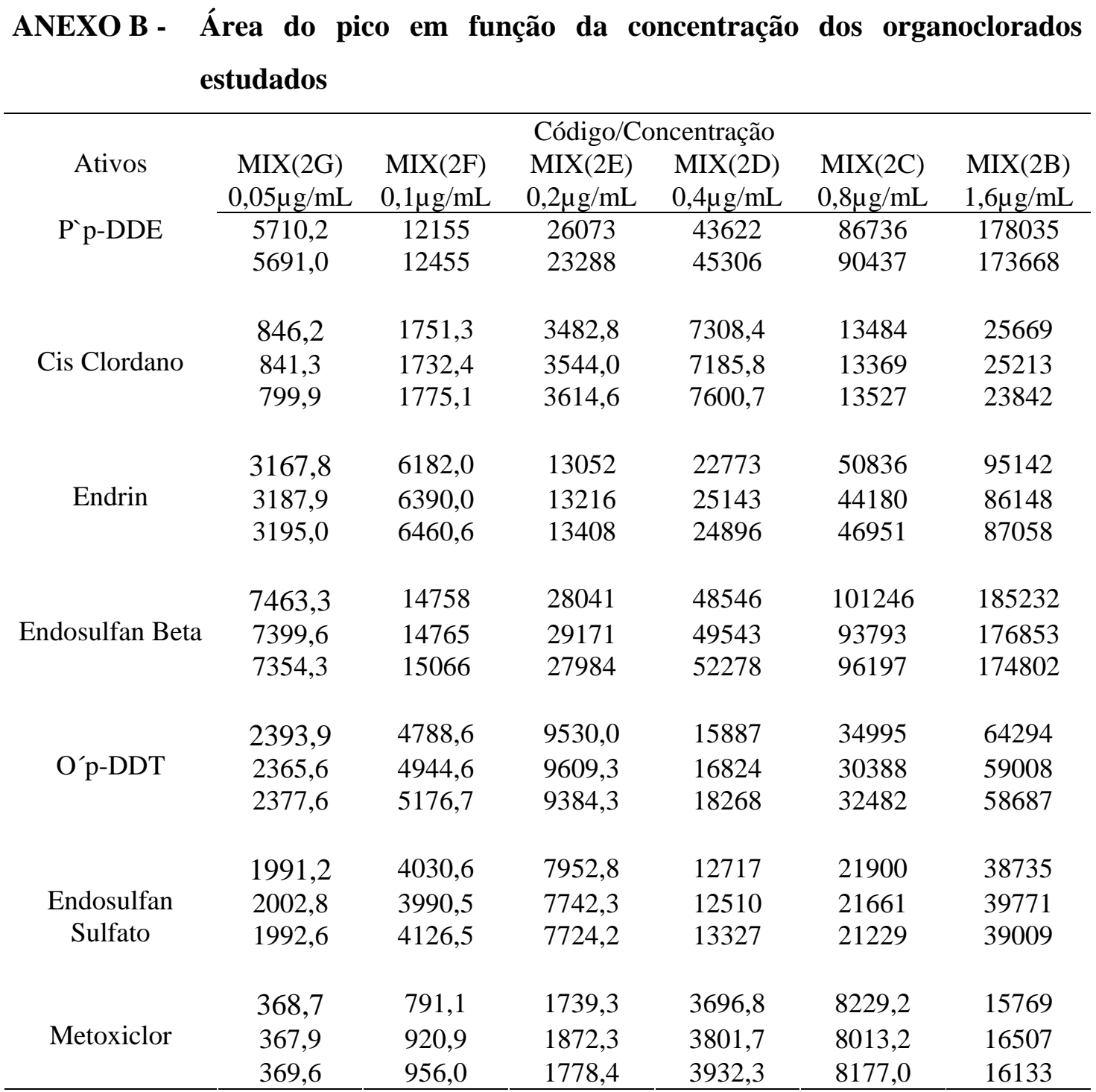


ANEXO C - Área do pico em função da concentração dos ingredientes ativos estudados

\begin{tabular}{|c|c|c|c|c|c|}
\hline \multirow[b]{2}{*}{ Ativos } & \multirow[b]{2}{*}{$\begin{array}{c}\text { Solução } \\
\text { (MIX) }\end{array}$} & \multirow{2}{*}{$\begin{array}{c}\text { Concentração } \\
\text { Ingred. Ativo } \\
(\mu \mathrm{g} / \mathrm{mL})\end{array}$} & \multicolumn{3}{|c|}{ Área do pico } \\
\hline & & & Rep. 1 & Rep.2 & Rep.3 \\
\hline \multirow{6}{*}{ Paclobutrazol } & $3 G$ & 0,1 & 95671 & 95462 & 94559 \\
\hline & $3 \mathrm{~F}$ & 0,2 & 187134 & 184264 & 188517 \\
\hline & $3 \mathrm{E}$ & 0,4 & 383349 & 363998 & 365143 \\
\hline & 3D & 0,6 & 556262 & 571356 & 579913 \\
\hline & $3 \mathrm{C}$ & 0,8 & 743526 & 747512 & 751707 \\
\hline & 3B & 1,0 & 1009889 & 976862 & 965438 \\
\hline \multirow{6}{*}{ Fention } & $3 G$ & 0,25 & 306451 & 298074 & 295935 \\
\hline & $3 \mathrm{~F}$ & 0,5 & 608232 & 587741 & 606954 \\
\hline & $3 \mathrm{E}$ & 1,0 & 1217917 & 1199813 & 1161409 \\
\hline & 3D & 1,5 & 1752218 & 1798636 & 1805509 \\
\hline & $3 \mathrm{C}$ & 2,0 & 2331752 & 2355590 & 2442916 \\
\hline & 3B & 2,5 & 29858119 & 2835386 & 2963554 \\
\hline \multirow{6}{*}{ Bromuconazol } & 3G & 0,25 & 217246 & 214751 & 219440 \\
\hline & $3 \mathrm{~F}$ & 0,5 & 434324 & 430339 & 435303 \\
\hline & $3 \mathrm{E}$ & 1,0 & 875600 & 843000 & 862871 \\
\hline & 3D & 1,5 & 1290946 & 1355625 & 1356997 \\
\hline & $3 \mathrm{C}$ & 2,0 & 1695144 & 1665973 & 1783269 \\
\hline & 3B & 2,5 & 2243237 & 2170130 & 2298562 \\
\hline \multirow{6}{*}{ Tetraconazol } & 3G & 0,5 & 1008876 & 977167 & 984557 \\
\hline & $3 F$ & 1,0 & 1987371 & 1927034 & 1976067 \\
\hline & $3 \mathrm{E}$ & 2,0 & 3964351 & 3815681 & 3858762 \\
\hline & 3D & 3,0 & 6156857 & 6089663 & 5923862 \\
\hline & $3 \mathrm{C}$ & 4,0 & 8005744 & 7985700 & 7993664 \\
\hline & 3B & 5,0 & 9556359 & 9467256 & 9454382 \\
\hline \multirow{6}{*}{ Tebuconazol } & 3G & 0,5 & 445584 & 448546 & 436968 \\
\hline & $3 \mathrm{~F}$ & 1,0 & 881455 & 861940 & 888629 \\
\hline & $3 \mathrm{E}$ & 2,0 & 1815969 & 1685937 & 1743326 \\
\hline & 3D & 3,0 & 2663553 & 2726284 & 2740876 \\
\hline & $3 C$ & 4,0 & 3321323 & 3326727 & 3421495 \\
\hline & 3B & 5,0 & 4594343 & 4392859 & 4406483 \\
\hline
\end{tabular}


ANEXO C - Área do pico em função da concentração dos ingredientes ativos estudados

\begin{tabular}{cccccc}
\hline \multirow{2}{*}{ Ativos } & $\begin{array}{c}\text { Solução } \\
\text { (MIX) }\end{array}$ & $\begin{array}{c}\text { Concentração } \\
\text { Ingred. Ativo } \\
(\mu \mathrm{g} / \mathrm{mL})\end{array}$ & Rep. 1 & $\begin{array}{c}\text { Área do pico } \\
\text { Rep.2 }\end{array}$ & Rep.3 \\
\hline \multirow{5}{*}{ Procloraz } & 3G & 1,0 & 474820 & 496513 & 488031 \\
& 3F & 2,0 & 976345 & 955552 & 1016279 \\
& 3E & 4,0 & 2009523 & 1923740 & 2176530 \\
& 3D & 6,0 & 2826154 & 2979124 & 3083425 \\
& 3C & 8,0 & 3971550 & 3706318 & 3883771 \\
& 3B & 10,0 & 4977519 & 5066336 & 4890328 \\
& & & & & \\
Difenoconazol & 3G & 1,0 & 1584999 & 1690862 & 1558702 \\
& 3F & 2,0 & 3096490 & 3095105 & 3219920 \\
& 3E & 4,0 & 6392915 & 6143289 & 6651694 \\
& 3D & 6,0 & 9364186 & 9560672 & 9585295 \\
& 3C & 8,0 & 12301017 & 12795522 & 12895050 \\
& 3B & 10,0 & 16297383 & 15238402 & 15793621 \\
\hline
\end{tabular}




\begin{tabular}{|c|c|c|c|c|}
\hline Ingrediente Ativo & $\begin{array}{c}\text { Fortificação } \\
\mathrm{mg} / \mathrm{kg}\end{array}$ & $\begin{array}{c}\text { Recuperação } \\
(\%)\end{array}$ & $\begin{array}{c}\text { Desvio Padrão } \\
( \pm)\end{array}$ & $\begin{array}{l}\text { CV } \\
(\%) \\
\end{array}$ \\
\hline Triclorfon & 0,1 & $95^{*}$ & 3,6 & 3,8 \\
\hline Triclorfon & 1,0 & $93^{* *}$ & 2,1 & 2,2 \\
\hline Malation & 0,1 & $98 *$ & 1,6 & 1,7 \\
\hline Malation & 1,0 & $97^{* *}$ & 5,2 & 5,4 \\
\hline Monocrotofos & 0,05 & $97 *$ & 4,4 & 4,5 \\
\hline Monocrotofos & 0,5 & $94^{* *}$ & 7,4 & 7,8 \\
\hline Diclorvos & 0,05 & $93^{*}$ & 7,6 & 8,2 \\
\hline Diclorvos & 0,5 & $84^{* *}$ & 4,7 & 5,6 \\
\hline Diazinon & 0,05 & $87 *$ & 4,4 & 5,1 \\
\hline Diazinon & 0,5 & $92^{* *}$ & 7,3 & 8,0 \\
\hline Dimetoato & 0,05 & $85^{*}$ & 3,3 & 3,9 \\
\hline Dimetoato & 0,5 & $81^{* *}$ & 3,7 & 4,6 \\
\hline Fention & 0,05 & $91^{*}$ & 2,3 & 2,5 \\
\hline Fention & 0,5 & $97 * *$ & 5,3 & 5,5 \\
\hline Paration & 0,05 & $97 *$ & 2,7 & 2,8 \\
\hline Paration & 0,5 & $95^{* *}$ & 5,2 & 5,5 \\
\hline Etion & 0,05 & $94 *$ & 2,9 & 3,1 \\
\hline Etion & 0,5 & $92^{* *}$ & 6,2 & 6,7 \\
\hline
\end{tabular}

* - Média de 7 determinações ** - Média de 5 determinações 
ANEXO E - Recuperação de organoclorados das amostras de manga fortificadas com concentrações crescentes dos ativos

\begin{tabular}{|c|c|c|c|c|}
\hline Ingrediente Ativo & $\begin{array}{c}\text { Fortificação } \\
\mathrm{mg} / \mathrm{kg}\end{array}$ & $\begin{array}{c}\text { Recuperação } \\
(\%)\end{array}$ & $\begin{array}{c}\text { Desvio Padrão } \\
( \pm)\end{array}$ & $\begin{array}{l}\mathrm{CV} \\
(\%)\end{array}$ \\
\hline Hexaclorobenzeno & 0,01 & $74 *$ & 2,5 & 3,3 \\
\hline Hexaclorobenzeno & 0,1 & $80^{* *}$ & 3,3 & 4,1 \\
\hline Lindano & 0,01 & $88 *$ & 5,7 & 6,5 \\
\hline Lindano & 0,1 & $107 * *$ & 6,5 & 6,0 \\
\hline Heptacloro & 0,01 & $87 *$ & 7,4 & 8,5 \\
\hline Heptacloro & 0,1 & $91^{* *}$ & 6,6 & 7,2 \\
\hline Aldrin & 0,01 & $105^{*}$ & 4,8 & 4,5 \\
\hline Aldrin & 0,1 & $105^{* *}$ & 3,9 & 3,8 \\
\hline Metalacloro & 0,01 & $79 *$ & 7,5 & 9,6 \\
\hline Metalacloro & 0,1 & $73 * *$ & 1,6 & 2,2 \\
\hline Heptacloro Epoxido & 0,01 & $81 *$ & 5,7 & 7,0 \\
\hline Heptacloro Epoxido & 0,1 & $92^{* *}$ & 4,2 & 4,6 \\
\hline Trans Clordano & 0,01 & $81 *$ & 4,4 & 5,5 \\
\hline Trans Clordano & 0,1 & $90 * *$ & 2,7 & 3,0 \\
\hline O’p-DDE & 0,01 & $76^{*}$ & 2,0 & 2,7 \\
\hline O’p-DDE & 0,1 & $91^{* *}$ & 2,6 & 2,9 \\
\hline Endosulfan Alfa & 0,01 & $75 *$ & 5,1 & 6,7 \\
\hline Endosulfan Alfa & 0,1 & $96 * *$ & 3,3 & 3,4 \\
\hline Dieldrin & 0,01 & $97 *$ & 3,7 & 3,8 \\
\hline Dieldrin & 0,1 & $109 * *$ & 5,7 & 5,2 \\
\hline P'p-DDE & 0,01 & $75^{*}$ & 3,8 & 5,1 \\
\hline P'p-DDE & 0,1 & $85^{* *}$ & 3,2 & 3,8 \\
\hline Cis Clordane & 0,01 & $88 *$ & 7,3 & 8,4 \\
\hline Cis Clordane & 0,1 & $106 * *$ & 3,9 & 3,7 \\
\hline Endrin & 0,01 & $90 *$ & 4,4 & 4,9 \\
\hline Endrin & 0,1 & $104 * *$ & 4,3 & 4,1 \\
\hline
\end{tabular}


ANEXO E - Recuperação de organoclorados das amostras de manga fortificadas com concentrações crescentes dos ativos

\begin{tabular}{ccccc}
\hline Ingrediente Ativo & $\begin{array}{c}\text { Fortificação } \\
\mathrm{mg} / \mathrm{kg}\end{array}$ & $\begin{array}{c}\text { Recuperação } \\
(\%)\end{array}$ & $\begin{array}{c}\text { Desvio Padrão } \\
( \pm)\end{array}$ & $\begin{array}{c}\text { CV } \\
(\%)\end{array}$ \\
\hline Endosulfan Beta & 0,01 & $97^{*}$ & 9,7 & 10,0 \\
Endosulfan Beta & 0,1 & $101^{* *}$ & 5,7 & 5,6 \\
O’p-DDT & 0,01 & $85^{*}$ & 6,8 & 8,0 \\
O'p-DDT & 0,1 & $100^{* *}$ & 4,0 & 4,0 \\
& & & & \\
Endosulfan Sulfato & 0,01 & $88^{*}$ & 6,4 & 7,2 \\
Endosulfan Sulfato & 0,1 & $95^{* *}$ & 6,3 & 6,7 \\
& & & & \\
Metoxicloro & 0,01 & $101^{*}$ & 7,5 & 7,4 \\
Metoxicloro & 0,1 & $92^{* *}$ & 6,7 & 7,4 \\
\hline
\end{tabular}

* - Média de 7 determinações

** - Média de 5 determinações 
ANEXO F - Recuperação de triazois + fention das amostras de manga fortificadas com concentrações crescentes dos ativos

\begin{tabular}{|c|c|c|c|c|}
\hline Ingrediente Ativo & $\begin{array}{c}\text { Fortificação } \\
\mathrm{mg} / \mathrm{kg}\end{array}$ & $\begin{array}{c}\text { Recuperação } \\
(\%)\end{array}$ & $\begin{array}{c}\text { Desvio Padrão } \\
( \pm)\end{array}$ & $\begin{array}{l}\text { CV } \\
(\%)\end{array}$ \\
\hline Fention & 0,05 & $90 *$ & 6,7 & 7,4 \\
\hline Fention & 0,5 & $96 * *$ & 6,0 & 6,3 \\
\hline Tetraconazol & 0,05 & $97 *$ & 7,5 & 7,8 \\
\hline Tetraconazol & 0,5 & $98 * *$ & 5,1 & 5,3 \\
\hline Paclobutrazol & 0,02 & $96 *$ & 5,1 & 5,4 \\
\hline Paclobutrazol & 0,2 & $105 * *$ & 7,4 & 7,1 \\
\hline Tebuconazol & 0,1 & $97 *$ & 6,0 & 6,2 \\
\hline Tebuconazol & 1,0 & $101^{* *}$ & 5,5 & 5,5 \\
\hline Bromuconazol & 0,05 & $82 *$ & 6,4 & 7,8 \\
\hline Bromuconazol & 0,5 & $87 * *$ & 4,4 & 5,0 \\
\hline Procloraz & 0,1 & $95 *$ & 5,8 & 6,1 \\
\hline Procloraz & 1,0 & $99 * *$ & 6,5 & 6,5 \\
\hline Difenoconazol & 0,1 & $92 *$ & 6,7 & 7,3 \\
\hline Difenoconazol & 1,0 & $90 * *$ & 8,3 & 9,3 \\
\hline
\end{tabular}




\section{REFERÊNCIAS BIBLIOGRÁFICAS}

ANDERSON, A.; PAELSHEDEN, H. Fresenius'z Journal of Analytical Chemistry, v.339, n.6, p.365-367,1991.

ANALYTICAL METHODS FOR PESTICIDE RESIDUES IN FOODSTUFFS. 6. ed. General Inspectore for Health Protection. Ministery of Public Health, Welfare and Spot The Netherlands, 1996. sv.

AGÊNCIA NACIONAL DE VIGILÂNCIA SANITÁRIA (ANVISA). http://www.anvisa.gov.br (02 dez. 2004)

AZEVEDO, L.A.S. Proteção integrada de plantas com fungicidas: teoria, prática e manejo. São Paulo, 2001. 230p.

BATISTA, G.C. Fundamentos de química e toxicologia dos inseticidas. Piracicaba: Escola Superior de Agricultura "Luiz de Queiroz, 1974. 257p.

BRASIL-Leis Decretos, etc. Lei 7802, de 11/07/1989. Legislação Federal de Agrotóxicos e afins, Brasília, Ministério da Agricultura, Departamento de Defesa e Inspeção Vegetal, 1998a.

BRASIL-Leis Decretos, etc. Portaria 3, de 16/01/1992. Legislação Federal de Agrotóxicos e afins, Brasília, Ministério da Agricultura, Departamento de Defesa e Inspeção Vegetal, 1998b.

BULL, D.; HATHAWAY, D. Pragas e venenos: agrotóxicos no Brasil e no terceiro mundo. Petrópolis: Ed. Vozes, 1986. 235p. 
CAMPANHOLA, C.; RODRIGUES, G.S.; BETTIOL, W. Evolução, situação atual, projeção e perspectiva de sucesso de um programa de racionalização do uso de agrotóxicos no Brasil. In: SEMINÁRIO INTERNACIONAL DE RACIONALIZAÇÃO DO USO DE PESTICIDAS NO CONE SUL; Campinas, SP, 1997.

CONCEIÇÃO, M.A., Resíduos de pesticidas em tomates: metodologia analítica e avaliação da exposição humana. Brasília, 2002. Tese (Doutorado) - Universidade de Brasília.

DAVIS, P.L.; MUNROE, K.A. Journal of Agricultural and Food Chemistry, v.27, n.4, p.918-920, 1979.

DAY, R.A.; UNDERWOOD, A.L. Quantitative analysis. 6.ed. New Jersey: PrenticeHall, 1991. 685p.

ETO, M. Organophosphorus pesticides: organic and biological chemistry, Cleveland, Ohio: CRC, 1977. 387p.

FAO. Guidelines for the registration and control of pesticide, Rome, 1985. 45p.

FELLENBERG, G. Introdução aos problemas de poluição ambiental. São Paulo, E.P.U., 1980. 196p.

FERNANDES, M.S.; FERRAZ, M.S.; OLIVEIRA, V. Mais espaço no mercado mundial de frutas. In: AGRIANUAL 2004. São Paulo: FNP Consultoria \& Agroinformativos.

FIFIELD, F.W.; KEALEY, D. Analytical chemistry, principles and practice. 4.ed. Londres: Blackie Academic \& Prof., 1995. 560p.

GARCIA, E.G. Pesticide control experiences in Brazil. Pesticide Safety News, v.2, Sep. p.5, 1997. 
GARCIA, E.G. Segurança e saúde no trabalho rural: a questão dos agrotóxicos. São Paulo: Fundacentro; 2001. p.16.

GARCIA, E.G.; ALMEIDA, W.F. Exposição de trabalhadores rurais aos agrotóxicos no Brasil. Revista Brasileira de Saúde Ocupacional. v.19, n.72, p.7-11, 1991.

GELMINI, G.A. Agrotóxico: legislação básica. São Paulo: Fundação Cargill, 1991. v.12.

IWATA, Y.; SUGITANI, A.; YAMADA, F. Shokuhin Eiseigaku Zasshi, v.24, n.1, p.47-51, 1983.

KATO, Y.; SAEKI, M. Chiba-ken Eisei Kenkyusho Kenkyu Hokoku, v.7, p.7-11, 1983.

LARA, W.H.; DE BATISTA, G.C. Química Nova, v.15, n.2, p.161, 1992.

LEMES, V.R.R., INOMATA, O.N.K., BARRETO, H.H.C., Resíduos de Endosulfan em Tubérculos e frutos. Revista do Instituto Adolfo Lutz. v. 53 n.1/2, p. 49-54, 1993.

LISKA, I.; KRUPCIK, J.; LECLERCQ, P.A. The use of solid sorbents for direct accumulation of organic compounds from water matrices: a review of solid-phase extraction techniques. Journal High Resolution Chromatography, v.12, p.577590, 1989.

MAJORS, R.E. Sample preparation for HPLC and gas chromatography using solidphase extraction, LC-GC, v.4, n.10, p.972-984, 1986.

MAJORS, R.E. A review of modern solid-phase extraction. LC-GC, p.S8-S15, May/Suppl. 1998.

MATOLESY, G.; NADASY, M.; ANDRISKA,V. Pesticide chemistry. Amsterdam: Elsevier, 1988. p.9. 
MEDINA, J.C.; BLEINROTH, E.W. Manga: da cultura ao processamento e comercialização. Campinas: ITAL, 1981. 399p.

MULLER, A.T.; BURT, J.R. Post-harvest storage control of mango stem-end rot with fungicidal dips. Australian Jornal of Experimental Agriculture and Animal Husbandry, v.29, p. 125-127, 1989.

PASCHOAL, A.D. Pragas, praguicidas e a crise ambiental: problemas e soluções. Rio de Janeiro: Fundação Getúlio Vargas, 1979. p.28.

PYYSALO, H.; KIVIRANTA, A.; LAHTINEN, S. Journal of Chromatograph, v.168, n.2, p.512-516, 1979.

REGITANO, R.L. DE O.; DE BATISTA, G.C.; TEOFILO SOBRINHO, Jornal Analítico Sociedade Entomológica Brasileira, v.11, n.1, p.123-128, 1982.

RICHARDSON, M. Pesticides - Friends or Foe? Water Science and Technology, v.37, n.8, p.19-25,1998.

ROZANE, D.E.; DAREZZO R.J.; AGUIAR, R.L.; AGUILERA, G.A.H.; ZAMBOLIM, L. Manga - produção integrada, industrialização e comercialização. Viçosa: UFV, p.2-8, 2004.

RUSSO, C.; LANZA, C.M.; TOMASELLI, F. Industrie Alimentari, v.22, n.1, p.12-14, 1983.

SCALON, S.P.Q.; OLIVEIRA, J.J.V.; LIMA, L.C.O.L. Resíduos de benomil em polpas de mangas haden armazenadas em atmosfera modificada. Pesticidas, v.6, p. 42-53, 1996.

VETTORAZZI, G.; RADAELLI-BENVENUTTI, B.M. International regulatory aspects for pesticides chemicals. Boca Raton: CRC Press, 1982. v.2. 
WORLD HEALTH ORGANIZATION (WHO). Public health impact of pesticides used in agriculture. Geneva; p.22-23, 1990.

WORLD HEALTH ORGANIZATION (WHO). Principles for safety assessment of food additivies and contaminants in food. Geneva: WHO, 1987. (Environmental Health Criteria, 70).

ZADROZINSKA, J.; KWAST, M.; LUDWICKI, J.; MATRASZEK, S.G. Determination of pesticide residues in citrus fruits - Rocz Panstw Zakl Hig. v.34, n.2, p.189-195, 1983. 